\title{
Prognosis on recurrent stroke, functional outcome, and mortality : a comparative study of ischemic stroke subtypes
}

Citation for published version (APA):

de Jong, G. (2001). Prognosis on recurrent stroke, functional outcome, and mortality : a comparative study of ischemic stroke subtypes. [Doctoral Thesis, Maastricht University]. Datawyse / Universitaire Pers Maastricht. https://doi.org/10.26481/dis.20010531gj

Document status and date:

Published: 01/01/2001

DOI:

10.26481/dis.20010531gj

Document Version:

Publisher's PDF, also known as Version of record

\section{Please check the document version of this publication:}

- A submitted manuscript is the version of the article upon submission and before peer-review. There can be important differences between the submitted version and the official published version of record.

People interested in the research are advised to contact the author for the final version of the publication, or visit the DOI to the publisher's website.

- The final author version and the galley proof are versions of the publication after peer review.

- The final published version features the final layout of the paper including the volume, issue and page numbers.

Link to publication

\footnotetext{
General rights rights.

- You may freely distribute the URL identifying the publication in the public portal. please follow below link for the End User Agreement:

www.umlib.nl/taverne-license

Take down policy

If you believe that this document breaches copyright please contact us at:

repository@maastrichtuniversity.nl

providing details and we will investigate your claim.
}

Copyright and moral rights for the publications made accessible in the public portal are retained by the authors and/or other copyright owners and it is a condition of accessing publications that users recognise and abide by the legal requirements associated with these

- Users may download and print one copy of any publication from the public portal for the purpose of private study or research.

- You may not further distribute the material or use it for any profit-making activity or commercial gain

If the publication is distributed under the terms of Article $25 \mathrm{fa}$ of the Dutch Copyright Act, indicated by the "Taverne" license above, 
PROGNOSIS ON RECURRENT STROKE, FUNCTIONAL OUTCOME, AND MORTALITY 
(c) Gosse de Jong, Dalfsen 2001

Universitaire Pers Maastricht

ISBN 9052783098

Vorngeving en druk

Datawyse | Universitaire Pers Maastricht

\section{Cover illustration}

position after 22 moves in one of the games of the author. white to move.

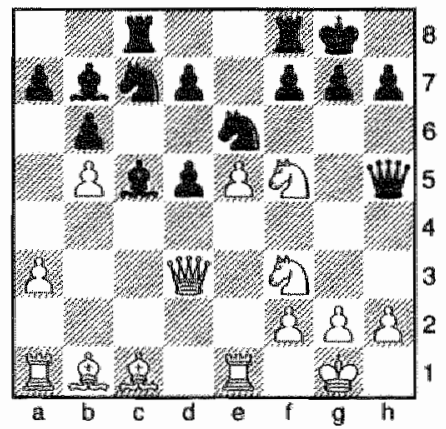




\section{PROGNOSIS ON RECURRENT STROKE, FUNCTIONAL OUTCOME, AND MORTALITY}

A comparative study of ischemic stroke subtypes

PROEFSCHRIFT

ter verkrijging van de graad van doctor aan de Universiteit Maastricht, op gezag van de Rector Magnificus, Prof. Dr. A.C. Nieuwenhuijzen Kruseman, volgens het besluit van het College van Decanen, in het openbaar te verdedigen op donderdag 31 mei 2001 om 16.00 uur

door

GOSSE DE IONG

geboren 5 juli 1957 


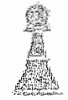

PROMOTOR

Prof. dr. J. Troost

CO-PROMOTOR

Dr. J. Lodder.

BEOORDELINGSCOMMMISSIE

Prof. dr. M.J.A.P. Daemen, voorzitter

Prof. dr. H.J.G.M. Crijns

Dr. P.A.M. Hofman

Prof. dr. C.P. van Schayck

Prof. dr. M. Vermeulen (Universiteit van Amsterdam) 
the race is not to the surift, nor the battle to the strong

Ecclesiastes

Voor Geke, en onze jongens Jelle en Gosse Voor mijn ouders, wier inspanningen en opofferingen mijn studie mogelijk makkten 
Contents 
List of abbreviations

CHAPTER 1 Introduction 11

CHAPTER 2 The Maastricht Stroke Registry: Patients and methods 15

CHAPTER 3 The Maastricht Stroke Registry: Baseline characteristics 29

CHAPTER 4 Survival after stroke: A prognostic study in 998 patients with a first cerebral infarct

CHAPTER 5 Timing and prediction of recurrent stroke following a first cerebral infarct

CHAPTER 6 Functional outcome after a first cerebral infarct

CHAPTER 7 Subtype and brain territory of recurrent stroke point at homogeneity of underlying stroke cause over time

CHAPTER 8 Two types of lacunar infarcts: Further evidence from a study on prognosis

CHAPTER 9 General discussion

CHAPTER 10 Summary

CHAPTER 11 Samenvatting

References

Publications

Dankwoord

Curriculum vitae 


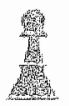

List of abbreviations 
adl

functional dependency as measure of stroke severity

aptc anti platelet trialists collaboration

asla asymptomatic lacunar infarction

at atherothrombotic subtype

at- atherothrombotic type without hypertension, diabetes, ihd and ica

at $\frac{1}{8}$ atherothrombotic type with at least one of hypertension, diabetes, ihd or ica

caprie clopidogrel vs aspirin in patients at risk of ischemic events

cast chinese acute stroke trial

ce cardioembolic subtype

ci confidence interval

copd chronic obstructive pulmonary disease

ct computer tomography

$\mathrm{dm}$ diabetes mellitus

eaft european atrial fibrillation trial

ecst european carotid surgery trial

esps 2 european study prevention of stroke 2

hr hazard ratio

ica internal carotid artery

ind ischemic heart disease

ist international stroke trial

$\mathrm{km}$ kaplan-meier

la leukoaraiosis

laci lacunar subtype

laci- lacunar infarct without asymptomatic lacunar lesions on $\mathrm{ct}$

Laci- - lacunar infarct without asymptomatic lacunar lesions or leukoaraiosis on ct

lacit lacunar infarce with one or more asymptomatic lacunar lesions on $\mathrm{ct}$

lacit+ lacunar infarce with both asymptomatic lacumar lesion(s) and leukoaraiosis on $\mathrm{ct}$

Ir logistic regression mri magnetic resonance imagging

masr mastricht stroke registry

nascet north american symptomatic carotid endarterectomy trial

ocsp oxford community stroke project

or odds ratio

paci partial anterior circulation infarction

pich primary intracerebral hemorrlige

poci posterior circulation infarction

rr hypertension

sah subarachnoid hemorrhage

sd standard deviation

sten stenosis

sutc stroke unit trialists collaboration

taci total anterior circulation infarction

tia transient ischemic attack 


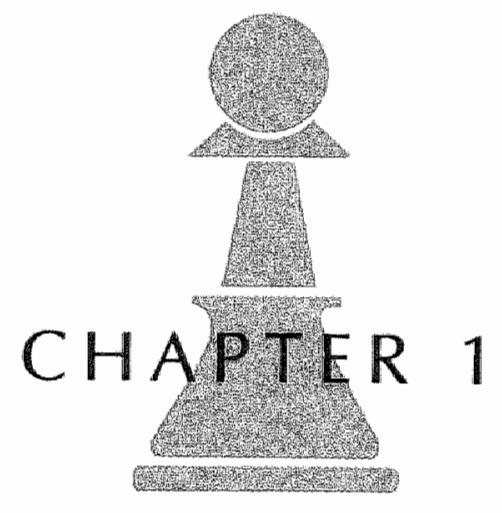


INTRODUCTION 
Stroke is a disease with a high incidence and prevalence. Each year there are about 30.000 new stroke cases in the Netherlands. ${ }^{13]}$ Besides ranking third as death cause, stroke is also a major cause of disability, especially in the elderly. $[43,54,103,135,252,2811]$ Stroke incidence will probably increase over the coming decennia $_{y}$ as the number of elderly people in our society will increase. $\{155,43,206,187,198,277]$ The economic burden stroke causes for society is enormous. $[36,59,131]$ Not only patients, but caregivers as well suffer from stroke. ${ }^{[74,239]}$ Prognosis after a TIA or first ischemic stroke has improved due to the fact that in numerous clinical trials various secondary preventive therapies were proven to be effective, such as: anti-platelet drugs, ${ }_{*}[1,14,77]$ ora anticoagulants in patients with atrial fibrillation, $[10]$ carotid surgery, ${ }^{[5,12]}$ and anti-hypertensive treatment. $[4,9,160,161,185,186]$ Testing neuroprotection in acute stroke has so far been disappointing, but patient admittance to a specialised stroke unit was proven effective. $[13,131,146,212,213]$ Also, thrombolysis as acute stroke therapy has largely gained acceptance as an effective means to improve prognosis, although the proportion of patients that qualify for this treatment will probably not exceed 10 percent. $[8,54,100]$

Considering the evidence on the efficacy of various acute treatments and preventive modalities, one may wonder what possible relevance a study on prognosis may have.

Well, first of all, it is by no means clear in what way the application of the various treatments affects prognosis in heterogeneous stroke populations, such as those that visit a general hospital. Clinical trial populations are usually rather homogeneous or at least exclude patients with certain characteristics systematically. For example, most secondary stroke prevention trials selected patients with TIA or stroke with only minor deficit. But for various other reasons, patients included in clinical trials do not invariably reflect stroke patients in general, whereas estimates on prognosis are relevant for all kinds of patients, their family, or both. Therefore, from the individual patient's perspective, prognosis is still important given a certain spectrum of therapies that have become common practice. An additional point that has received insufficient attention so far, is that when studying prognosis stroke subtypes, distinguished on the basis of likely underlying pathophysiology, should be taken into account, as this may largely determine prognosis. However, to what extent (ischemic) stroke subtypes are homogeneous 
over time in this respect, is unclear, but again, important from the patient"s perspective.

Besides this practical, clinical motive to perform a study on prognosis, there is a fundamental issue. Without doubt, the cause of stroke is a complex interaction between environmental factors (such as life style, for example), concomitant disease(s) such as hypertension and diabetes mellitus, and de-arrangements on a cell-biological level. The complexity of the problen might be reduced if stroke subtypes of more homogeneous underlying vascular pathology can be identified. Some years ago we hypothesized that lacunar stroke patients with concomitant silent small ischemic lesions constitute a separate stroke entity. [40] In this thesis evidence is provided that such patients are prognostically different from lacunar stroke patients without silent lesions, which sustains the idea of a separate lacunar stroke entity. Numerically this group makes up approximately 10 percent of all ischemic strokes (see chapter 8). Thus, a rather small homogeneous ischemic stroke subtype may have been identified. A next step may be to look for differences on a cell-biological level between the different lacunar stroke types. Of course, differences found between subtypes in this study may have been affected or even come about by differential effects of the various applied therapies during follow-up, whereas, if so, we do not know in which direction associations have been influenced. So, prior hypotheses should be biologically plausible, in which case eventual differences may still be valuable. In any case, "natural history" studies in stroke patients without any therapy, although scientifically desirable, are not ethically acceptable.

So, the relevance of this thesis lies in its study of prognosis in a well defined, rather large patient sample, whereas it provides data that are clinically relevant and scientifically challenging, in that it may provide a rational basis to invoke further study into the nature of atherosclerotic disease of the cerebral and pre-cerebral vessels. 


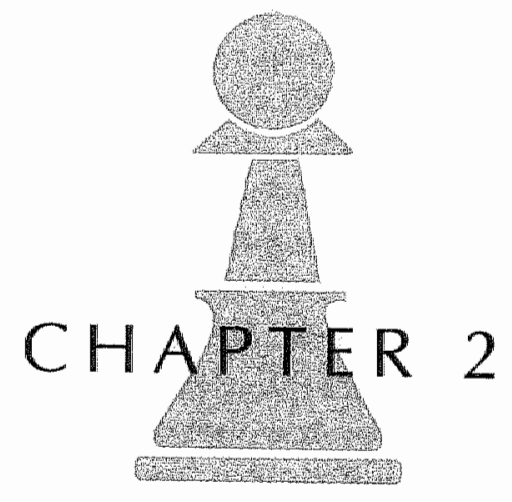




\section{PATIENTS AND METHODS:}

The Maastricht Stroke Registry 


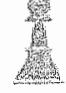

\section{GENERAL ASPECTS}

Patients included in the studies for this thesis have been registered in the Maastricht Stroke Registry (MSR), which is a prospective registry at the University Hospital of Mastricht of all stroke patients older than 18 years with symptoms lasting longer than 24 hours. Patients were registered prospectively and consecutively between July 1987 and March 1992. Last follow-up was completed in may 1995.

\section{INVESTIGATIONS}

All patients were examined as soon as possible after admission, or at the first outpatient clinic wisit. Routine investigations included standard blood and urine analysis, a 12-lead electrocardiogram (ECG), a chest X-ray, non-invasive carotid studies (multi-gated pulsed doppler with spectral frequency analysis, duplex scanning, or continuous wave doppler) and a cerebral CT-scan or MRI. At the time of patient inclusion for this study, MRI was not available for regular use, so neuro-imaging data were based on CT. Echocardiography, 24-hours (Holter) monitoring, and cerebral angiography were performed in selected patients. Data were registered on standard forms.

\section{DERNITIONS}

A CEREARAL (SUPRA-TENTORUALCY LOCATED) INFARCT OR ISCHEMIC STROKE was defined as rapidly evolving clinical signs of focal disturbance of cerebral function, lasting longer than 24 hours or leading to death, with no other apparent cause than a vascular dysfunction. $C T$-scan showed an area of low attenuation compatible with the clinical signs and/or the clinical symptoms, or was without a specific abnormality. In the absence of CT or autopsy data we used the Allen score (Guy Hospital Stroke Diagnostic Score) which is a clinical scoring system that has been validated in 2 different data-sets. $121,60,2331$ It yields a probability of a stroke being due to infarction or haemorrhage using a combination of clinical signs and symptoms. A score lower than 4 predicts the ischemic cause of a stroke 


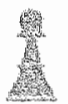

with an accuracy of more than ninety percent. CT-scans were examined without knowledge of the clinical details, separately and independently by 2 neurologists. Four subtypes of ischemic stroke were distinguished: lacunar, atherothrombotic, cardioembolic infarcts, and infarcts of undetemined origin. Apart from these four types a separate group with rare causes, such as cerebral vasculitis, carotid artery dissection, fibromuscular dysplasia, coagulation disorders, moya moya disease, venous occlusion etc. was defined, but not included in this study because they were too heterogeneous to fit our study aim.

LACUNAR INFARCT was defined as an acute stroke syndrome with a CT-lesion compatible with the occlusion of a single perforating artery, consisting of a subcortical small sharply demarcated hypodense lesion with a diameter less than fifteen millimeter. If no such lesion was visible or if no CT was performed we used the established criteria of unilateral motor - and/or sensory signs that involved the whole of at least two of the three body parts (face, arm, leg) without disturbance of consciousness, visual fields, language or other cortical functions. We distinguished four lacunar syndromes: pure motor stroke (PMS), sensorimotor stroke (SMS), pure sensory stroke (PSS) and atactic hemiparesis /dysarthria clumsy hand syndrome (AH/DCHS). [34]

ATHEROTHROMBO'TIC INFARCT was defined as an acute stroke syndrome with CT findings compatible with infarction involving the cortex. If no such lesion was present or if no CT was performed we used established clinical criteria consisting of unilateral motor and/or sensory symptoms in combination with signs of disturbance of consciousness, visual fields, language or other cortical functions. Also, patients with an isolated monoparesis were included as well as patients with incomplete involvement of two body parts, or with isolated cortical dysfunction (mostly aphasia). Apart from this, patients had no evidence of an existing source of cardiac embolism. Patients with a large subcortical infarct (striatocapsular or large deep infarct) were included in this group because of probable similar pathogenesis.

INFARCT OF UNDETERMINED ORIGIN (AT-) was defined in patients fulfilling the criteria for atherothrombotic infarct but with no evidence of diabetes mellitus, hypertension, ischemic heart disease or signs of ipsilateral significant $(>50 \%)$ carotid stenosis, or if carotid ultrasound or radiological investigations were not performed. Patients with this stroke subtype were similar to atherothrombotic patients with respect to other baseline characteristics and every outcome measure. 


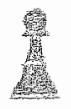

we used. Therefore, in this thesis data for this subtype will not be mentioned separately, and this subtype will be included in the atherothrombotic subtype. CARDIOEMPOLIC INFARCT Was diagnosed in the case of an acute stroke syndrome with CT findings compatible with infarct involving the cortex or a cortical stroke syndrome if CT showed no specific abnormalities or if CT was not performed, in the presence of atrial fibrillation, a recent myocardial infarct (less than 6 weeks), prosthetic valves, endocarditis, cardiomyopathy, mitral stenosis, left ventricular aneurysm or intracardiac thrombus. In the case of one of these abnormalities and co-existing large vessel atherosclerosis patients were classified as cardioembolic. Patients with a large subcortical infarct (striatocapsular infarct) were included in this group because of probable similar pathogenesis. Patients with stroke fitting the criteria for lacunar infarction were classified as lacunar, despite the presence of a potential cardioembolic stroke source.

\section{VASCULAR RISK FACTORS}

Apart from age and sex the following vascular risk factors were recorded: HYPERTENSION was defined as known, treated hypertension or at least two blood pressure recordings higher than $160 / 90 \mathrm{~mm} \mathrm{Hg}$ before stroke or later than one week after stroke.

DLABETES MELLTus was defined as known, treated diabetes or either fasting serum glucose $>7 \mathrm{mmol} / 1$ or a postprandial serum glucose level $>11 \mathrm{mmom} / 1$ on at least two separate occasions before or after stroke, but not in the acute phase of stroke (the first 72 hours).

ISCHEMIC HEART DISEASE was defined as known or treated angina pectoris, or the presence of an old myocardial infarction (older than 6 weeks), or typical ECG - changes of myocardial ischemia.

SIGNIFICAN" CAROTIO sTENOSIS was defined as a diameter reduction of more than $50 \%$ of the internal carotid artery, documented on non-invasive investigation with ultrasound or angiography. 


\section{OTHER DEFINITIONS}

HANDICAP was assessed using the modified Rankin score. This is a clinical handicap score assessing interference with lifestyle and with independent living. It is a well-known and frequently used outcome measure in stroke research and should. be viewed as a global functional health index with a strong emphasis on physical disability. $[71,72,265]$ In our studies, we used a modified Rankin score instead of a specific stroke scale to measure initial stroke severity. Although we realized that the Rankin scale was not designed to measure the degree of functional handicap in the acute stroke phase, because of its familiarity, and convenience in application, we decided to use this scale. Using the Rankin scale, the following grades were distinguished:

Grade $0=$ no symptoms

Grade $1=$ minor symptoms which do not interfere with lifestyle

Grade $2=$ symptoms which lead to some restriction in lifestyle but do not interfere with the patient's capacity to look after him/herself

Grade 3 = symptoms which significantly restrict life style and prevent totally independent existence

Grade $4=$ symptoms which clearly prevent independent existence, though the patient does not need constant attention

Grade $5=$ totally dependent on others, requiring constant attention night and day

Grade $6=$ death

We dichotomised the results in two categories: functionally independent (Rankin 0,1,2 or 3) and. functionally dependent (Rankin 4 or 5) for ultimate statistical analyses in the study of functional outcome. These distinctions were made to facilitate analysis using the Rankin score as a measure of overall functional handicap. These clustered categories are relevant from a functional point of view, whereas significant differences in overall functional handicap may insufficiently be reflected in the separate consecutive grades.

CHRONTC OBSTRUCTIVE PULMONARY DISEASE was defined as known history of or treatment for this entity.

LEUkOARArosis was defined as (a) focal or diffuse hypodensitie(s) in the periventricular or deep white matter, not involving the cortex, and with ill-defined margins to distinguish them from infarction. 


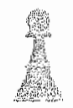

RECURRENT STROKE Was defined as rapidly evolving clinical signs of focal disturbance of cerebral function lasting longer than 24 hours or leading to death with no apparent other cause than a vascular dysfunction. Information regarding stroke symptoms, severity, and brain area following any recurrent stroke was obtained, including the Rankin score.

There had to be evidence of either a new neurological deficit or exacerbation of a pre-existent deficit that could not be ascribed to a side effect of drug therapy or intercurrent illness. Patients suffering deterioration in activities of daily function without such new deficits were not registered as recurrent stroke cases. Also, new asymptomatic lesions on any repeat CT-scan were not included. The subtype of the recurrent stroke was defined using CT scan, or on the ground of clinical information alone if no CT was performed. For the different ischemic stroke types the same definitions as for the first event were used.

Intracerebral hemorrhage ( $\mathrm{PICH}$ ) was recorded as a recurrent stroke if a $\mathrm{CT}$-scan showed a hyperdense lesion, radiologically compatible with an intracerebral hematoma, or if the clinical picture was strongly suggestive for intracranial hematoma if no scan was made. These were mainly patients who died within two days of stroke onset with signs of transtentorial herniation but without observed initial focal abnormalities, or who had severely depressed consciousness with reported headache, vomiting, or both, directly following stroke onset. $[31,33,93,242,257]$ Furthermore, we ascertained use of anticoagulants in case of PICH as recurrent stroke type. None of the patients with this recurrent stroke type used anticoagulants.

We performed a CROSS SECTIONAL FOLLOW-UP of every patient in our registry. No patient was lost to follow-up. Data of patients readmitted in our hospital after a recurrent stroke were obtained. Data of patients still regularly visiting the outpatient department were recorded. If patients no longer visited the outpatient department, our first step was a telephone interview of the patient's general practitioner. Information was obtained using a standard telephone interview. If the patient's general practitioner was unknown, or if the patient had moved out of the Maastricht area, we interviewed the patient by telephone, or the patient"s relatives. Also, we visited nursing homes if the patient was admitted to such an institution, including interviews with the attendant physicians.

DETAILS ON THE CAUSE OF DEATH OF PATIENTS who died during the study period were collected. Cause of death was defined as due to the first stroke, 
recurrent stroke, a myocardial infaret, other cardiac disease, non-cardiac vascular events, pulmonary disease, cancer, any other specific cause of death, or as unknown when no data were available. Vascular death was defined as death due to first or recurrent stroke, myocardial infarction, other cardiac disease, other vascular disease, or sudden death.

\section{STATISTICAL EVALUATION}

For age, we created three categories: $18-67$ years, $67-76$ years, and older than 76 years. To compare differences between subtypes in univariate analyses we used Chi square statistic expressed as odds ratios (OR), with $95 \%$ confidence intervals with Yates correction for small numbers (CI), and in case of statistical significant difference a p-value was determined. We determined 30-day, one-year, and total mortality; and stroke recurrence on these same intervals for the whole group, and for the separate subtypes (actual and Kaplan-Meier estimates). To determine significant independent predictors for 30-day and one-year mortality, and 30-day and one-year stroke recurrence, we used multivariate logistic regression analyses (enter method) with odds ratios (OR), 95\% confidence intervals (CI), and $\mathrm{p}$-values in case of statistical significant associations. For 30-day and one-year data we censored for shorter follow-up. For total mortality, and stroke recurrence we used time-dependent Cox proportional hazard analyses with hazard ratios (HR), $95 \%$ confidence intervals (CI), and p-value in case of statistical significant associations. We used. Kaplan-Meier survival analyses with log rank test for statistical significance to compare survival curves between the subtypes, for both mortality and stroke recurrence (survival free of stroke). We measured functional outcome (modified Rankin scale) for the whole group, and for the separate subtypes, and determined significant independent predictors for unfavourable functional outcome (logistic regression analysis). Stroke recurrence was ascertained for all patients, with type of recurrence verified by CT in $61 \%$. For patients without CT verification of a recurrent stroke, we used clinical characteristics to distinguish between infarct and hemorrhage, as described earlier. Apart from this, we are not aware of studies who defined their stroke recurrence in a more thorough way than we did. Specifically, to the best of our knowledge, we are not aware of any 
table 2.1 baseline characteristics Maastricht Stroke Regisiry

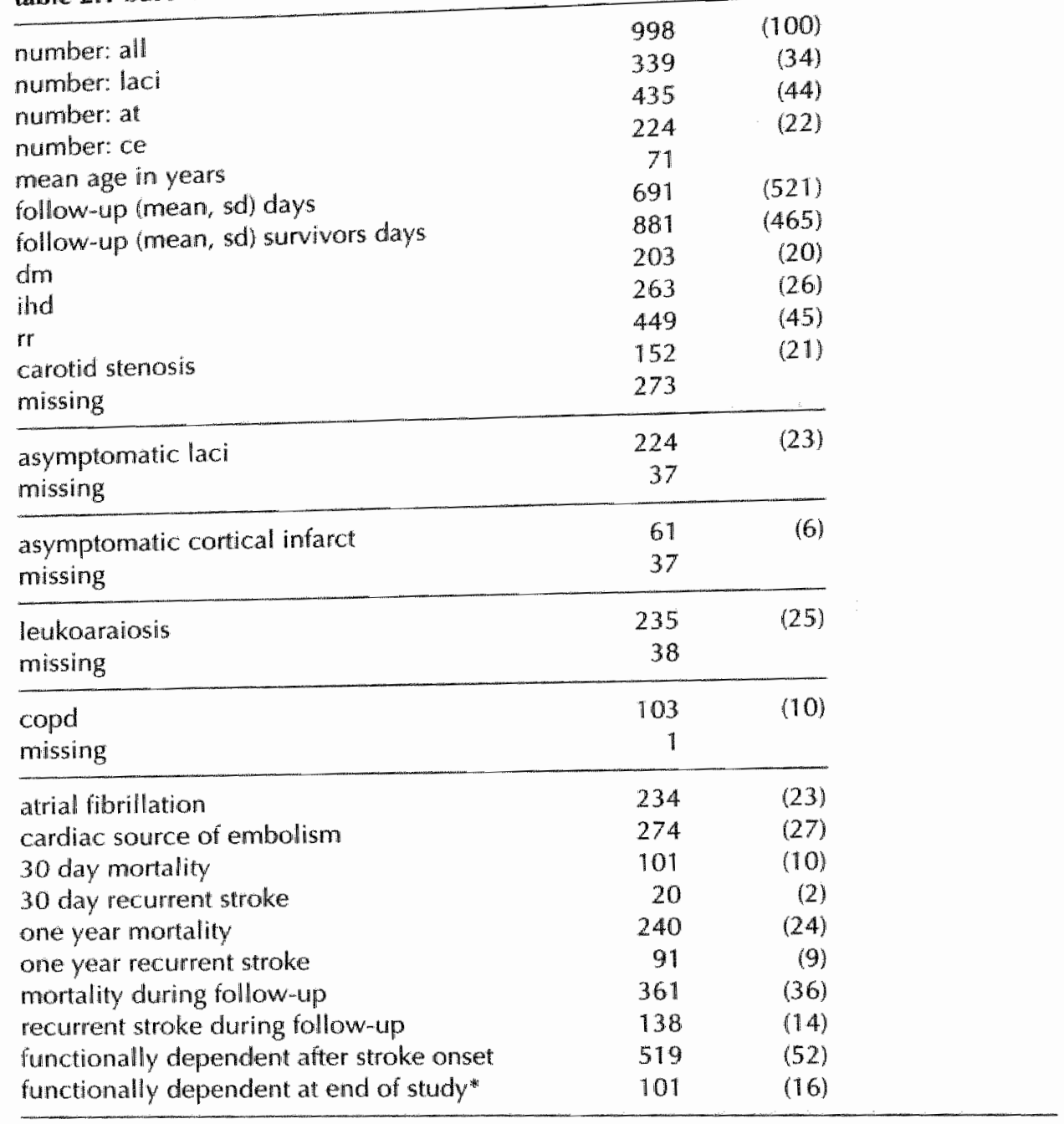

numbers are absolute numbers; numbers in brackets are percentages of numbers censored for missing values. unless indicated otherwise; *percentage of survivors 


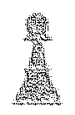

study of other stroke registries that have done CT or have reported CT to any extent in cases of recurrent stroke.

\section{PATIENT CHARACTERISTICS}

There were 998 patients with a first ever ischemic stroke. In table 2.1 the baseline characteristics for the whole group are given. The distribution in the subgroups was: LACI 339, AT 435 (AT+ 346, AT- 89), and CE 224 patients (table 2.1). Duration of follow-up was 691 days (mean, SD 521) for the whole group, and for those surviving 881 days (mean, SD 465) (see table 7.1). CT was performed in $961(96 \%)$, on the day of onset in $153(16 \%)$, within one week of onset in 597 $(62 \%)$, within three weeks in 877 (91\%). There were 138 recurrent strokes, in 84 (61\%) cases of which CT after recurrence was performed. Following recurrence, CT was made on the day of onset in 9 (11\%), within the first week in $31(37 \%)$, and within three weeks in 65 (77\%). During the follow-up period, a total of 361 (36\%) patients died. Immediately after stroke onset, $519(52 \%)$ were functionally dependent. At the end of the study, 101 of 637 (16\%) surviving patients were functionally dependent.

\section{DISCUSSION}

This study includes only patients with a first-ever cerebral infarct. Infarcts in the brainstem and cerebellum were left out from the study, mainly because not only signs and symptoms of such infarcts may vary widely, but also because elucidation of the underlying cause is difficult in such infarcts. ${ }^{[39,50]}$ They are, therefore, more heterogeneous than supra-tentorially located infarcts. Infarcts in the brainstem and cerebelllum make up about $10-15$ percent of all brain infarcts, $\left[30,50,117,168_{0} 182,285\right]$ and therefore, in an analysis on stroke subtypes they constitute a rather small group, which may allow only rough estimates on the features studied in this thesis. On the other hand, some of the lacunar infarct patients, especially those without a symptomatic lesion on CT, might have had the symptomatic lesion in the brainstem. ${ }^{[16]}$ Infarcts in the area of the posterior cerebral artery could be considered as vertebro-basilar artery territory infarcts, an be 


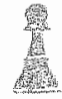

subjected to the same reservation as made above with regard to brainstem or cerebellar infarcts in general. However, ACP infarcts may also be caused by thromboembolism in the anterior circulation area. ${ }^{258,259,261]}$ Again, from a pragmatic point of view these infarcts were included in the present study. It is unlikely that this caused major bias with regard to the eventual conclusions, as posterior circulation infarcts exclusively located above the tentorium, make up only a small proportion of all brain infarcts, approximately $5 \%,[30,182]$ whereas in approximately 30 percent the ACP is supplied by the anterior circulation. $[258,259,261]$ Lacunar infarcts, even in the presence of significant large artery disease, such as an ipsilateral ICA stenosis of more than $50 \%$, or a potential cardiac source of embolism, were grouped in the lacunar stroke type. Especially in the presence of such alternative stroke causes, one can not be completely certain about the definite cause of a lacunar stroke in an individual stroke patient. Lacunar stroke patients less often have pre-cerebral versel obstruction or a source of cardiogenic embolism than territorial infarcts. Therefore, such potential, alternative stroke causes could be considered as coincidental to small vessel disease, rather than causal. $[153,154,156,188,251,260]$ In this thesis lacunar strokes were grouped together, without considering the presence of an alternative stroke cause. However, in the analyses we accounted for the presence of eventual concomitant stroke causes in the lacunar infarct patients.

Carotid ultrasound investigations could not be performed in 27 percent of the patients. These were mainly patients with more severe deficit, and those with high age. Frequently, the patient's attending physician did not consent on these investigations, because it was considered too burdening for the patient, whereas findings would not influence clinical decision or treatment in any way. Patients with undetermined stroke cause who did not undergo carotid ultrasound investigations might, therefore, have had large vessel disease. Therefore, in the eventual analyses they were considered to have large vessel disease. Besides, there were no arguments to consider them pathologically distinct from large vessel AT. On the other hand, had we been able to investigate all patients with "undetermined cause" sufficiently, a group without any signs of atherosclerosis apart from the fact that they suffered a brain infarct, and without any of the classical vascular risk factors would have been an interesting group. ${ }^{[49]}$ What basically determines the development of brain infarction in such patients may differ from patients with one or more of the classical vascular risk factors. However, one has to realise that 


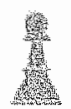

any such difference might be relative rather than absolute, as we investigated a limited number of vascular risk factors and manifestations of atherosclerosis. Besides, new risk factors may be discovered as time goes by, as may specific stroke causes, such as atheromatosis of the ascending aorta. [3]

The infarct subtypes as we defined them in this study were in accord with those used in the literature. $[19,33,130,138,167,182,268]$ The distinction of these subtypes is based on the assumption that they are homogeneous as to the underlying stroke cause. This distinction, furthermore, enables comparison with other studies. Depending on the underlying stroke cause, prognosis may vary, and so may the impact of any measures to improve prognosis. Apart from this clinical perspective, future studies into the cause of stroke on a more basic level may be facilitated by the distinction of different ischemic stroke entities that are homogeneous in vascular pathology and prognosis.

The fact that the study is hospital-based and not community-based may imply limitations as to the generalisability of its results. On the other hand, community-based studies may lack certainty of a clinico-pathological relationship, especially when cases are not examined by a neurologist, or when a substantial proportion of patients lacks neuroimaging. Even when CT or MRI has been performed in all patients in a community-based study, but patients were not examined by a neurologist, such study may be biased towards inclusion of patients with asymptomatic lesions. The present hospital-based series contains. patients who were all examined by a neurologist, whereas CT was missing in only a few (4\%). Case ascertaininent, therefore, especially with regard to subtype diagnosis, may be more valid in hospital than community-based series.

Compared to various other studies on prognosis following stroke, our series has a rather high proportion of patients who underwent CT following a recurrent stroke, $61 \%$ percent. Therefore, ascertainment as to the characterisation of recurrent stroke subtype is rather reliable in our study. However, the reliability of the clinical information on which the decision on a recurrent stroke is based, is of paramount importance, especially when the patient has not been admitted to hospital. The way this information is obtained may be criticised in case a patient is not admitted. However, telephone interview of the patient, his or her relatives, or general physician to ascertain stroke has been shown to be reliable. Also, the use of the modified Rankin scale by telephone has been shown to be reliable, 
whereas general physicians have been shown to be a very teliable source of clinical information. [31]

A drawback of the study is that the follow-up was essentially cross-sectional. Because of this, as time of death marked the end of our follow-up, the calculated duration of this follow-up period is shorther compared to the same period if other methods are used. Naturally, we circumvented part of this problem by using time dependent analyses (Cox proportional hazard and Kaplan-Meier methods) when appropriate. In order to obtain the most reliable information, all patients should be seen at regular and pre-specified time intervals. However, in a disease like stroke many patients are physically and/or mentally disabled and unable or unwilling to comply with rigid methodological requirements. Pragmatically, though, one should not decline to attempt the study of relevant clinical questions for the sole reason that the answers may have a certain degree of uncertainty. One of the endpoints in the study was mortality, which is a definite and clearly verifiable event. Recurrent stroke diagnosis may have been less valid, but nevertheless, our study is one of the best in its kind in the ascertainment of recurrent stroke and especially recurrent stroke subtype (see chapter 3 and 7). Establishing the degree of functional handicap using the Rankin scale either in face-to-face contact with the patient or by telephone is also a valid method. Therefore, study endpoint ascertainment has unlikely been subjected to any major bias in whatever direction.

How the study methods and the patient's basic characteristics compare to other studies on prognosis following stroke, is discussed in the next chapter. 
CHAPER 2

Patients and methods

$\sqrt{6}$ 


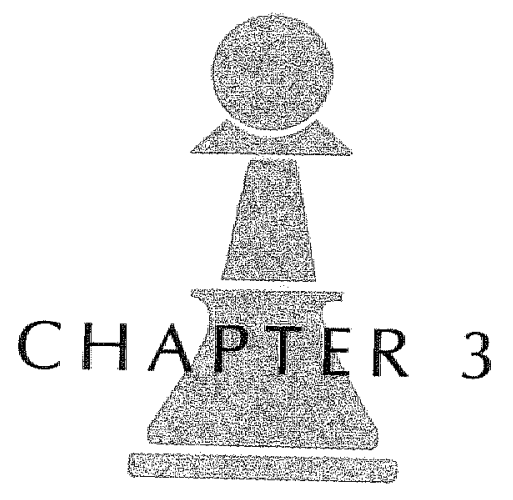


BASELINE CHARACTERISTICS OF

998 ISCHEMIC STROKE PATIENTS IN THE MAASTRICHT STROKE REGISTRY:

Comparison with other stroke registries 


\section{$\sqrt{1}$}

\section{INTRODUCTION}

Data of the 998 ischemic stroke patients that constitute the basis of the studies described in this thesis, were collected in the Maastricht Stroke Registry (MSR). At the time these patients were included, the MSR registered only first-ever ischemic stroke patients in whom the lesion was most likely located in the supratentorial region of the brain. The main reason at that time was that one of the major aims was to study various aspects of rather homogeneous stroke sub-types. Because stroke, and even ischemic stroke in the so-called posterior circulation (vertebro-basilar area) constitute a rather heterogeneous group, $[39,50,285]$ they were not included in our study. Another consideration was that large vessel disease in the vertebro-basilar system may not a priori be similar in various aspects to large vessel disease in the carotid tenitory. For example: a territorial infarct in the internal carotid artery territory is, in the presence of a potential cardiac source of embolism, considered as caused by an embolus from the heart. For infratentorial infarcts, there is less consensus on this issue. ${ }^{[32,50,117,182]}$ Although these would in itself be interesting questions to study, it was not the aim of this thesis. Besides, numerically, infarcts in the vertebro-basilar system constitute only about 10-15 percent of all brain infarcts, and therefore very large stroke numbers would be required to allow reliable conclusions with respect to various aspects of these infarcts. The more so, since they are quite heterogeneous as to cause and clinical manifestation. So, there was also a pragmatic reason not to include vertebro-basilar infarcts. On the other hand, we include occipital located infarcts, whereas it is not clear how often these result from posterior or anterior circulation obstruction, with approximately ten to thirty percent of occipital infarcts being caused by anterior circulation obstruction. $[258,259,261]$ Ideally, a clinical-epidemiological study on stroke should be performed in the community. However, to eventually obtain sufficient numbers of strokes to allow reliable estimates, especially when accounting for stroke subtypes, would require a very large population to be studied for a considerable period. A pragmatic alternative is a hospital-based study, but such study may contain considerable bias, especially when the study hospital is not the only hospital in the area where patients come from. In such case, differentiall referral patterns may exist between hospitals, which create bias. This is, without doubt, most likely the case with university hospitals, as in general these act as tertiary referral centres. 


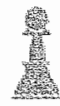

Although the Maastricht Hospital is a university hospital, such referral bias is unlikely. First of all, the hospital serves a well-defined area, with a population of almost 200,000 people, and is the only hospital for that region. Furthermore, besides being a secondary and tertiary referral centre, it also acts as primary care facility for the Maastricht area. Therefore, general practitioners refer acute stroke patients in the area to our hospital. Traditionally, there has been a high preference of the local population in favour of the Maastricht Hospital over other hospitals outside this area. In addition, referral of strokes from outside the Maastricht area is very unusual, and confined to young stroke patients. We did not register patients younger than eighteen years. In addition, we did not include patients from outside the Maastricht area in our stroke dlata base. Therefore, we think that a referral bias in our study is rather unlikely.

Whether results from a hospital-based stroke study can be generalised could also be a problem if a large number of strokes, or certain stroke subtypes, would not be admitted. First of all, we included both patients admitted, and those that visited the outpatients clinic, thereby preventing bias of the data set towards more severe strokes. We certainly missed stroke patients who died before reaching the hospital, but most of these suffered probably SAH, $\mathrm{PICH}$, or a brainstem infarct, and these were a priori not included in the study. Patients not even visiting the outpatients clinic might rather have had remitting symptoms, such as TIA, who were also not included. So, major bias towards inclusion or exclusion of certain stroke categories is not likely. Comparison with other stroke registries, especially those that are community-based, could further sustain this, and strengthen the validity of our study. In this chapter, therefore, we present the baseline characteristics of our study population, and make comparisons with various stroke data bases.

\section{PATIENTS AND METHODS}

Patients included in the studies for this thesis had been registered in the Maastricht Stroke Registry (MSR), which is a prospective registry at the Univer-sity Hospital of Maastricht of stroke patients older than 18 years with symptoms lasting longer than 24 hours. Patients were registered prospectively and consecutively between July 1987 and March 1992. Last follow-up was completed in May 1995 (See chapter 2 for detailed description). 


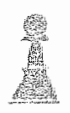

\section{RESULIS}

Table 3.1 shows the baseline characteristics for our study population, for the whole group as well as for the separate stroke subtypes. Table 3.2 compares the distribution of the ischemic stroke subtypes in our registry with data from the literature. In this table, data from other registries were recalculated to express data on stroke subtypes in percentages of the total number of ischemic strokes with exclusion of PICH and SAH. The unknown or uncertain subtype was used only if PICH and SAH were not included in this subtype. CT verification of stroke subtype varied widely between studies. Fourteen studies distinguished between AT, LACI, and CE, although definitions varied between studies. Some studies distinguished stroke of undetermined cause, although here also, definitions varied. The numbers of AT show a wide range. Studies that distinguished stroke with undetermined cause, had the lowest AT number. The number of AT patients in our study complies with the nean AT number of the fourteen studies. We had more LACI patients than any other study, whereas the number of CE complies with the mean number of CE patients in the other studies.

Table 3.3 shows the data on 30-day and one-year mortality, and 30-day and one-year stroke recurrence, in comparison with data from the literature. There were only two studies that, besides ours, measured 30-day and one-year stroke recurrence rate and mortality. The data on these features were rather similar in the three studies.

Table 3.4 shows 30-day and one-year stroke recurrence rate and mortality in ischemic stroke subtypes. Apart from our study, only the Rochester study presented these data. The two studies differed most in regard to the numbers in the AT stroke type: the Rochester study found a much higher early and one-year stroke recurrence rate in AT patients, whereas one-year mortality was lower than half of that in our study. One of the reasons for the high early recurrence rate in the AT type in Rochester may be the mandatory presence of carotid artery stenosis in this type, apart from a considerable percentage of early recurrence being caused by investigative procedures. 2021 Figures on CE stroke type were rather similar between studies. When we compare our figures with those of studies which only measured death rates, findings were rather similar as well. 
table 3.1 baseline characteristics for the maastricht stroke registry: all patients and the ischemic subtypes

\begin{tabular}{|c|c|c|c|c|c|c|c|c|}
\hline & all & & llaci & & at & & ce & \\
\hline number & 998 & & 339 & $(34)$ & 435 & (44) & 224 & (22) \\
\hline age in years & 71 & & 69 & & 71 & & 75 & \\
\hline $\mathrm{dm}$ & 203 & $(20)$ & 65 & (19) & 86 & $(20)$ & 52 & (23) \\
\hline ind & 263 & (26) & 70 & $(21)$ & 86 & $(20)$ & 78 & (35) \\
\hline rr & 449 & (45) & 160 & $(47)$ & 182 & $(42)$ & 107 & $(48)$ \\
\hline carotid stenosis & 152 & (21) & 26 & (10) & 115 & (33) & 11 & (10) \\
\hline missing & 273 & & 74 & & 85 & & 114 & \\
\hline asymptomatic laci & 224 & (23) & 104 & (31) & 85 & $(20)$ & 35 & (16) \\
\hline missing & 37 & & 6 & & 20 & & 11 & \\
\hline asymptomatic cortlicall infarct & 61 & (6) & $\pi 4$ & $(6)$ & 29 & (7) & 18 & (9) \\
\hline missing & 37 & & 6 & & 20 & & 11 & \\
\hline leukoaraiosis & 235 & (25) & 96 & (29) & 93 & $(22)$ & 46 & (22) \\
\hline missing & 38 & & 7 & & 20 & & 11 & \\
\hline copd & 103 & $(10)$ & 40 & (12) & 39 & (9) & 24 & (11) \\
\hline missing & 1 & & 1 & & & & & \\
\hline atrial fibrillation & 234 & $(23)$ & 43 & (13) & & & 191 & (85) \\
\hline cardiac source embolism & 274 & $(27)$ & 50 & (15) & & & 224 & (100) \\
\hline 30 day mortality & 101 & (10) & 7 & (2) & 43 & $(110)$ & 51 & (23) \\
\hline 30 day recurrent stroke & 20 & (2) & 3 & (1) & 10 & (2) & 7 & (3) \\
\hline one year mortality & 240 & $(24)$ & 46 & (13) & 105 & (24) & 89 & (40) \\
\hline one year recurrent stroke & 91 & (9) & 30 & (9) & 37 & (9) & 24 & (10) \\
\hline mortality during follow up & 361 & (36) & 88 & (26) & 156 & $(36)$ & 117 & (52) \\
\hline $\begin{array}{l}\text { recurrent stroke during } \\
\text { follow up }\end{array}$ & 138 & (114) & 49 & $(14)$ & 53 & $(12)$ & 36 & (16) \\
\hline $\begin{array}{l}\text { functionally dependent } \\
\text { at stroke onset }\end{array}$ & 519 & $(52)$ & 105 & $(3 i)$ & 261 & $(60)$ & 153 & (68) \\
\hline $\begin{array}{l}\text { functionally dependent } \\
\text { end of study }\end{array}$ & 101 & (16) & 18 & $(7)$ & 61 & $(22)$ & 22 & (21) \\
\hline
\end{tabular}

numbers are absolute numbers; numbers in brackets are percentages 
CHAPTE 3

Baseline characteristics of 998 ischemic stroke patients

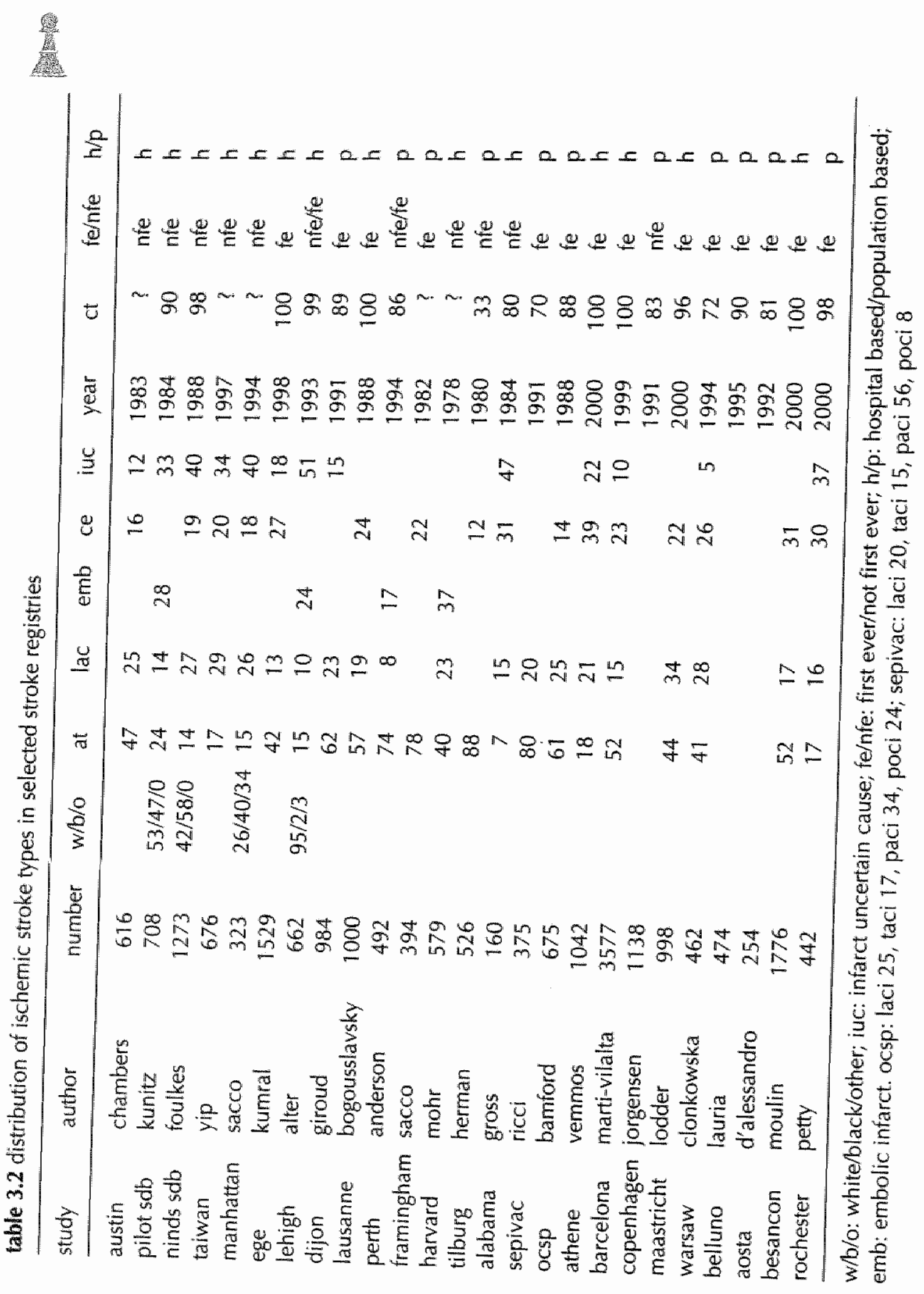


table 3.3 30-day and one year mortality. and 30-day and one-year recurrent stroke in the MSR compared with data from the literature

\begin{tabular}{|c|c|c|c|c|}
\hline study & $\mathrm{d} 30$ & $\mathrm{r} 30$ & dlyr & rlyr \\
\hline $\mathrm{m} 5 \mathrm{r}$ & 10 & 2 & 24 & 9 \\
\hline framingham & 15 & & & \\
\hline dijon & 23 & & & \\
\hline rochester & 14 & 4 & 27 & 12 \\
\hline ocsp & 10 & & 23 & \\
\hline malmo & 10 & & & \\
\hline aosta & 13 & 2 & & \\
\hline belluno & 26 & 2 & & \\
\hline perth & 12 & & 26 & \\
\hline ege & 17 & & & \\
\hline barcelona & 12 & & & \\
\hline sepivac & 10 & & & \\
\hline$s \mathrm{db}$ & & 3 & & \\
\hline copenhagen & 13 & & & \\
\hline lehigh & & & & 9 \\
\hline besancon & 14 & & & \\
\hline erlangen & 12 & & 30 & \\
\hline manhattan & 8 & 6 & 22 & 12 \\
\hline warsaw & & & & 11 \\
\hline
\end{tabular}

numbers are percentages; data concern ischemic index stroke. $\mathrm{d} 30: 30$ day mortality; d lyr: one year mortality; 30 : 30 day recurrent stroke; r1yr: one year recurrent stroke: 
able 3.4 30-day and one-year mortality, and 30-day and one-year recurrent stroke for the ischemic subtypes: Maastricht Stroke Registry compared with the literature

\begin{tabular}{|c|c|c|c|c|c|c|c|c|c|c|c|c|}
\hline \multirow[t]{2}{*}{ study } & \multicolumn{4}{|l|}{ laci } & \multicolumn{4}{|l|}{ at } & \multicolumn{4}{|l|}{ ce } \\
\hline & $\mathrm{d} 30$ & 130 & d $1 y r$ & rly,r & $\mathrm{d} 30$ & $\mathrm{r} 30$ & dlyr & rlyr & $\mathrm{d} 30$ & 30 & $d t y r$ & rllyr \\
\hline $\mathrm{msr}$ & 2 & 1 & 13 & 9 & 10 & 2 & 24 & 9 & 23 & 3 & 40 & 11 \\
\hline framingham & & & & & & & 46 & & 16 & & 70 & \\
\hline dijon & 10 & & 13 & & & & & & & & & \\
\hline rochester & 0 & 4 & 3 & 10 & & & & & 23 & 2 & 54 & 5 \\
\hline rochester & 1 & 1 & 7 & 7 & 8 & 19 & 11 & 24 & 30 & 5 & 53 & 14 \\
\hline ocsp & 1 & 2 & 10 & 12 & & & & & & & & \\
\hline perth & 0 & & 14 & & 11 & & 25 & & 26 & & 41 & \\
\hline lausanne & 1 & & & & 5 & & & & 5 & & & \\
\hline ege & 2 & & & & 18 & & & & 25 & & & \\
\hline barcelona & 0 & & & & 15 & & & & 16 & & & \\
\hline sepivac & 0 & & & & & & & & & & & \\
\hline$s d b$ & 1 & 2 & & & 13 & 8 & & & 11 & 4 & & \\
\hline boiten & 2 & & 15 & & 12 & & 28 & 2 & & & & \\
\hline lehigh & & & 9 & & & & & & & & & \\
\hline besancon & 3 & & & & & & & & & & & \\
\hline athene & 1 & & & & 7 & & & & 26 & & & \\
\hline shatin & 2 & & & & 21 & & & & & & & \\
\hline
\end{tabular}

numbers are percentages; $\mathrm{d} 30: 30$ day mortality; dilyr: one year mortality; $r 30: 30$ day recurrent stroke; rlyr: one year recurrent stroke

\section{DISCUSSION}

Quite a number of studies distinguished between different ischemic stroke subtypes in patients with a first-ever ischernic stroke. Numbers varied between studies due to differences in definitions, patient inclusion, stroke type ascertainment by $C T$, and the use of other types of ancillary investigations. The frequency of $\mathrm{AT}$ in our study complied with the average number of the other studies, but we had more $\mathrm{LACl}$. This could relate to our exclusion of brain stem and cerebellar infarcts. However, lacunar strokes, especially those with negative CT, can be located in the brain stem, and these were included.[116] Another explanation could be that we included not only patients who were admitted to hospital, but also those seen at the out patients clinic. The sole inclusion of admitted patients 
biases the registry towards more severe strokes, whereas milder strokes are more often lacunar. $[29,31,34,138,182,201,202,268]$

There were only two studies that looked at 30-day and one-year mortality, and only one study that collected data for stroke subtypes. So, despite that many 'prognosis' or 'follow-up' studies in stroke have been performed, only two, including the present study provide data on stroke recurrence and mortality accounting for ischemic stroke subtypes. The scarcity of follow-up studies in this respect probably relates to the amount of work involved in long-term follow-up. We also compromised in this respect as we conducted a cross-sectional follow-up. However, compared to other follow-up studies, our data do not point at major inconsistencies in our study, and therefore, our study results are not less valid than those of the other studies. Besides, our study is the only one with a rather high rate of $\mathrm{CT}$ ascertainment of the recurrent stroke type, which makes the study rather unique, as it is so far the only one that allows reliable conclusions on issues related to the recurrent stroke subtype. One could argue that data on prognosis may be collected from stroke trials' control groups. However, such trials used various exclusion criteria, thereby biasing towards the inclusion of particular patient groups. Furthermore, trials that used stroke subtypes for subgroup analysis, mostly defined these subtypes post hoc using clinical information which was collected to classify the degree of stroke severity, which is basically a non-validated method. $[2,7,12]$

Accurate epidemiological data should be collected prospective, using a large, well defined and representative population, obtain complete case ascertainment, have early detailed neurological investigations and a high proportion of cases with confirmed pathology. ${ }^{[3,49,164]}$ Many previous studies do not meet most of these criteria and therefore provide limited utility of data. Stroke registries, although not meeting all strict epidemiological criteria, are used for clinical research and can be seen as positioned between traditional case series and population based studies.

The strength of a stroke data base or registry lies in jts ability to accumulate a large set of data within specified time frames using a defined set of diagnostic procedures.

In 1994 Brainin published an overview of stroke data banks. ${ }^{[99]}$ In the selection of data bases he used 10 criteria: 
- pre-specified diagnostic criteria for stroke and stroke subtypes

- separate analysis of first-ever strokes or first-ever stroke only

- CT investigation rate $>70 \%$

- integration of autopsy data

- prospective collection of data

- planning of a pilot phase and inter-rater studies

- screening procedures of patients enrolled and constant timeframe of examinations

- a large spectrum of clinical and investigative data

- 12 month follow-up examinations

- a baseline paper describing the procedures tised.

Other criteria are important as well: missing data of baseline characteristics and investigations should be mentioned, as well as missing data of follow-up (drop-outs). Data concerning disability or handicap at the time of stroke and at the end of the follow-up period should be provided. It might be important that the inclusion period is not interrupted. It is important to use first-ever cases because residual symptoms of previous stroke makes accurate description of clinical aspects of the subsequent stroke impossible. Furthermore, case fatality rates for non-first-ever stroke have been shown to be higher. ${ }^{\left[130_{2}\right.}$ 148] Subgroup analysis must be used because of possible inherently different prognosis. The MSR complies with most of these criteria.

Our registry is rather similar to other registries in the literature, both population and hospital based, as far as distribution of subtypes, mortality and stroke recur-rence is concerned. Furthermore, the MSR has CT investigation in more than 90 percent. Although some registries claim prospective follow-up, events (recurrent stroke, or death) were only studied at pre-specified times after stroke, so that almost a year could elapse between event and time of study. ${ }^{[33,31]}$ The Rochester studies are conducted with the use of a medical record linkage system, and are thus essentially based on retrospective case note reviews, albeit in a highly perfected form that allows detection of virtually all cases. [200,201,202] The studies in the Framingham population are conducted in a sample of the general population ( $\mathrm{n}=5184$ ), free of stroke, aged $30-62$ year, starting in 1949 , with biennially follow-up examinations. $|96,219|$ Only approximately eighty percent of the subjects take each follow-up visit. In both Rochester and Framingham, much more time is needed to assemble populations of stroke patients that are as large as 


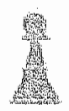

the numbers in stroke registries that include all patients in a certain period of tume. Although these are 'community-based' studies, one should realize that study methods and definitions may change over time, affecting the validity of the data.

Inclusion of patients in a registry should not only be prospective, but consecutive as well. In the OCSP registry, inclusion of stroke patients was suspended for one year while inclusion of TIA's continued. ${ }^{[33]}$ If data were reported for all cases, including TIA, bias towards the inclusion of less severe cases with an inherently better prognosis may exist.

If a registry center is a tertiary referral center, $[138]$ a bias towards more severe, or younger, or unusual stroke cases may be introduced. Ideally, a registry should be assembled in one center, as this minimizes variations in diagnosis, investigations, referral patterns and treatment. Many registries however are a collaboration of more than one center. ${ }^{[23,92,88,167,208,70,148]}$ Population- based studies may include almost all stroke cases in a given population in a given time, including those not admitted to hospital, with the major advantage of the possibility to determine the relevance of findings for stroke patients in general. However, we circumvented this problem by also including outpatients not admitted. Another drawback of population-based studies is the uncertainty of the clinico-pathological relationship in those patients who are not examined by neurologists, or who do not have ancillary investigations. A major advantage of hospital-based studies is the possibility to have patients studied by neurologists with a special interest in stroke, and to have the patients undergo detailed and pre-specified ancillary investigations. In conclusion, we think the MSR database complies with rather strict criteria set for hospital-based data bases, and, therefore, provides a valid basis for studies on mortality, recurrent stroke, and functional outcome in ischemic stroke patients. 


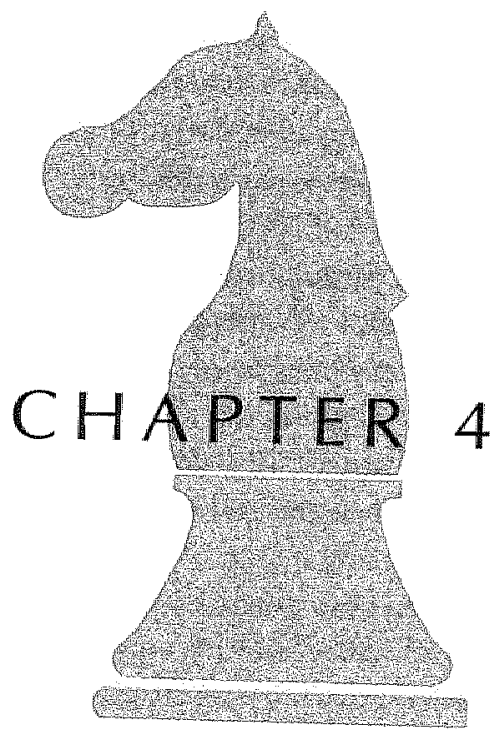


SURVIVAL AFTER STROKE:

A prognostic study in 998 patients with a first cerebral infarct 


\section{NTRODUCTION}

Survival is the most fundamental measure of outcome after stroke. [27] Although the literature is rich in follow-up studies on survival after stroke, most are based on selected series of patients, and the factors which correlated with death have usually been determined in univariate statistical analyses. Few studies have evaluated factors predicting long term mortality after stroke in an unselected series of patients in whom the underlying cerebrovascular pathology was clearly defined. $[26,27,28]$

Survival after brain infarction is significantly more unfavourable than in the general population. Mortality is highest in the first year, but for a long time thereafter as well. $175,96,201]$ The annual risk of dying after stroke is $9.1 \% /$ year (2.3 times the risk of the general population), $[75,102]$ in the first year the risk is 15\%. [75] This excessive death risk also exists in younger patients. [75] Even 20 year survivors show a greater mortality than controls. [96]

Average loss of life after stroke is estimated to be fourteen years, $[244]$ indicating a vital prognosis two to three times more unfavourable than for the general population. After 20 years, $92.5 \%$ of the Framingham stroke population had died compared to $81 \%$ of controls. Long term mortality in stroke survivors is inexorable and greater than that of stroke free controls, following a similar pattern at a somewhat higher level. [96]

Preventive measures are very important in this situation, but risk factors for death after stroke have not extensively been studied, which is even more true for ischenic stroke subtypes. Apart from this, it is unknown if treatment of possibly identified risk factors lowers the risk of death. Hypertension has been identified most frequently in this respect, but results are contradictory. In the Framingham population, no excessive risk was found after one year if hypertension and heart disease were excluded, which may imply that excess death is more related to risk factors than to stroke. [219] In the general population a primary prevention project on risk factors did not reduce total mortality in the intervention group as a whole. [35] In Australasia only marginal improvements in mean population blood pressure were found despite a high risk treatment strategy . [46] Treatment of hypertension accounts for approximately $10 \%$ of the observed reduction in death from stroke. [45] Improvements in the community control of hypertension in the USA have contributed only in a minor way to the decline in mortality from 
stroke. ${ }^{44,45]}$ Moreover, the decline in mortality had started before the era of hypertension treatment. $[134,147]$ A recent swedish study stated that the improvements in stroke mortality are not explained by changes in known confounding factors. [197] Several trials and other evidence have shown a protective effect from blood pressure reduction on recurrent stroke and vascular events after minor ischemic stroke or TIA. $19,11,66,67,160,161,162,185,186]$ Time-trend studies show a declining stroke mortality (stronger decline than coronary mortality) but regions with the highest mortality rate also show the least favourable trend or even an increase in mortality $[44,234]$ Case fatality rates also show a trend in decline. ${ }^{911}$ Opposing national and ethnic trends in stroke mortality occurring in just one generation suggest major effects of lifestyle, socioenvirommental and medical care determinants, [1691 rather than effects of medical (secondary) stroke prevention. The decline in mortality from stroke is partly due to the increasing competitiveness from cancer and degenerative diseases as cause of death. 1210 The impact of modern imaging techniques and the detection of milder cases may play a role, [55] as well as better record keeping, better care and decreased stroke severity. [173] The present analysis was performed to gain more insight into the factors predicting mortality following a first cerebral infarct, accounting for ischemic stroke subtype.

\section{PATIENTS AND METHODS}

These have been extensively described in chapter 2 .

\section{STATISTICAL EVALUATION}

Mortality rates (30-day, one-year, total during follow-up) were calculated for the whole group, and for the ischemic subtypes. Kaplan-Meier estimates are given as well. For the subtypes, these rates were compared with each other (chi square, odds ratio, $95 \%$ confidence interval, p-values).

We performed logistic regression analyses to detemine associations of the variables in our standard model (dm, ihd, age, sex, hypertension) for 30-day and one-year mortality, after which the other potential predictors were stepwise added to and withdrawn from the model. The associations are given as odds ratios with $95 \%$ confidence intervals, and in case of a significant association with the 


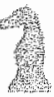

corresponding p-value. These results are given for the whole group with the ischemic subtype included in the standard model, and for the ischemic subtypes separately.

Data are censored for follow-up less than 30 days or one year respectively in surviving patients. We also, in the same manner, performed time dependent Cox proportional hazard analyses, with resulting hazard ratios.

Apart from this we performed Kaplan-Meier survival analyses to compare the respective subgroups, with $\log$ rank tests for significance.

\section{RESULTS}

Table 4.1 shows mortality figures for all patients and the separate stroke subtypes. Thirty-day stroke mortality was highest in CE, and lowest in LACI. This pattern was similar for one-year, and end of follow-up mortality. Of all deaths within one year 42 percent occurred within 30 days. This figure was 15,41 , and 57 percent for $\mathrm{LACI}, \mathrm{AT}$, and $\mathrm{CE}$, respectively. After the first year mortality declined with 44 percent to the end of follow-up. This figure was 39,40 , and 33 percent for LACI, AT, and CE, respectively. Table 4.2 compares mortality figures between the three stroke subtypes. Mortality was significantly lower at all three measured time points in LACI than in the other two subtypes. Mortality in CE was significantly higher than in AT and in LACI.

Table 4.3 shows the causes of death in all patients and in the three stroke subtypes separately. Death directly due to the first infarct was lowest in LACI, and highest in CE, whereas death due to recurrent stroke was similar in the three stroke subtypes. Logistic regression analysis in all patients revealed DM, high age, stroke subtype, and stroke severity as independent predictors of 30-day mortality. Recurrent stroke just missed statistical significance as independent predictor (table 4.4). In LACl patients DM and stroke severity were independent predictors. In AT patients DM, high age, recurrent stroke, and stroke severity, and in CE patients high age and stroke severity were independent predictors of 30-day mortality (table 4.5).

Logistic regression analysis of one-year mortality in all patients (table 4.6) detected DM, ITD, high age, stroke subtype, stroke recurrence, and COPD as independent predictors. Ipsilateral internal carotid artery stenosis just missed 
table 4.1 mortality following first cerebral infarct

\begin{tabular}{llrrrr}
\hline & all 998 & laci 339 & at 435 & \multicolumn{1}{c}{ ce 224 } \\
\hline 30 day & $101(10.1)$ & 7 & $(2.1)$ & $43(9.9)$ & $51(22.8)$ \\
one year & $240(24.0)$ & $46(13.6)$ & $105(24.1)$ & $89(39.7)$ \\
end of follow-up & $361(36.2)$ & $88(26.0)$ & $156(35.9)$ & $117(52.2)$ \\
\hline
\end{tabular}

numbers in brackets are percentages; numbers are absolute numbers

table 4.1.1 kaplan-meier estimates for cumulative survival

\begin{tabular}{llll}
\hline & laci & at & ce \\
\hline 30 day & 0.9794 & 0.9057 & 0.7813 \\
one year & 0.8604 & 0.757 & 0.6026 \\
end of follow-up & 0.5549 & 0.3883 & 0.294 \\
\hline
\end{tabular}

table 4.1 .2 cumulative survival (mean, $95 \%$ ci) days

\begin{tabular}{lrr}
\hline laci & 1469 & $1385-1554$ \\
at & 1230 & $1144-1316$ \\
ce & 939 & $812-1066$ \\
\hline
\end{tabular}

statistical significance. In the subtypes (table 4.7), higher age and stroke recurrence were predictors in the LACI group, whereas hypertension just missed statistical significance. In AT patients DM, high age, recurrent stroke, stroke severity and ICA stenosis were independent predictors of one-year stroke mortality. In CE patients high age and stroke severity were independent predictors, whereas DM just missed statistical significance.

Time-dependent analysis using Cox modelling for all stroke patients (table 4.8) revealed various factors as independent predictors of death following first cerebral infarct: DM, IHD, age, stroke subtype, stroke severity, COPD, whereas ICA stenosis just missed statistical significance. In the subtypes (table 4.9), predictors in the LACI patients were: age and COPD, in AT patients: DM, age and stroke 


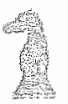

table 4.2 prognosis for mortality comparing infarct subtypes

\begin{tabular}{lll}
\hline mortality & OR $(\mathrm{Cl})$ & P-value \\
\hline 30 day & $0.19(0.09-0.41)$ & $<0.001$ \\
laci vs at & $0.07(0.04-0.14)$ & $<0.001$ \\
laci vs ce & $0.37(0.24-0.58)$ & $<0.001$ \\
at vs ce & & \\
& & \\
one year & $0.49(0.35-0.73)$ & $<0.001$ \\
laci vs at & $0.24(0.16-0.36)$ & $<0.001$ \\
laci vs ce & $0.48(0.34-0.69)$ & $<0.001$ \\
at vs ce & & \\
& $0.63(0.46-0.86)$ & $<0.001$ \\
end of follow-up & $0.32(0.22-0.46)$ & $<0.001$ \\
laci vs at & $0.51(0.37-0.71)$ & $<0.001$ \\
laci vs ce & & \\
at vs ce & & \\
\hline
\end{tabular}

table 4.3 cause of death in 998 first ischernic stroke patients

\begin{tabular}{llrrr}
\hline & all & laci & at & ce \\
\hline index infarction & $81(26)$ & $3(4)$ & $32(25)$ & $46(44)$ \\
recurrent stroke & $44(14)$ & $10(13)$ & $20(16)$ & $14(13)$ \\
heart failure & $47(15)$ & $17(23)$ & $19(15)$ & $11(10)$ \\
other cardiac diease & $19(6)$ & $8(11)$ & $7(5)$ & $4(4)$ \\
non cardiac wascular & $16(5)$ & $4(5)$ & $6(5)$ & $6(6)$ \\
pulmonary & $37(12)$ & $11(15)$ & $14(11)$ & $12(11)$ \\
cancer & $33(11)$ & $13(17)$ & $18(14)$ & $2(2)$ \\
rest & $31(10)$ & $9(12)$ & $12(9)$ & $10(10)$ \\
unknown & 53 & 13 & 28 & 12 \\
\hline
\end{tabular}

numbers are absolute numbers; numbers in brackets are percentage of known cause of death 
table 4.4 associations by logistic regression analysis for 30 -day mortality in 998 first ischemic stroke patients, infarct subtype included in standard model

\begin{tabular}{lccc}
\hline & odds ratio & $95 \%$ ci & p-value \\
\hline dm & 2.14 & $1.32-3.48$ & 0.0021 \\
ihd & 1.57 & $0.97-2.52$ & \\
age 1 & 0.85 & $0.42-1.72$ & \\
age 2 & 2.86 & $1.58-5.19$ & 0.0005 \\
rr & 0.95 & $0.60-1.50$ & \\
sex & 1.32 & $0.8-2.15$ & 0.0002 \\
str type at vs laci & 4.69 & $2.06-10.66$ & $<0.0001$ \\
str type ce vs laci & 9.88 & $4.32-22.60$ & \\
recurrent stroke & 2.87 & $0.98-8.43$ & \\
adl & 12.77 & $5.05-32.27$ & \\
asla & 0.82 & $0.45-1.49$ & \\
copd & 1.17 & $0.57-2.40$ & \\
la & 0.83 & $0.47-1.47$ & \\
sten* & 2.29 & $0.78-6.76$ & \\
\hline
\end{tabular}

*: dm nonsign

table 4.6 associations by logistic regression analysis for one-year mortality, ischemic subtype included in standard model

\begin{tabular}{lllr}
\hline & odds ratio & $95 \% \mathrm{ci}$ & p-value \\
\hline $\mathrm{dm}$ & 1.86 & $1.28-2.71$ & 0.0112 \\
ihd & 1.43 & $1.003-2.05$ & 0.0478 \\
age 1 & 1.57 & $0.99-2.50$ & \\
age 2 & 5.49 & $3.57-8.44$ & $<0.0001$ \\
rr & 0.88 & $0.63-1.22$ & \\
sex & 1.03 & $0.73-1.44$ & 0.0053 \\
stype at ws laci & 1.78 & $1.19-2.66$ & $<0.0001$ \\
stype ce vs laci & 2.76 & $1.77-4.29$ & 0.0016 \\
recurrent stroke & 2.26 & $1.36-3.75$ & \\
adl & 3.36 & $2.31-4.88^{3}$ & 0.0001 \\
asla & 0.85 & $0.56-1.28^{1}$ & \\
copd & 1.65 & $1.02-2.69$ & \\
la & 0.92 & $0.62-1.36^{1.4}$ & \\
sten & 1.72 & $0.98-3.041 .2,4.5$ & \\
\hline
\end{tabular}

1: ihd nonsign; 2: dm nonsign; 3 : str type at ws laci nonsign; 4: age 1 nonsign; 5: str type nonsign 


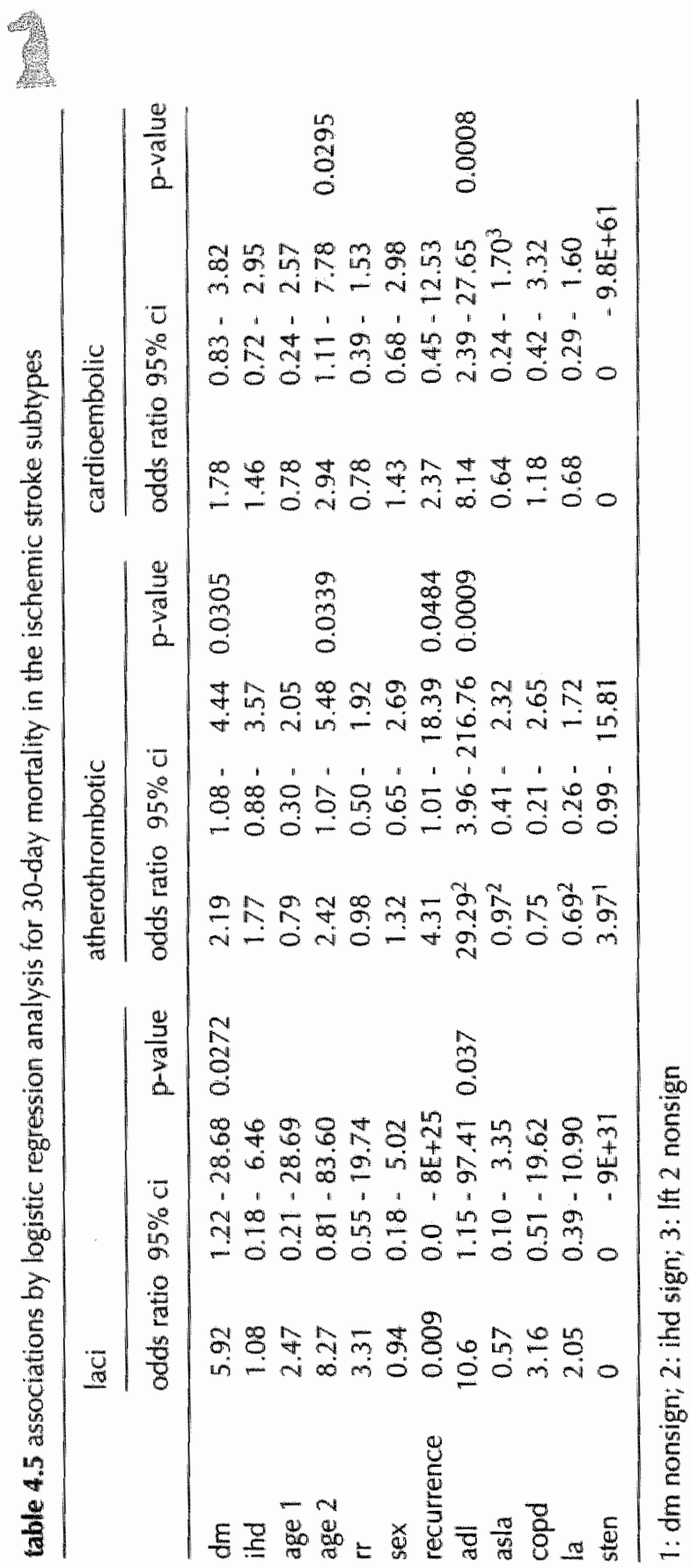


CHAPTE 4

Survival after stroke

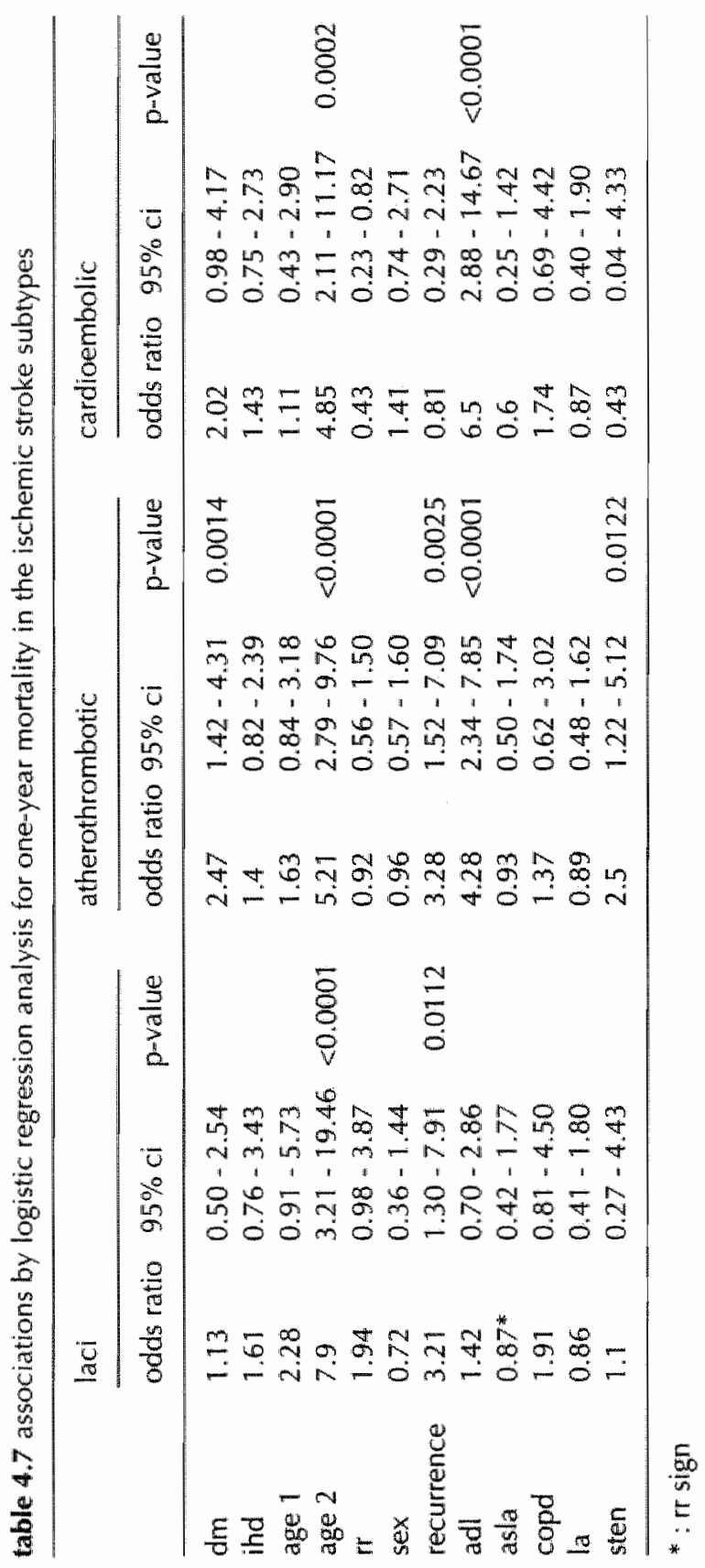


table 4.8 associations by cox proportional hazard analysis for mortality, ischemic stroke subtype inciuded in standard model

\begin{tabular}{llcc} 
& hazard ratio & $95 \% \mathrm{ci}$ & p-value \\
\hline $\mathrm{dm}$ & 1.65 & $1.30-2.09$ & $<0.0001$ \\
ihd & 1.28 & $1.02-1.61$ & 0.033 \\
age 1 & 1.83 & $1.31-2.55$ & 0.0004 \\
age 2 & 4.93 & $3.62-6.70$ & $<0.0001$ \\
ur & 0.96 & $0.78-1.19$ & \\
sex & 0.95 & $0.67-1.18$ & \\
str type at vs laci & 1.52 & $1.17-1.98$ & 0.0017 \\
str type ce vs laci & 2.09 & $1.57-2.78$ & $<0.0001$ \\
adl & 1.79 & $1.41-2.26$ & $<0.0001$ \\
asla & 1.07 & $0.83-1.37$ & 0.0083 \\
copd & 1.51 & $1.11-2.05$ & \\
la & 1.12 & $0.88-1.44$ & \\
sten & 1.43 & $0.99-2.06$ & \\
recurrent stroke & 1.15 & $0.88-1.50$ & \\
\end{tabular}

table 4.10 significant predictors for mortality per subtype

\begin{tabular}{|c|c|c|c|c|c|c|c|c|}
\hline \multicolumn{3}{|l|}{ laci } & \multicolumn{3}{|l|}{ at } & \multicolumn{3}{|l|}{$\mathrm{ce}$} \\
\hline 30 day & 1 year & end study & 30 day & 1 year & end & 30 day & 1 yeair & end \\
\hline $\mathrm{dm}$ & age & age & $d m$ & $d m$ & $\mathrm{dm}$ & age & age & $d m$ \\
\hline \multirow[t]{3}{*}{ sev } & rec & copd & age & age & age & sev & sev & age \\
\hline & $(r)$ & & rec & rec & sev & & $(\mathrm{dm})$ & sev \\
\hline & & & sev & sev & (sten) & & & copd \\
\hline
\end{tabular}

between brackets: just missed statistical significance 
CHAPTER 4

Strviwal after stroke

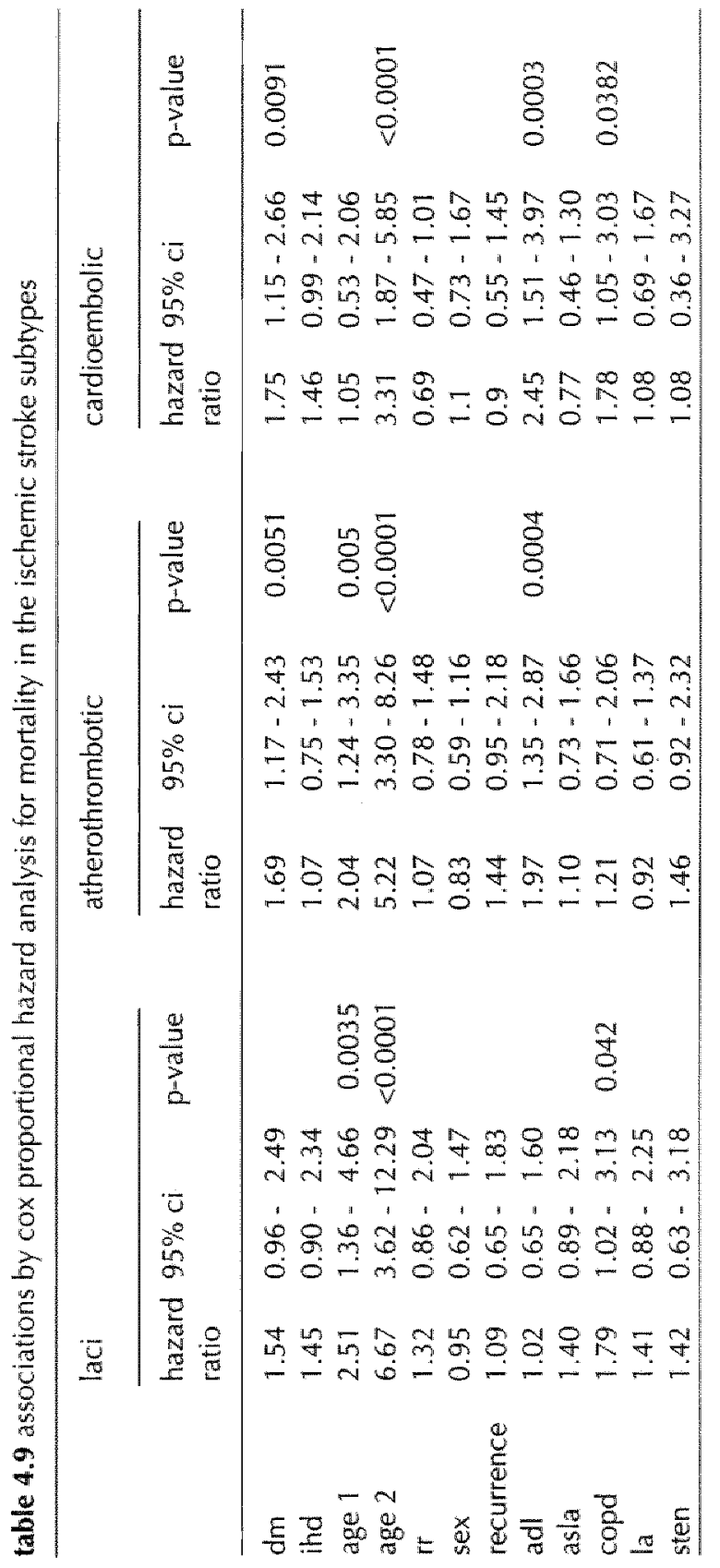


$\mathrm{CHARTR} 4$

Survival after stroke

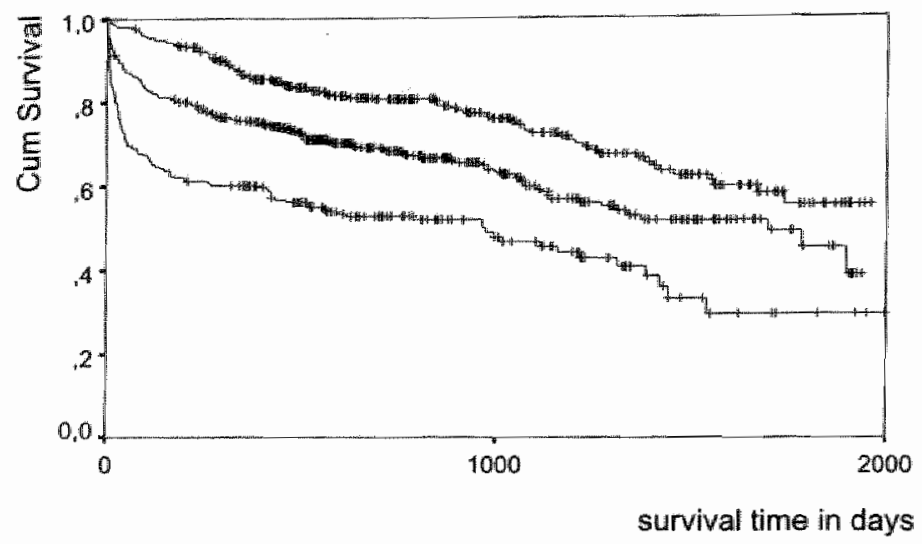

figure 4.1 survival time in days, comparison between laci, at and ce; upper line $=$ laci, middle line $=$ at, lower line $=$ ce; log rank 59.50; sign $<0.0001$

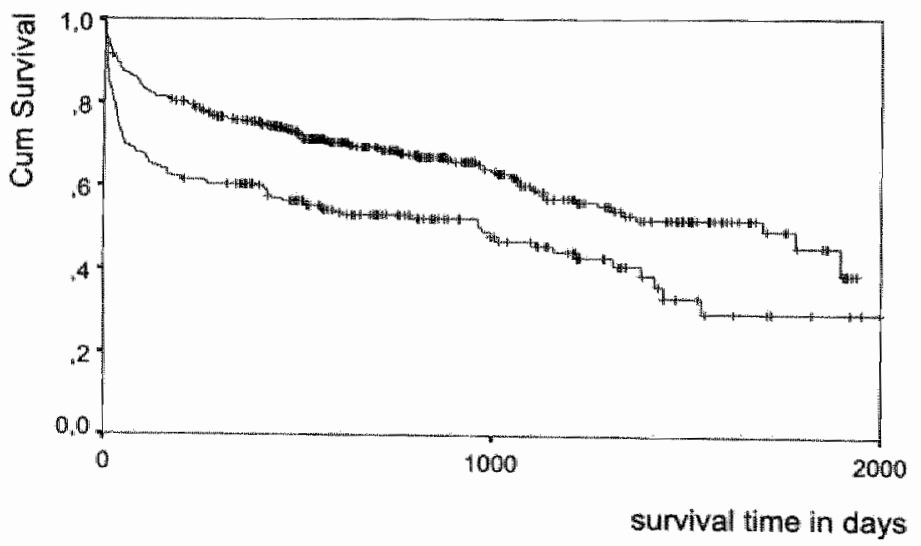

tigure 4.2 survival time in days, comparison between at and ce; upper line $=$ at, lower line $=c e ; \log$ rank 19.54; sign <0.0001 


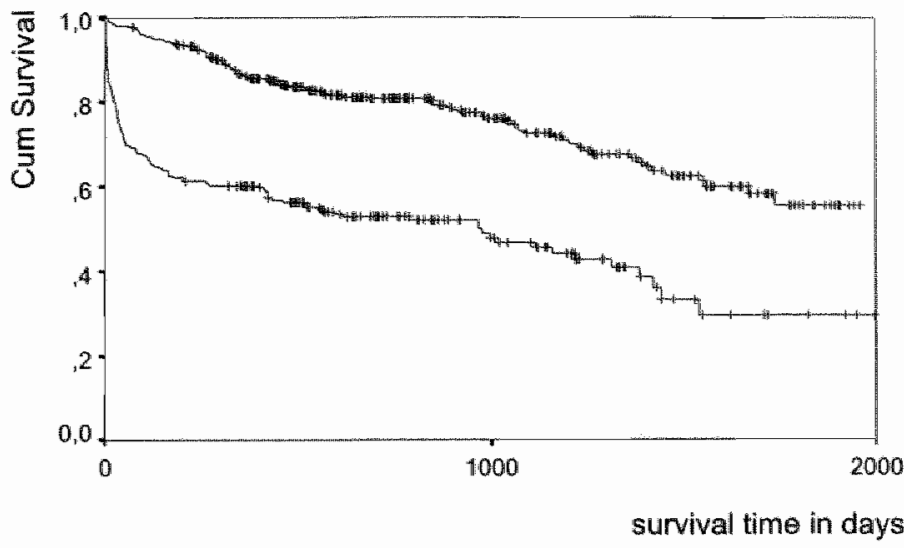

figure 4.3 survival time in days, comparison between laci and ce; upper line = laci, lower line $=$ ce; log rank 61.48 ; sign $<0.0001$

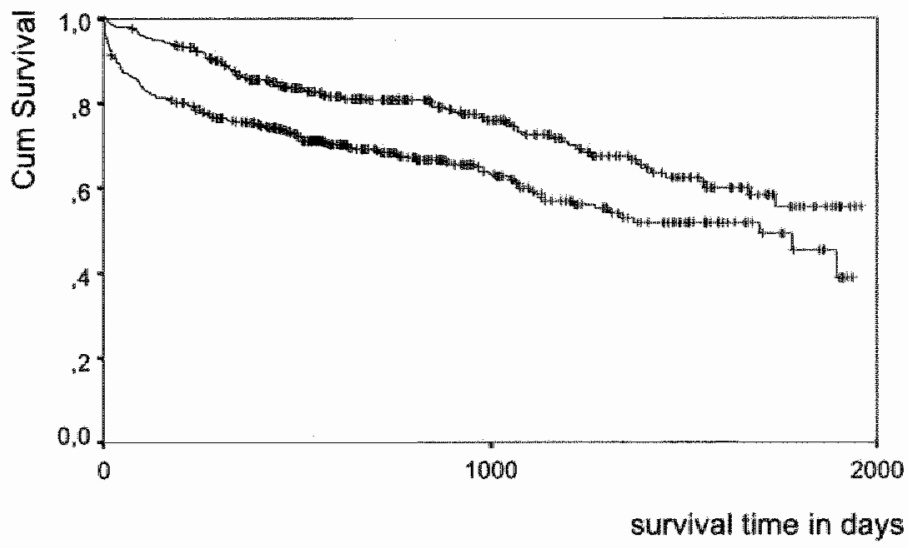

figure 4.4 survival time in dlays, comparison between laci and at; upper line = laci, lower line = at; log rank 15.32; sign 0.001 
severity, and in CE patients: DM, high age, stroke severity and COPD, whereas IHD just missed statistical significance.

So, in LACI stroke severity was only a predictor of 30-day mortality, whereas in $A T$ and $C E$ it remained an independent predictor over time. Higher age was a consistent predictor over time in all stroke subtypes. Recurrent stroke was an independent predictor of especially one-year mortality in LACI and AT, but not in CE. DM was a consistent predictor over time in AT but not in $\mathrm{LACI}$, whereas its significance in CE increased over time (table 4.10).

Log-rank testing of survival showed a significant difference between the three stroke subtypes; LACI versus CE: $p<0.0001 ; \mathrm{LACI}$ versus AT: $p=0.001 ; \mathrm{AT}$ versus $C E: p<0.0001$ (figures $4.1,4.2,4.3$ and 4.4 )

\section{DISCUSSION}

We found a 30-day mortality of ten percent in our 998 patients with a first cerebral infarct. This is similar to the OCSP, Malmo and Sepivac registries, while all other studies report higher values except the Northern Manhattan registry (see table 3.3).

There were significant differences, though, between the three stroke subtypes: lacunar infarct patients had the lowest, and cardioembolic infarct patients the highest 30-day mortality. Others also found a low early death rate among lacunar stroke patients, $[27,34,38,138,202,268]$ Death rates at one year and at the end of follow-up differed likewise. A low early case fatality rate was also reflected in the lowest first month proportion of one year deaths in lacunar patients. In AT and CE patients this proportion was high, approximately forty percent, and more than half of all first year's deaths, respectively.

Similar figures were given in the Dijon registry and OCSP registry. ${ }^{[75,93]}$ After the first year death rates declined in all three stroke subtypes similarly, with thirty to forty percent. It should be noted that at the end of the first year almost a quarter of all patients had died, and somewhat over one third at about two years. Our data concur in this respect to the results of the OCSP and Perth registries. ${ }^{775,102]}$

Although mortality is low in LACI, a first lacunar infarct harbours an unfavourable prognosis as to the chance of dying within a couple of years, as at one year 
over ten percent, and after some two years more than a quarter of LACI patients had died. Therefore, lacunar stroke can not be regarded as an innocent type of stroke. About half of the deaths following lacunar stroke had a vascular cause, whereas in half of these it was heart failure. Heart failure appeared to be a significant cause of death in our population. Heart-related death causes were high in the non-CE strokes, but heart ischemia (among "other cardiac disease") was unexpectedly low, as especially following TIA myocardial infarction is a frequent cause of death. ${ }^{75]}$ However, many patients with heart failure may also suffer IHD, whereas the cause of death could not be ascertained in almost fifteen percent of our patients who died. On the other hand, IHD did not turn out to be an independent predictor of death in our population.

Patients with a first stroke that is most likely caused by embolus from the heart have the most grimmest prognosis quad vitan, as almost a quarter died within the first month, and more than half of them within eighteen months. Age and stroke severity were the only two consistent, independent predictors of mortality in this group. Obviously, trying to prevent cardioembolic stroke to occur in the first place may be the only modifiable risk factor in this stroke subtype. Recurrent stroke was not an independent predictor of death in CE patients, which may be related to the fact that even before EAFT results appeared, long-term anticoagulation was our policy in most CE patients with a first stroke. ${ }^{[157]}$ In CE patients surviving the first year, DM and COPD may increasingly be of importance as risk factors for mortality. Treatment of these afflictions may, therefore, improve long-term prognosis quad vitam in CE patients.

Our findings in the LACI group do not point at major possibilities to improve prognosis for survival. As in CE patients, COPD was an independent predictor of long-term mortality. COPD in itself lowers life expectancy in general, but related to stroke more specific reasons may be involved, which are discussed in chapter 5. Hypertension just missed statistical significance as an independent predictor of one-year mortality in LACI, but could not be established as a consistent predictor in this nor the other stroke subtypes. This was also the case with silent lesions or leukoaraiosis on $\mathrm{CT}$, and IHD. These factors are predictors of recurrent stroke, and may, therefore, not independently from this be detected as predictors (see chapter 5 ).

With regard to hypertension, treatment of this condition may have weakened any effect on mortality. Besides, hypertension is highly prevalent in all stroke 


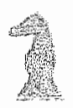

subtypes, and may, therefore, not be detected as a discriminator between stroke subtypes or even in stroke in general as an independent predictor.

In our AT patients DM, age, and stroke severity were consistent predictors over time, whereas recurrent stroke and ICA stenosis were less consistent. Obviously, in territorial infarcts the severity of first stroke neurological deficit remains a significant factor, which consistently implies an increased chance over time to die. Therefore, a worthwhile lowering of not only early but also late mortality might result from a therapy that first of all lowers the degree of neurological deficit in first ischemic stroke patients. Admittance to a stroke unit may have such effect, ${ }^{[13,146,212,213]}$ as thrombolysis was also shown to have, ${ }^{[8,54,100]}$ and, hopefully, eventually neuroprotection.

In conclusion: Our data indicate that a cerebral infarct significantly lowers life expectancy, not only early following stroke, but likely for the remaining survival period following stroke. Although there are differences between ischemic stroke subtypes, even lacunar stroke is a life-threatening affliction for the stroke patient's near future. Significant improvement of prognosis for survival by modification of known risk factors seems unlikely, besides that smoking should be discouraged strongly, but not only with the aim to lower future stroke risk. More is to be expected from anti-platelet drugs more effective than aspirin, ${ }^{(1,77)}$ drugs that lower serum cholesterol, (277) affect endothelial function (another effect of statins and ace-inhibitors), or lower serum homocysteine. (76,272) In AT and CE, treatment that lowers stroke severity may also exert a continuous improvement of life expectancy in these groups. Mortality rates and independent predictors of mortality vary significantly between ischemic stroke subtypes. This may reflect the difference in their underlying pathology, a difference that is consistent over time. 
CHAPTER

Survival after strolke

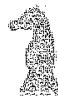




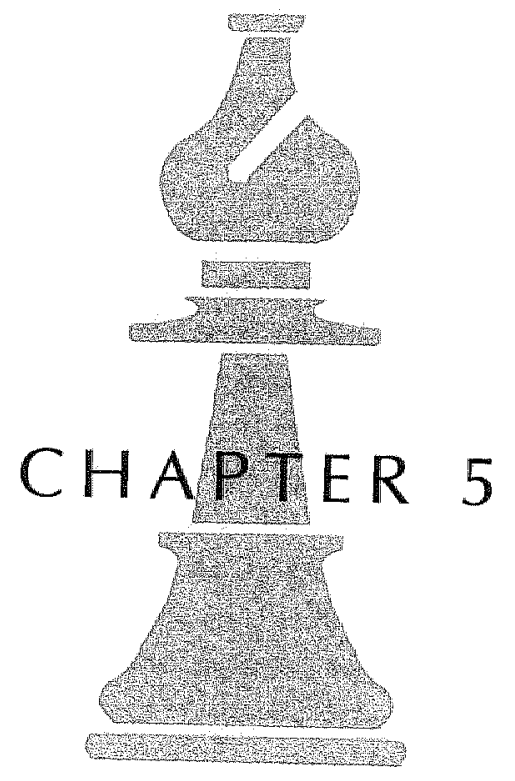


Timing and prediction of recurrent stroke following a first cerebral infarct 


\section{INTRODUCTION}

Reliable prediction of recurrent stroke may be relevant to guide secondary prevention strategies in individual patients. The most common vascular event during the first year after a cerebral ischemic event is a recurrent stroke with substantial morbidity and loss of quality of life ${ }^{[20]}$ Recurrent stroke not only increases the degree of already existing disability, but results in death twice as often as first ischemic stroke, whereas it is also associated with longer hospital stay. $[130,223,275]$ However, so far prediction models for stroke recurrence and other vascullar events following a first stroke are disappointing and better prediction is needed. $[78,112]$

A considerable proportion of stroke survivors do not, or no longer, take anti-platelet drugs, and therefore, secondary prevention may be improved by monitoring stroke survivors in this respect. ${ }^{[115,130,218]}$ Such effort could more selectively be employed in those patients who are predicted to have a strongly increased risk of future stroke. Dedicated monitoring of such patients may be of even more value since more effective anti-platelet regimes than Aspirin alone have become available. ${ }^{[1,77]}$ In the near future a statin, $[203,277]$ an ACE-inhibitor, $[4,186,290]$ or both, may be added to our secondary prevention arsenal, but this awaits results of ongoing studies.

Treatment of modifiable risk factors such as hypertension, for example, has been shown to lower the risk of vascular events following first stroke. $[9,11,66,67,160$, $161,162,163,186]$ Close patient monitoring following stroke is mandatory in this respect as only a minority of patients at risk for vascular events were on treatment for known modifiable risk factors when they had their stroke. Therefore, in the attempt to improve prediction of the risk of recurrent stroke, potential predictive factors that have not yet received attention, or only in a limited way, should be explored. One of such predictors may, for example, be the presence or number of silent ischemic lesions on neuroimaging. Silent lesions may predict the developm ment of new silent lesions, $[267]$ but whether they also predict new symptomatic stroke, is not clear. Another predictor of the occurrence and possibly the type of new stroke, is the index stroke subtype (see chapters 7 and 8 for more detail). Furthermore, prediction of when recurrent stroke is likely to occur is of importance; some studies describe a high early recurrence rate, but others did not. Early recurrence was especially high in the PACI type (according to the OCSP classifi- 
cation), ${ }^{[32]}$ and in the atherosclerotic with stenosis of the ICA type in Rochester, where it was partly due to iatrogenic and procedure related recurrent stroke. [202] One of the factors that may explain differences in stroke recurrence rate and timing is the varying degree of case ascertainment of recurrent stroke, which, ideally, requires CT or MRI. For various reasons this seems hard to pursuit, as to the best of our knowledge there are no registry based follow-up studies that used CT or MRI to any extent in cases of recurrent stroke, or reported their use of neuroimaging in this circumstance.

In this study we measured the rate of stroke recurrence, and mortality following stroke recurrence, and explored various potential predictors of recurrent stroke.

\section{PATIENTS AND METHODS}

These have extensively been described in chapter 2 .

\section{STATISTICAL EVALUATION}

We measured recurrence rates within 30 days, one year, and at the end of follow-up (actual, and Kaplan-Meier estimates) in the whole patient sample as well as in the stroke subtypes. We calculated duration of follow-up for the whole group and for the subtypes, given as mean and standard deviation (SD). Duration of follow-up is also given for the survivors.

We performed multivariate logistic regression analysis with a standard model of independent variables ( $\mathrm{dm}$, ihd, age, rr and sex) and 30-day and one-year recurrence as dependent variables. Results are represented as odds ratio (OR) and $95 \%$ confidence interval (CI) for all explored predictors, with p-value in case of significant association. The other potential predictors (stroke severity, asymptomatic lacunar infarction, chronic obstructive pulmonary disease (COPD), leukoaraiosis, and ipsilateral significant carotid stenosis) were then in a stepwise manner added and removed from the standard model described above. These analyses were done for the whole group, with stroke subtype added as an independent variable to the standard model; and for the ischemic subtypes separately. For $30-$ day and one-year data, we censored for shorter follow-up. We performed a time 


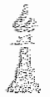

dependent proportional hazard analysis (Cox analysis) for recurrence, with hazard ratio (HR), 95\% confidence interval (CI) and in case of significant association, a p-value. In the same way as described in the logistic regression analysis we used the standard model and the other possible predictors. These analyses were done for the whole group, with inclusion of the ischemic subtype in the standard model; and for the ischemic subtypes separately. Kaplan-Meier curves were constructed for stroke recurrence (survival free of stroke) with log rank test for significance, comparing the respective ischemic subtypes.

\section{RESULTS}

Table 5.1 shows the stroke recurrence rate for all patients and separate stroke subtypes. There were no major differences in stroke recurrence rates between stroke subtypes at 30-days, one year, or at the end of follow-up. The difference was most pronounced for LACI vs ATH and LACI vs CE regarding 30 day recurrence, but these differences did not reach statistical significance (table 5.2) on actual analysis. On Kaplan-Meier testing however, a significant difference in survival free of recurrent stroke was detected between LACI and CE, and between $A T$ and $C E$. There was no significant difference between $L A C I$ and $A T$ (figures 5.1, 5.2, 5.3, and 5.4). Of all recurrent strokes that occurred within the first year, 22 percent occurred within 30 days; this percentage for AT was 27 , for LACI 10, and for CE 29 percent. From one year to the end of follow-up stroke recurrence rate declined with 58 percent in all patients, and with 54 , and 49 percent in $A T$ and LACI, respectively, whereas it increased with 5 percent in CE. The recurrence percentages are given in table 5.3.

Logistic regression analysis in all patients (table 5.4) detected IHD and COPD as independent predictors of 30-day stroke recurrence; OR: 3.81 and 4.19, respectively. DM and hypertension did not reach the level of statistically significant independent predictors. When we analysed the three stroke subtypes separately (table 5.5), various point estimates indicated increased chance of recurrent stroke, but, probably due to small recurrent stroke numbers, these were not statistically
significant.

Logistic regression analysis for all patients revealed IHD and COPD as independent predictors of one-year recurrent stroke (table 5.6). Analysis of the sepa- 


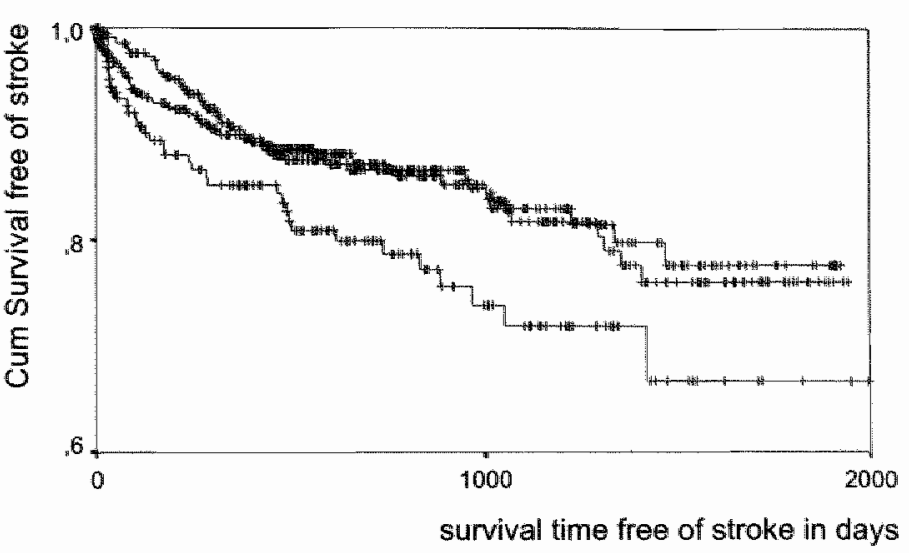

figure 5.1 survival time free of stroke in days, comparison between at. laci and ce;

upper line $=$ at, middle line $=$ laci, lower line $=c e ;$ log rank 6.62; sign 0.0365

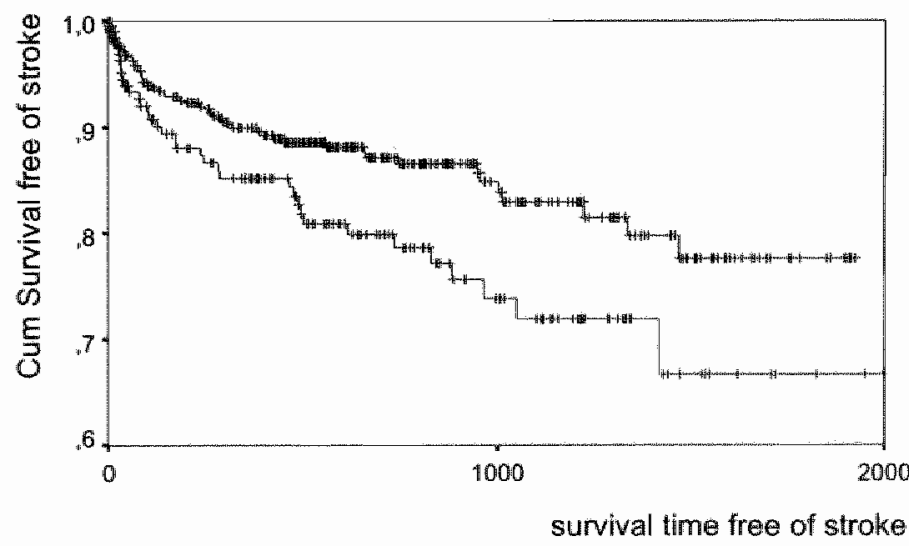

figure 5.2 survival time free of strake in days, comparison between at and ce;

upper line $=a t$, lower line $=c e ;$ log rank 5.16 ; sign 0.0232 
$\mathrm{CHATR} 5$

Timing and prediction of recurrent stroke

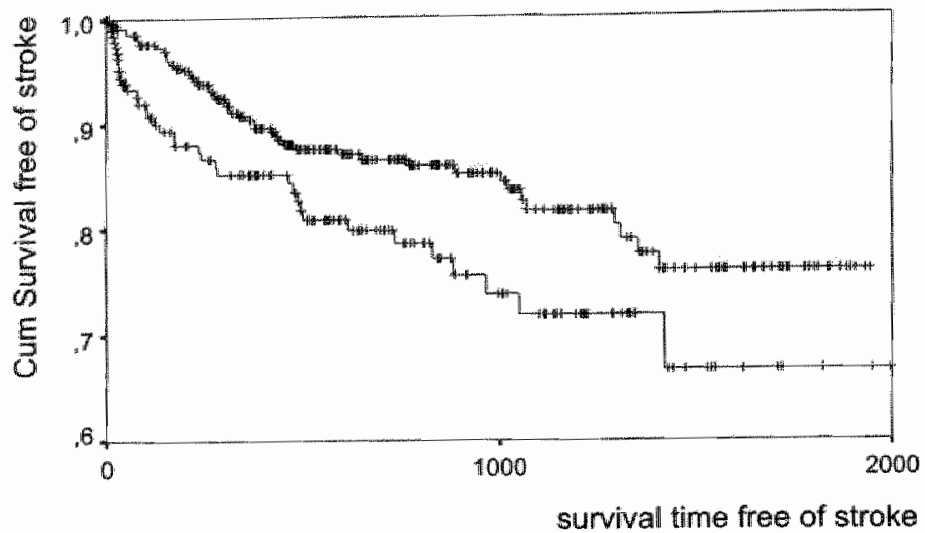

figure 5.3 survival time free of stroke in days, comparison between laci and ce;

upper line $=$ laci, lower line $=c e ;$ log rank 5.33; sign 0.0209

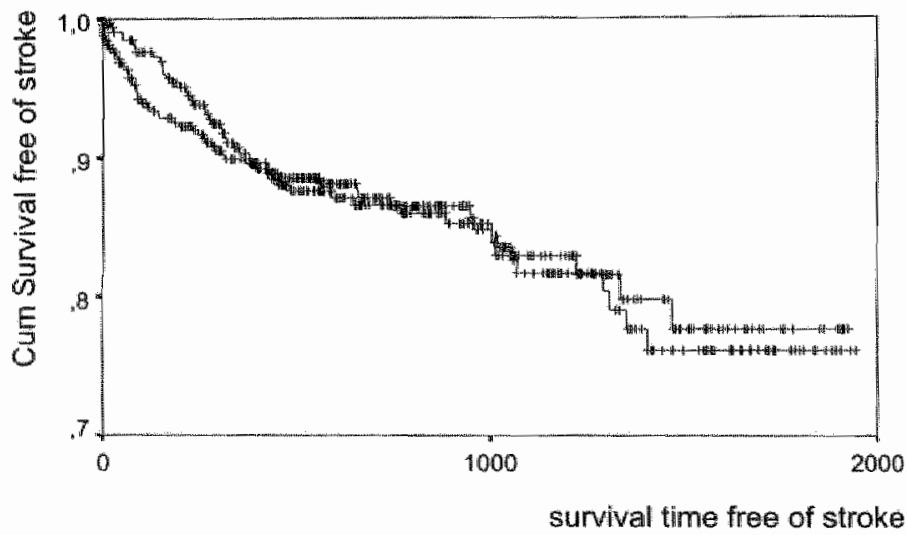

figure 5.4 survival time tree of stroke in days, comparison between at and laci;

upper line $=$ at, lower line $=$ laci; log rank 0.00; sign 0.9962 
table $\mathbf{5 . 1}$ stroke recurrence rates in the ischemic stroke subtypes

\begin{tabular}{lrrr}
\hline & laci & \multicolumn{1}{l}{ at } & \multicolumn{1}{c}{ ce } \\
\hline 30 day recurrence & $3(0.9)$ & $10(2.3)$ & $7(3.1)$ \\
one year recurrence & $30(8.8)$ & $37(8.5)$ & $24(10.7)$ \\
recurrence in follow-up & $49(14.5)$ & $53(12.2)$ & $36(16.1)$ \\
\hline
\end{tabular}

numbers are absolute numbers; numbers in brackets are percentages

table 5.1.1 kaplan-meier estimates for cumulative survival free of stroke

\begin{tabular}{llll}
\hline & laci & at & ce \\
\hline 30 day & 0.9911 & 0.9761 & 0.9624 \\
one year & 0.9036 & 0.8992 & 0.8519 \\
end of follow-up & 0.7607 & 0.7759 & 0.6669 \\
\hline
\end{tabular}

table 5.1 .2 cumulative survival free of stroke in days (mean, $95 \%$ ci)

\begin{tabular}{lll}
\hline laci & 1639 & $1561-1717$ \\
at & 1632 & $1557-1707$ \\
ce & 1521 & $1381-1661$ \\
\hline
\end{tabular}

table 5.2 prognosis for recurrent stroke comparing the ischemic stroke subtypes

\begin{tabular}{lll}
\hline & OR & Cl \\
\hline 30 day & & $0.08-1.76$ \\
laci ws at & 0.38 & $0.06-1.28$ \\
laci vs ce & 0.28 & $0.14-3.81$ \\
at vs ce & 0.73 & \\
one year & & $0.12-8.78$ \\
laci vs at & 1.04 & $0.40-1.64$ \\
laci ws ce & 0.81 & $0.41-1.47$ \\
at vs ce & 0.77 & \\
end follow-up & & \\
laci vs at & 1.22 & $0.76-1.95$ \\
laci vs ce & 0.88 & $0.48-1.62$ \\
at vs ce & 0.72 & $0.44-1.19$ \\
\hline
\end{tabular}


CHAPER 5

Twing and prediction of recurrent stroke

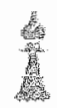

table 5.3 percentage recurrent stroke per year

\begin{tabular}{lcc}
\hline & all & survivors \\
\hline all & 7 & 9 \\
laci & 6 & 8 \\
at & 7 & 8 \\
ce & 11 & 14 \\
\hline
\end{tabular}

lable 5.4 associations by logistic regression analysis for 30 day stroke recurrence in 998 first ischemic stroke patients, infarct subtype included in standard model

\begin{tabular}{llll} 
& odds ratio & $95 \%$ ci & p-value \\
\hline dm & 1.82 & $0.53-6.24$ & \\
ihd & 3.47 & $1.12-10.74$ & 0.0311 \\
age 1 & 0.6 & $0.13-2.81$ & \\
age 2 & 1.54 & $0.39-6.03$ & \\
rr & 1.84 & $0.58-5.86$ & \\
sex & 1.08 & $0.32-3.59$ & \\
strtype at vs laci & 1.16 & $0.39-6.58$ & \\
strtype ce vs laci & 1.89 & $0.40-8.94$ & \\
adl & 0.48 & $0.14-1.61$ & \\
asla & 1.05 & $0.27-4.06$ & \\
copd & 4.16 & $1.17-14.73$ & \\
la & 2.57 & $0.69-9.58$ & \\
sten & 0.62 & $0.06-6.08$ & \\
\hline
\end{tabular}

rate stroke subtypes (table 5.7) yielded DM as a rather strong independent predictor in the lacunar stroke subtype, and also in CE.

Cox analysis for all patients (table 5.8) showed DM, IHD,COPD, and LA as independent predictors. For the subtypes (table 5.9), Cox analysis in the LACI type detected DM, asymptomatic lacunar lesions on CT, and LA as independent predictors. In the AT type, IHD, COPD, and an ipsilateral ICA stenosis were independent predictors, but only DM in the CE type.

Log-tank testing of survival free of recurrent stroke (figures 5.1, 5.2, 5.3, 5.4) showed a significant difference between CE and both AT and LACI; $=0.0209$ and $p=0.0232$, respectively, but no difference between $A T$ and $L A C I$. 
table 5.6 associations by logistic regression analysis for one year stroke recurrence, infarct subtype included in standard model

\begin{tabular}{llll}
\hline & odds ratio & $95 \%$ ci & p-value \\
\hline dm & 2.61 & $1.36-5.01$ & 0.0041 \\
ihd & 2.14 & $1.16-3.93$ & 0.0145 \\
age 1 & 0.55 & $0.27-1.11$ & \\
age 2 & 0.95 & $0.46-1.96$ & \\
rr & 0.89 & $0.50-1.61$ & \\
sex & 0.56 & $0.30-1.05$ & \\
strtype at vs laci & 0.81 & $0.42-1.58$ & \\
strtype ce vs laci & 1.35 & $0.62-2.91$ & \\
add & 0.65 & $0.34-1.25$ & \\
asla & 1.6 & $0.83-3.07$ & \\
copd & 2.97 & $1.43-6.18$ & \\
la & 1.52 & $0.75-3.09$ & \\
sten & 1.43 & $0.65-3.12$ & \\
\hline
\end{tabular}

table 5.8 associations by cox proportional hazard analysis for recurrent stroke, infarct subtype included in standard model

\begin{tabular}{llll}
\hline & hazard ratio & $95 \% \mathrm{ci}$ & p-value \\
\hline dm & 1.88 & $1.28-2.76$ & 0.0012 \\
ind & 1.55 & $1.07-2.23$ & 0.0192 \\
age 1 & 0.89 & $0.58-1.35$ & \\
age 2 & 1.46 & $0.96-2.22$ & \\
rr & 0.98 & $0.70-1.38$ & \\
sex & 0.91 & $0.64-1.30$ & \\
strype at vs laci & 0.97 & $0.65-1.43$ & \\
strtype ce vs laci & 1.43 & $0.92-2.23$ & \\
add & 0.9 & $0.63-1.29$ & 0.0009 \\
asla & 1.38 & $0.94-2.01$ & 0.0459 \\
copd & 2.18 & $1.37-3.45$ & \\
la & 1.51 & $1.01-2.25$ & \\
sten & 1.38 & $0.84-2.26$ & \\
\hline
\end{tabular}




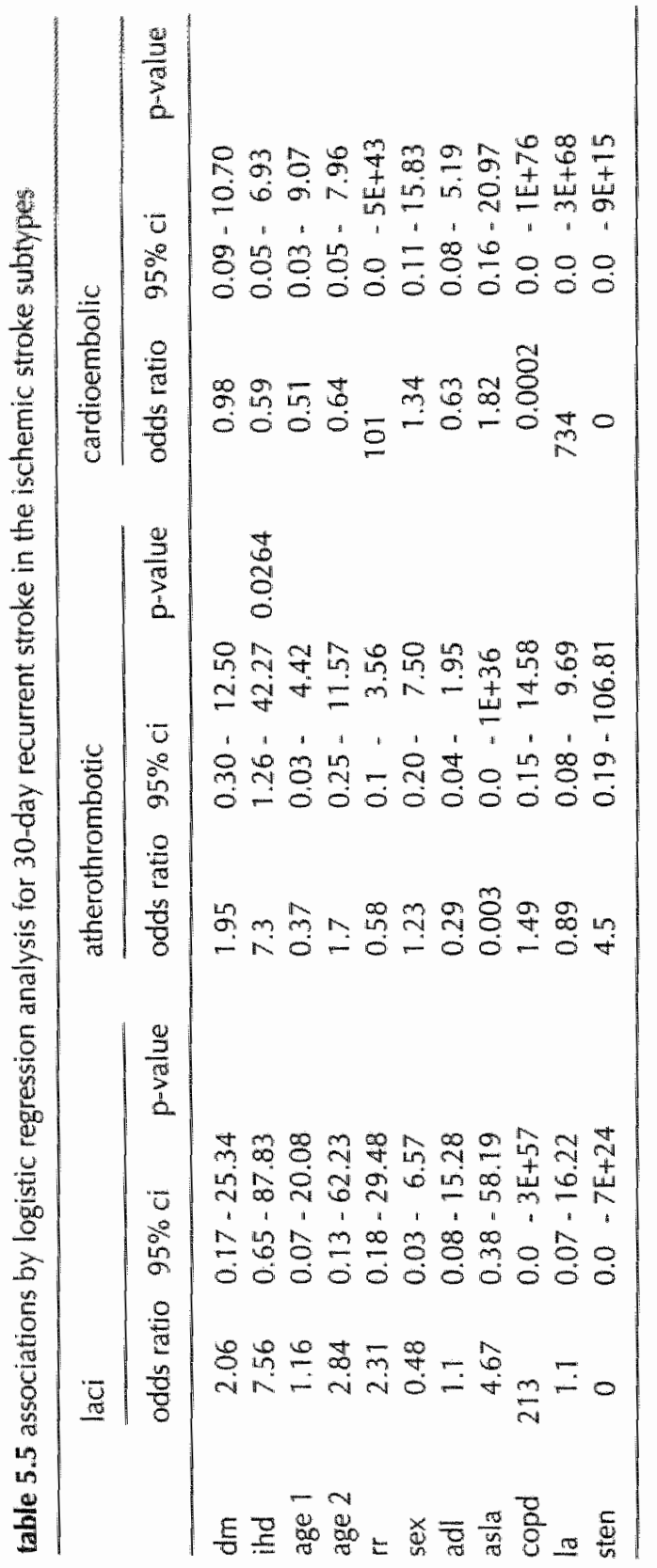


CHAPTR 5

Timing and prediction of recurrent stroke

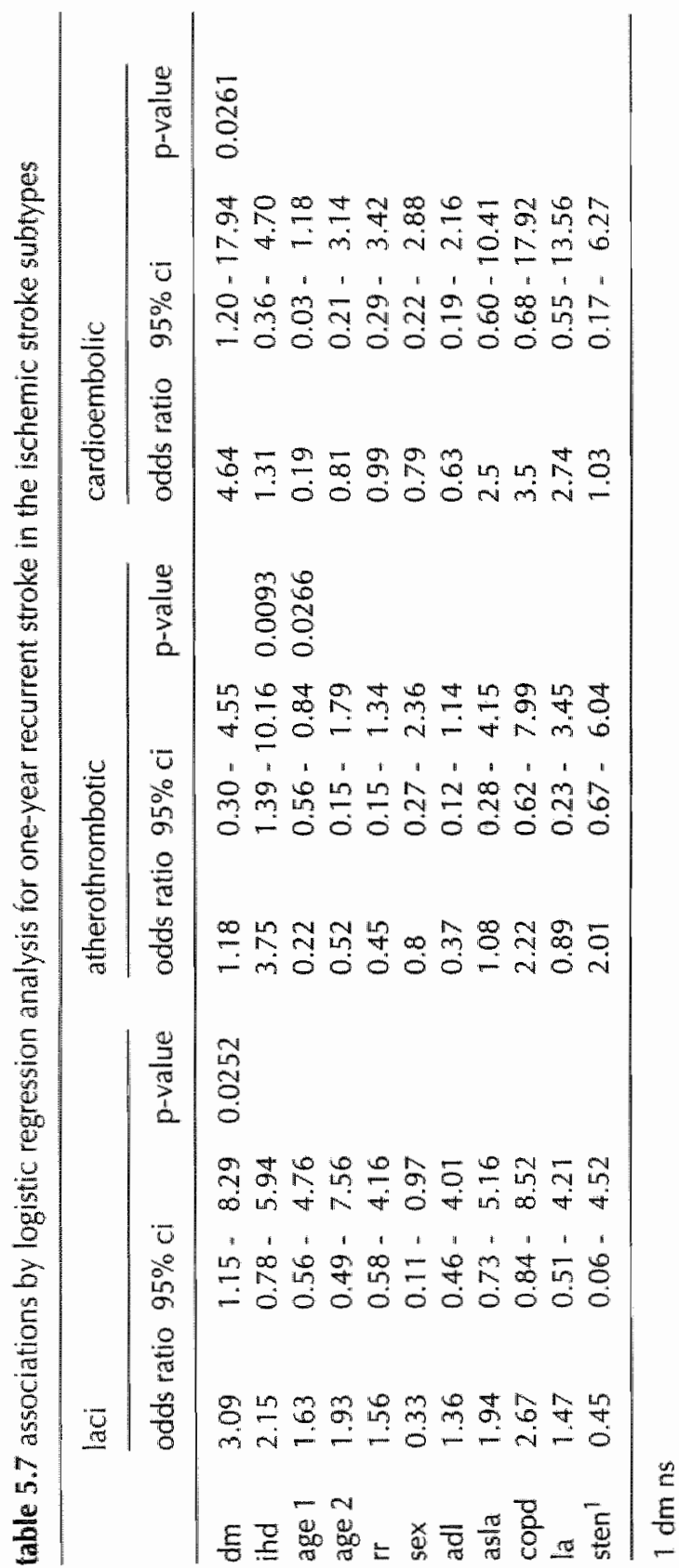




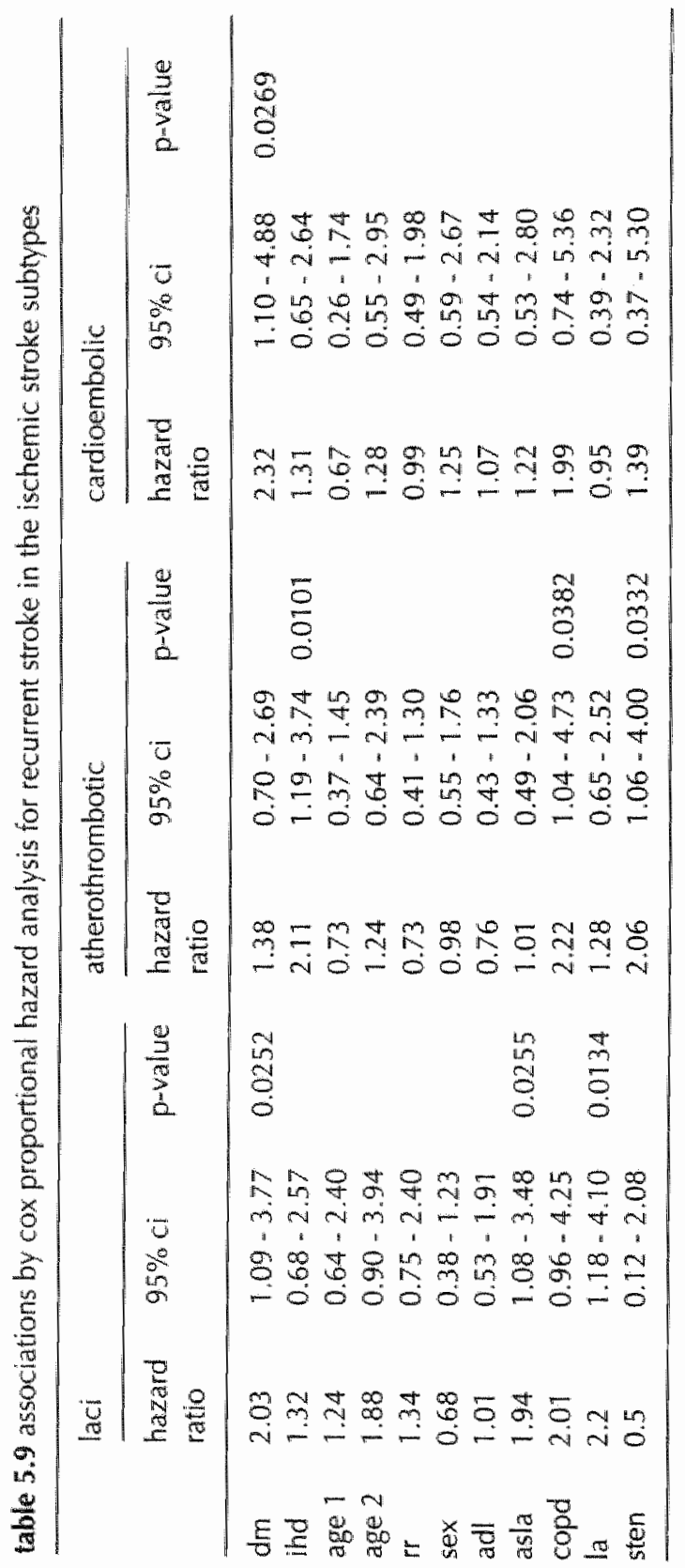




\section{DISCUSSION}

We found a one-year stroke recurrence rate following a first cerebral infarct of almost ten percent. This rate complies with those mentioned in the literature, where it varies from nine to twelve percent (see table 3.3) in the registry studies which reported their data for the whole ischemic group. Differences probably are due to differences in case mix, populations studied, inclusion of only first ever infarct patients or not, and different follow-up procedures.

We found no difference between stroke subtypes with respect to actual figures in thirty-days, one-year, or end of follow-up stroke recurrence rate. However, significant differences were found on Kaplan-Meier testing. These data for the other registries are mentioned in table 3.4 in chapter 3.

There was a certain degree of early clustering of recurrent strokes in AT and CE, as almost thirty percent of all first year recurrences occurred within the first thirty days in these subtypes. There was no evidence of early clustering in the $\mathrm{LACl}$ type as only ten percent of all first year's recurrences occurred in the first thirty days. These differences may relate to differences in underlying stroke mechanism between these subtypes: cerebral small vessel disease may manifest itself clinically more slowly over time than large vessel disease. In large vessel disease, and in cardioembolic stroke a continuing active source of embolism may be important with a high risk of early recurrence. ${ }^{[56,92,93,183,184]}$ The low even recurrence rate in our LACI group is similar to the OCSP data. ${ }^{34]}$

These data indicate that secondary preventive measures, be it modification of vascular risk factors, or the prescription of anti-platelet or anti-coagulant therapy, may best be started as soon as possible following first stroke. In fact, the IST and CAST studies showed that stroke patients may have increased benefit from aspirin when started early, $[6,7]$

We found that after the first year recurrent stroke rate declined with about fifty percent in AT and LACI patients, but not in CE. This may be related to the shorter follow-up period after the first year in $\mathrm{CE}$, which was due to higher mortality in this group. On the other hand, it could also mean that clinical manifestations of (pre-) cerebral atheromatosis not only differ between large and small vessel disease, but also between these entities and cardiogenic stroke.

We found IHD and COPD as significant predictors of early stroke recurrence in the whole ischemic group, but no clear predictors in the different stroke 


\section{点}

subtypes. For one-year recurrent stroke DM was a significant predictor in the whole group, which was also the case in the LACI and CE types.

Time-dependent analysis for the total follow-up period revealed DM, IHD, COPD, and $\mathrm{CA}$ as independent predictors of recurrent stroke in the total patient sample.

Although we did not investigate this, the influence of COPD may relate to a possible arthytmogenic side effect of anti-COPD medications. Another possible explanation for the COPD effect could be the frequent infectious episodes that accompany COPD, as in recent years a relationship between infectious disease and ischemic stroke has been established. [80,282]

From analysing stroke subtypes separately, ASLA emerged as a predictor in LACI, but not in AT or CE. This may point to a kind of coherence in the underlying stroke cause, which is small vessel disease in most lacunar stroke patients. $[83,84,85,86,87151]$ As ASLA are related to hypertension, $[40,265,266]$ it could also mean that stroke recurrence in lacunar first stroke is more strongly related to hypertension that the other stroke subtypes. However, hypertension did not emerge as an independent predictor of recurrent stroke. This may be due to the effect of hypertension treatment, or to the fact that hypertension is a strong risk factor for stroke in general, and may, therefore, not be detected as a discriminator between stroke subtypes regarding its prognostic significance. LA was also a predictor in lacunar stroke, which is a plausible finding, since it is associated with silent lacunar lesions, which mostly occur among lacunar stroke patients. $\{40,265,266\rceil$ However, LA independently predicted recurrent stroke in LACI patients, which sustains the idea that the presence of small vessel disease both in basal ganglia and cerebral white matter not only increases the risk of progression of these lesions over time ${ }^{265} \mid$, but also the risk of clinically manifest strokes. This isswe is further discussed in chapters 7 and 8 .

Apart from DM, no clear independent predictor for recurrent stroke was found in CE. This may indicate that the underlying cardiac cause of stroke in this group is the sole important risk factor for future stroke. The fact that oral anti-coagulant treatment is highly efficacious in this stroke subtype in lowering the chance of recurrent stroke, sustains this idea 1101

We found ipsilateral ICA stenosis to be a significant predictor only in the AT type. This finding is pathologically plausible and concurs with data from the carotid surgery trials. $[5,12]$ This finding does not mean that a significant ICA 
stenosis should never be regarded as the cause of stroke in lacunar stroke. First of all, carotid artery ultrasound investigations were not performed in all our patients, which may have created bias. However, as patients with more severe deficit due to territorial infarcts rather than lacunar patients could not undergo ultrasound investigations, our finding may rather be biased towards under- than overestimating the association between ICA stenosis and AT. Furthernore, some patients with small vessel disease may also develop clinical manifestations of concomitant large vessel disease, whereas it can not be excluded that large vessel artery-to-artery embolism caused a first lacunar stroke (see chapter 7 and 8). Besides, carotid endarterectomy has also been proven to lower the chance of recurrent stroke in lacunar infarct patients with a high-grade ICA stenosis. $[122,217]$

In conclusion: although the chance of recurrent stroke is similar among ischemic stroke subtypes, risk factors and temporal manifestation are different. This may point not only at a heterogeneity in underlying pathology among stroke subtypes, but also in the way they manifest themselves clinically over time. Consistency in findings pointing towards different ischemic stroke "phenotypes", may facilitate further exploration into the nature of the underlying vascular pathology. 


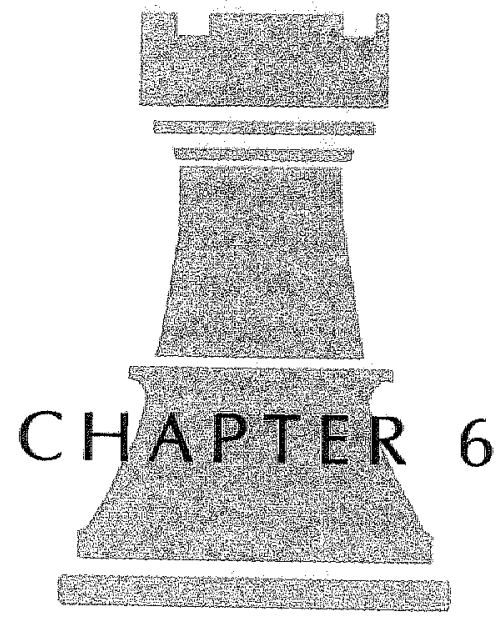


FUNCTIONAL OUTCOME AFTER A FIRST CEREBRAL INFARCT 


\section{INTRODUCTION}

Despite the fact that stroke is a life-threatening disease, most patients survive a first stroke, prognosis being better in ischemic than in hemorrhagic stroke. $\{31,70,93,126,148,207,209\}$ In those who survive a stroke, the degree of functional handicap varies. After one year, approximately $30-40$ percent is still partially or totally dependent on the support of others. $[129,96,133,138,202]$ Because of the increasing life expectancy in the Western World, and increased survival rate following stroke, especially the number of functionally handicapped elderly stroke patients is likely to rise in the near future. Accurate prediction of the degree of functional handicap is not only of importance to individual patients, but also from the prospect of health care management. Various factors that are related to functional outcome after stroke, have been studied, such as: age, the degree of motor deficit, aphasia, lesion site, lesion size, emotionalism, neglect, dysarthria, and bladder incontinence. [review 141] Factors that may serve as independent predictors of functional outcome have varied widely between studies, which is probably due to differences in study design and study methods. Obviously, functional outcome is difficult to predict, which may relate to the possibility that various functional outcome predictors have different impact depending on the stroke subtype. Outcome prediction has often been studied without accounting for possible differences between stroke subtypes. As the degree of initial neurological deficit and the underlying pathology differs between stroke subtype, the impact of any prognostic factors may vary between stroke subtypes.

Ideally, functional outcome prediction should be reliable and robust, using a limited number of predictors that are easy to measure in all patients. The OCSP classification of ischemic stroke in only four categories, ${ }^{[32]}$ based on clinical syndromes has proven its use in clinical trials, although one should realise that an OCSP syndrome diagnosis was allotted post hoc in most trials. However, the OCSP classification does not distinguish individual predicting factors. Identifying independent predictors of stroke outcome could offer the possibility to modify these factors to try and improve prognosis following stroke.

Therefore, in this study we explored a number of easy to measure clinical and CT scan features that could possibly predict functional outcome in 998 patients with a first cerebral infarct, accounting for stroke subtype. 


\section{PATIENTS AND METHODS}

These are extensively described in chapter 2 . For this study we used the dichotomised modified Rankin scale (grades $0-1-2-3$ versus grades 4-5) as a measure for functional independency versus functional dependency in surviving patients. This Rankin grade was determined at the end of the follow-up period.

\section{STATISTICAL EVALUATION}

We calculated the proportion of dependent survivors for the ischemic subtypes at the end of the follow-up period. For duration of follow-up, see table 7.1

We performed multivariate logistic regression analysis to determine associations for unfavourable functional outcome defined as Rankin grades 0-1-2 or 3 versus grades 4 or 5 in surviving patients. In this analysis we used a standard model of risk factors (DM, IHD, age, RR, and sex) to which the other risk factors one by one were subsequently added and removed. Results are represented as odds ratio (OR) with $95 \%$ confidence interval (CI), and p-value in case of significant associations. These analyses were done for the whole group, and for the ischemic subtypes.

\section{RESULTS}

Table 6.1 shows the numbers of survivors at the end of follow-up, and proportion of patients functionally dependent, independent, or dead. Tables 6.2 and 6.3 show the differences in dependency at stroke onset and at the end of the follow-up. Table 6.4 shows the results of the logistic regression analysis for unfawourable functional outcome in survivors at the end of follow-up. Age, stroke subtype (LACI better than both AT and CE), degree of neurological deficit at first stroke, the presence of asymptomatic LACI or LA on CT, and stroke recurrence were significant independent predictors of functional outcome in stroke survivors. More severe neurological deficit was the most powerful predictor of unfavourable outcome, and lacunar stroke subtype the most powerful predictor of favourable functional outcome at the end of follow-up. 
table 6.1 functional dependency at stroke onset and at end of follow wp in the infarct subtypes

\begin{tabular}{lccl}
\hline & laci & at & ce \\
\hline number & 339 & 435 & 224 \\
dependent at stroke onset & $105(31)$ & $261(60)$ & $153(68)$ \\
mortality end of follow-up & $88(26)$ & $156(36)$ & $117(52)$ \\
survivors & 251 & 279 & 107 \\
dependent end of follow-up & $18(7)$ & $61(22)$ & $22(21)$ \\
\hline
\end{tabular}

numbers are absolute numbers; numbers in brackets are percentages

table 6.2 comparison of functional dependency at end of follow-up between the ischemic stroke subtypes

\begin{tabular}{llll}
\hline & odds ratio & $\begin{array}{l}\text { confidence } \\
\text { interval }\end{array}$ & p-value \\
\hline lacivs at & 0.28 & $0.16-0.48$ & $<0.001$ \\
laci vs ce & 0.3 & $0.15-0.59$ & $<0.001$ \\
at vs ce & 1.08 & $0.36-3.21$ & \\
\hline
\end{tabular}

table 6.3 comparison of functional dependency at stroke onset between the ischemic stroke subtypes

\begin{tabular}{llll}
\hline & odds ratio & $\begin{array}{l}\text { confidence } \\
\text { interval }\end{array}$ & $p$-value \\
\hline laci vs at & 0.3 & $0.22-0.40$ & $<0.001$ \\
laci vs ce & 0.21 & $0.15-0.30$ & $<0.001$ \\
at vs ce & 0.7 & $0.49-0.99$ & $<0.05$ \\
\hline
\end{tabular}


table 6.4 associations by logistic regression analysis for functional dependency in stroke survivors, ischemic stroke subtype included in standard model

\begin{tabular}{lllr}
\hline & odds ratio & \multicolumn{1}{c}{$95 \% \mathrm{ci}$} & p-value \\
\hline dm & 1.57 & $0.89-2.78$ & \\
ihd & 0.85 & $0.50-1.46$ & \\
age 1 & 2.26 & $1.26-4.03$ & 0.0059 \\
age 2 & 4.9 & $2.69-8.94$ & $<0.0001$ \\
ri & 0.82 & $0.51-1.30$ & \\
sex & 1.22 & $0.77-1.96$ & \\
str type at vs laci & 3.76 & $2.12-6.69$ & $<0.0001$ \\
str type ce vs laci & 2.69 & $1.34-5.41$ & 0.0053 \\
adi & 5.67 & $3.28-9.80$ & $<0.0001$ \\
asla & 2.38 & $1.42-4.01$ & 0.0011 \\
copd & 2.01 & $0.96-4.24$ & \\
la & 2.25 & $1.32-3.84$ & 0.0028 \\
sten & 1.75 & $0.89-3.43^{1}$ & \\
recurrent stroke & 3.39 & $1.81-6.36$ & 0.0001 \\
\hline
\end{tabular}

1: age $1 \mathrm{~ns}$; functional disability as measured at the end of the follow-up

Table 6.5 shows the results of the logistic regression analysis for unfavourable functional outcome separately in the three stroke subtypes. In LACI high age, stroke severity, LA, and recurrent stroke were all powerful, independent predictors of unfavourable outcome. In AT high age, stroke severity, and recurrent stroke were predictors, and in CE stroke severity, and asymptomatic L.ACI. Most remarkable are the findings of LA in LACI, and of asymptomatic LACI in CE as predictors of functional outcome. 


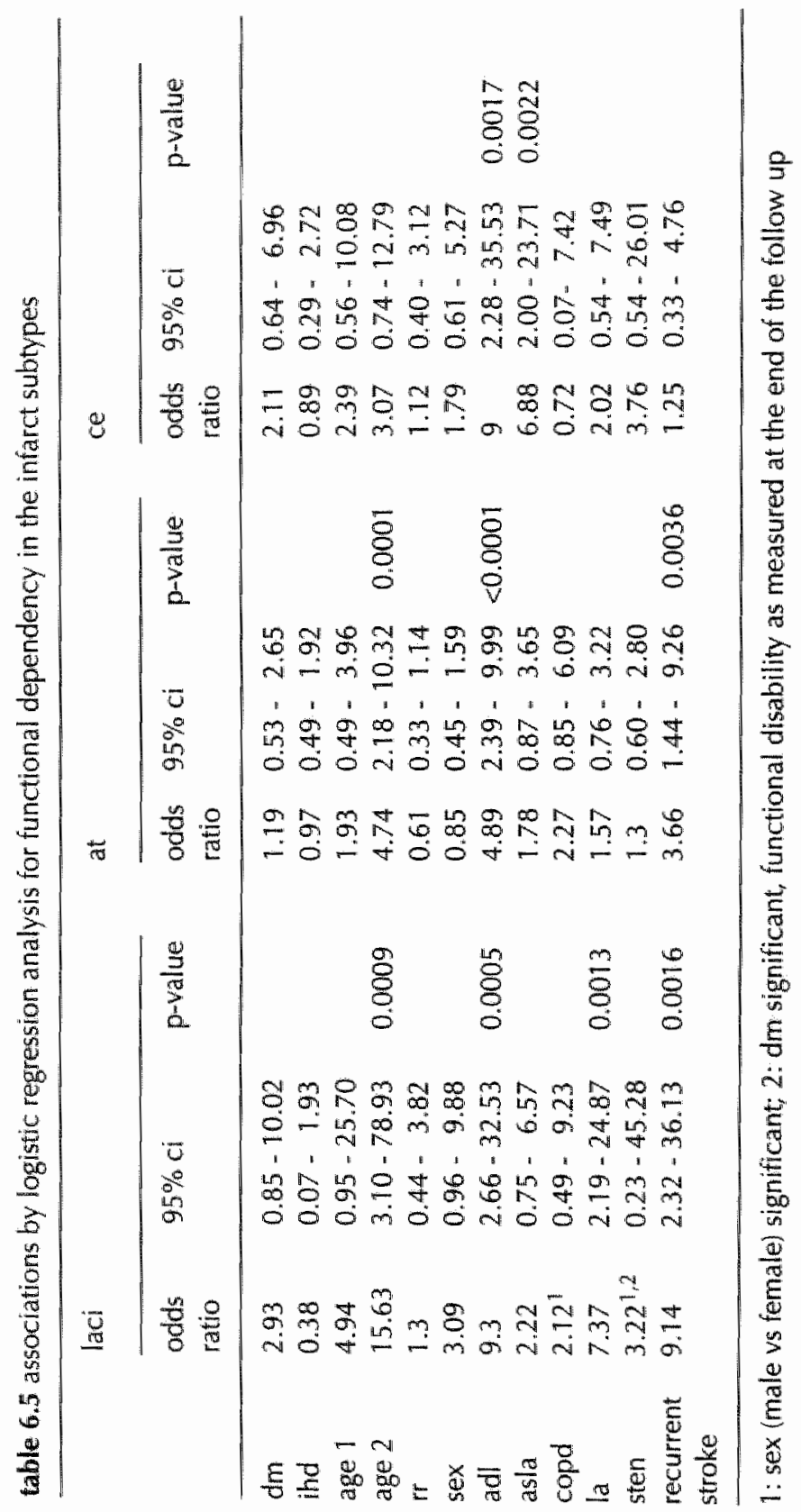




\section{DISCUSION}

This chapter explored independent predictors of unfavourable functional outcome of ischemic stroke survivors at the end of follow-up. Stroke subtype was an independent predictor, with LACr predicting favourable, and CE most strongly predicting unfavourable functional outcome. The number of independent predictors depended on stroke subtype, with most predictors in $\mathrm{LACI}$ and the lowest number in CE. Stroke severity was the least powerful predictor in $\mathrm{LACl}$, whereas it was the strongest predictor in CE. Obviously, eventual functional outcome in stroke survivors is influenced by a number of factors depending on initial stroke severity, which is related to stroke subtype. What determines functional outcome in the first place is initial stroke severity related to stroke subtype. In $\mathrm{CE}$ the usual vascular risk factors do not contribute to risk of unfa-vourable functional outcome. Even age nor recurrent stroke contributed to this risk, which reflects the strong predictive power of the stroke subtype itself for unfavourable functional outcome. A remarkable finding was asymptomatic LACI as independent predictor in the CE subtype. This could reflect the possibility that in CE not only infarct volume but also infarct multiplicity contributes to the degree of functional handicap. In AT patients age and recurrent stroke, besides initial stroke severity were independent predictors. In LACI, obviously, not the degree of initial stroke severity but the impact of various factors dictate the degree of eventual functional handicap in survivors. LA was an evident predictor in this stroke subtype. That "silent" lacunar lesions and LA influence functional outcome is biological plausible: these lesions may damage various neuronal projections, which result in disturbances of coordination, motor pattern activation, sensory integration, and mental speed, among others.

Why the stroke subtypes vary widely in the number of predictors of functional outcome may, besides the impact of stroke subtype-related degree of initial stroke severity, also relate to differences between the subtypes in risk of recurrent stroke and its severity, and the risk of death. As more CE patients had died during follow-up, the duration of follow-up in CE stroke survivors was considerably shorter than in the other two subtypes (see chapter 5), as death marked the end of follow-up in our cross sectional study. In the Rochester population, ${ }^{[202]}$ functional disabilities were different across the ischemic types as well, similar to our 


\section{解}

study, LACI being associated with milder neurological defects compared to the other subtypes.

The classical vascular risk factors had hardly any significant associations with functional outcome. They are however predictors of recurrent stroke, death, or both, which in turn influence analysis on global outcome (see chapters 4 and 5). These findings suggest that the risk of unfavourable functional outcome in stroke survivors is unlikely to be lowered by more diligent treatment of risk factors. They also suggest however, that the patients with one or more of the classical risk factors do not have a higher risk of more unfavourable functionall outcome than patients without the classical risk factors. Attempting to lower the degree of initial stroke severity looks more promising. This can be achieved by stroke unit treatment, thrombolysis, and hopefully in the near future, by acute stroke neuroprotective measures. Also, lowering the risk of recurrent stroke may ameliorate prognosis on eventual functional outcome in stroke survivors (see chapter 5).

A drawback of the study is the fact that a single cross-sectional follow-up on the degree of functional handicap was performed in stead of follow-up at regular pre-specified time intervals. Differences in stroke survival and consequent duration of follow-up between stroke subtypes may have influenced the differences we found between them. On the other hand, findings were rather consistent between stroke subtypes on the (absent) role of vascular risk factors, and on the predictive value of age, and of initial stroke severity. Therefore, we think that the follow-up method did not render the data on functional outcome in our sample of stroke survivors invalid, or biased in any major way.

We conclude that the degree of eventual functional outcome in ischemic stroke survivors is unlikely to be improved by more diligent treatment of modifiable risk factors, independent of lowering the risk of recurrent stroke. Therapies that limit the degree of initial stroke severity may contribute substantially to more favourable long-term functional outcome. Admittance to a stroke unit, and thrombolytic treatment are currently established means to this end. 
CHAPTE 6

Functional outcome after a first cerebral infarct

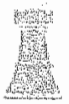




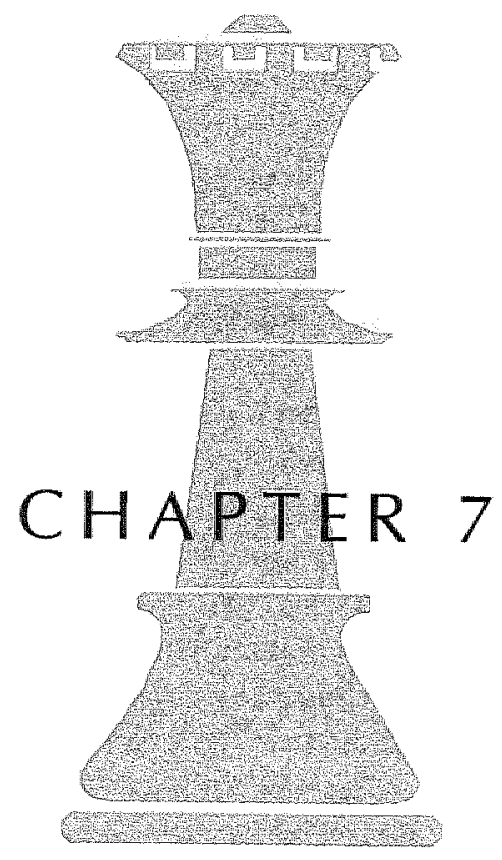


SUBTYPE AND BRAIN TERRITORY OF RECURRENT STROKE POINT AT HOMOGENEITY OF UNDERLYING STROKE CAUSE OVER TIME 


\section{INTRODUCTION}

Stroke is a recurrent disease. Approximately one fourth of hospital admissions for stroke are for recurrent stroke. [130,138] Risk factors for the development of first ever stroke are well defined, [53] whereas those for recument stroke are less clear. No independent factor has been associated with an increased or decreased risk or recurrent stroke. $[101,105]$ This indicates that the mechanisms underlying recurrent stroke are complex and multi-factorial, and that they may differ from the mechanisms underlying furst-ever stroke.

Not only the risk of recurrence, but also stroke severity and consequent prognosis of recurrence may differ between stroke subtypes. [56] Therefore, knowledge on how often recurrent stroke is of the same type as the first-ever stroke is relevant for prognosis, as is knowledge on factors that predict a certain recurrent stroke subtype. Data on these issues are scarce and contradictory as studies so far were small; $[57,145,183,184,231]$ used selected patients such as those from clinical trials, whereas subtype diagnosis in these patients was done in retrospect using non-validated symptom lists [2,12]; studies were retrospective $[228,284]$; recurrent stroke subtype ascertainment was insufficient; $[34,56,111,143,240,219,220,223,201,202]$ studies were restricted to stroke subgroups, mainly lacunar stroke; $[34,65,90,100,175,204,226,229,230,231]$ did not use first ever stroke patients; $[65,97,107,111,125,130,139,172,183,184,273,274,276]$ or used insufficient ischemic subtyping. $[16,57,62,125,192,273,274,276$, Other problems were: insufficient CT in first (and recurrent) stroke, inclusion of hemorrhage or TIA, or restricted age populations. In addition to their relewance for patient management, data on recurrent stroke may provide information about heterogeneity of the underlying vascular pathollogy and how this develops over time. Pathogenetically homogeneous vasculopathies may be detected, which may eventually lend themselves better to study the nature of cerebral vascular diseases on a cell-biological level.

In this study, we present the follow-up results of 998 patients with first-ever ischemic brain infarct prospectively registered, with CT confirmation of the recurrent stroke type in the majority, and report on the following issues concerning stroke recurrence: subtype of recurrence in relation to type of presenting infarct, independent predictors for type of recurrence, and whether stroke recurrence occurred in the same brain territory as the first stroke. 


\section{PATIENTS AND METHODS}

The methodology of the study has been described extensively in chapter 2 . For this chapter we established type of recurrent stroke. We also studied whether recurrent stroke occurred in the same brain territory as the first stroke (cerebtal hemisphere, or brainstem/cerebellum).

\section{STATISTICAL EVALUATION}

Differences between groups were compared by unadjusted odds ratios with $95 \%$ confidence interval (chi square). We performed logistic regression analyses to look for independent predictors of type of recurrence (dependent variable LACI versus nonLACI; AT vs nonAT, and $\mathrm{LACI}$ or PICH vs nonLACI and nonPICH). For further details of logistic regression analysis see chapters $2,4,5,6$.

\section{RESULTS}

Mean follow-up was 691 days \pm 521 (SD) for all patients (death marking the end of the cross sectional follow-up), for survivors $881 \pm 465$ (SD). Table 7.1 shows the number of first recurrent stroke and the duration of follow-up in the different stroke subgroups. Differences in follow-up duration are related to differences in death rate between the stroke subgroups. Table 7.2 shows the recurrent stroke subtype related to the first stroke subtype. Nine recurrent strokes could not be classified because no CT had been performed, or due to the absence of sufficient clinical information, or both. Fifty-seven percent of lacunar, 83 percent of atherothrombotic, and 94 percent of cardioembolic strokes were of the same subtype as the first stroke. Table 7.3 shows how often recurrent stroke of the same subtype as the first stroke was in the same brain territory as the first stroke. Seventy percent of lacunar (OR: $3.36 ; 95 \% \mathrm{Cl}: 0.97-11.67$ ), and seventy nine percent of AT recurrent strokes that were 'true to type' occurred in the same brain territory as the first stroke (OR: $5.31 ; 95 \% \mathrm{Cl}: 1.72-16.45$ ), whereas this was the case in only thirty-nine percent of CE recurrent strokes. Recurrent lacunar infarcts that were "true to type" occurred after a mean of $382 \pm 335$ (SD) 


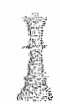

table 7.1 duration of follow-up in days and number of recurrent strokes

\begin{tabular}{lllll}
\hline & $\mathrm{n}$ & $\begin{array}{l}\text { recurrent } \\
\text { strokes }\end{array}$ & follow-up & \\
\cline { 4 - 5 } & & & all & survivors \\
\hline all & 998 & 138 & $691(521)$ & $881(465)$ \\
laci & 339 & 49 & $832(521)$ & $927(509)$ \\
at & 435 & 53 & $661(498)$ & $843(441)$ \\
ce & 224 & 36 & $537(509)$ & $870(412)$ \\
\hline
\end{tabular}

numbers in brackets are standard deviation; follow-up in days is given as mean and (standard deviation)

table 7.2 type of recurrent stroke following first ischemic brain infarct

\begin{tabular}{|c|c|c|c|}
\hline \multirow[b]{2}{*}{ recurrent type } & \multicolumn{3}{|c|}{ index type } \\
\hline & laci & at & $\mathrm{ce}$ \\
\hline laci & $27(57)$ & $4 \quad(9)$ & $0 \quad(0)$ \\
\hline at & $10(21)$ & $38(83)$ & $0 \quad(0)$ \\
\hline ce & $419)$ & $0 \quad(0)$ & $33(94)$ \\
\hline pich & $6(13)$ & $4 \quad(9)$ & 2 (6) \\
\hline sah & $0 \quad(0)$ & $0 \quad(0)$ & $13)$ \\
\hline unknown & 2 (4) & $7(13)$ & $0 \quad(0)$ \\
\hline
\end{tabular}

numbers in columns are absolute numbers of recurrent stroke; numbers in brackets are percentage of recurrent stroke. leaving unknown, sah, and undetermined out 
C HA TER 7

Subtype and brain teritory of recurrent stroke

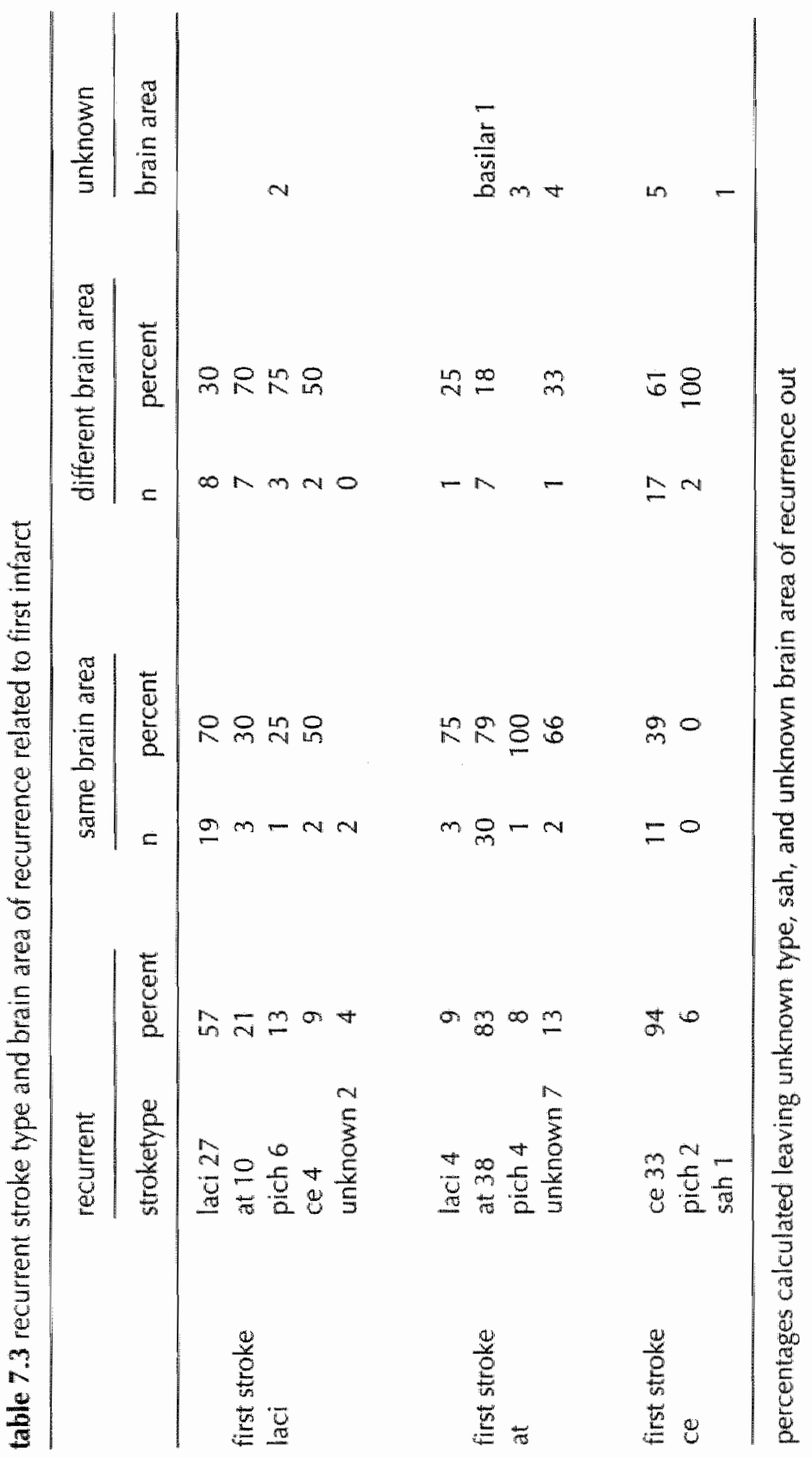


CHA I I E 7

Sabtype and brain temtory of recurrent stroke

table 7.4 time interval between first and recurrent stroke (days)

\begin{tabular}{lllll}
\hline & rec & delay & $\begin{array}{l}\text { same } \\
\text { brainarea }\end{array}$ & $\begin{array}{l}\text { different } \\
\text { brain area }\end{array}$ \\
\hline laci & laci & 456 & 382 & 630 \\
& at & 703 & 864 & 638 \\
& ce & 128 & 53 & 203 \\
at & at & 257 & 258 & 251 \\
& laci & 777 & 1002 & 102 \\
& ce & 357 & 324 & 356 \\
\hline
\end{tabular}

table 7.5 associations by logistic regression analysis for recurrent stroke type; lacunar versus nonlacunar recurrent stroke

\begin{tabular}{lccc}
\hline & adds ratio & $95 \% \mathrm{Cl}$ & p-value \\
\hline $\mathrm{dm}$ & 0.77 & $0.22-2.67$ & \\
ihd & 0.87 & $0.25-2.99$ & \\
$\mathrm{ir}$ & 3.49 & $1.09-11.16$ & 0.0314 \\
sex & 0.31 & $0.09-1.15$ & \\
age group 2 vs 1 & 1.23 & $0.34-4.40$ & \\
age group 3 vs 1 & 0.79 & $0.18-3.60$ & \\
first type laci vs nonlaci & 14.29 & $4.00-50.00$ & $<0.0001$ \\
\hline
\end{tabular}

table 7.5.1 associations by logistic regression analysis for recurrent stroke type; lacunar infarction or PICH versus nonlacunar non PICH

\begin{tabular}{llll}
\hline $\begin{array}{l}\text { dependent } \\
\text { variable }\end{array}$ & odds ratio & $95 \% \mathrm{Cl}$ & p-value \\
\hline $\mathrm{dm}$ & 0.78 & $0.27-2.28$ & \\
ihd & 0.78 & $0.28-2.22$ & \\
age group 2 vs 1 & 1.2 & $0.37-3.90$ & \\
age group 3 vs 1 & 1.2 & $0.34-4.24$ & \\
if & 2.03 & $0.76-5.46$ & \\
sex & 0.58 & $0.20-1.71$ & \\
index laci vs at & 10 & $3.70-33.33$ & $<0.0001$ \\
index laci vs ce & 33.33 & $7.69-200$ & $<0.0001$ \\
\hline
\end{tabular}


table 7.6 associations by logistic regression analysis for recurrent stroke type; atherothrombotic versus non-atherothrombotic

\begin{tabular}{lccc}
\hline & odds ratio & $95 \% \mathrm{Cl}$ & p-value \\
\hline dm & 1.73 & $0.49-6.08$ & \\
ihd & 0.87 & $0.24-3.17$ & \\
age group 2 ws 1 & 1.05 & $0.26-4.21$ & \\
age group 3 ws 1 & 0.56 & $0.12-2.56$ & \\
hypertension & 0.17 & $0.05-0.59$ & 0.0053 \\
sex & 2.37 & $0.62 \times 9.11$ & \\
index at vs laci & 24.12 & $6.92-84.02$ & $<0.001$ \\
\hline
\end{tabular}

table 7.7 30-day case fatality rate after recurrent stroke compared with first infarct

\begin{tabular}{lrrrrrrr} 
& 30 day cf & rec stroke & $\begin{array}{l}30 \text { day cf } \\
\text { recurrence }\end{array}$ & OR $(95 \%$ ci) & p-value \\
\hline laci 339 & 7 & $(2)$ & 49 & $7(14)$ & $7.90(2.78-22.48)$ & $<0.001$ \\
at & 435 & $43(10)$ & 53 & $14(26)$ & $3.27(1.62-6.60)$ & $<0.001$ \\
ce 224 & $51(23)$ & 36 & $11(31)$ & $1.47(0.55-3.93)$ & \\
\hline
\end{tabular}

cf: case fatality; numbers are absolute numbers; numbers in brackets are percentages

table 7.8 percentage recurrent stroke per year

\begin{tabular}{lrc}
\hline & all & survivors \\
\hline all & 7 & 9 \\
laci & 6 & 8 \\
at & 7 & 8 \\
ce & 11 & 14 \\
\hline
\end{tabular}


: i

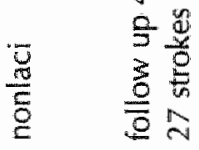
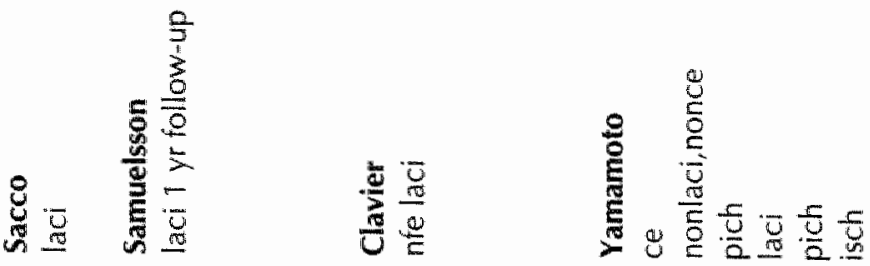


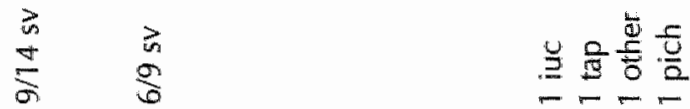

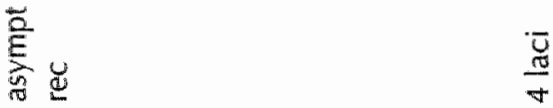

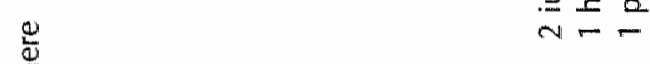

$\frac{5}{\frac{2}{5}}$

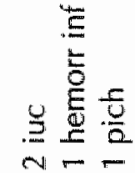

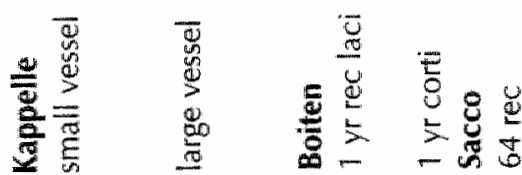

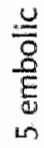

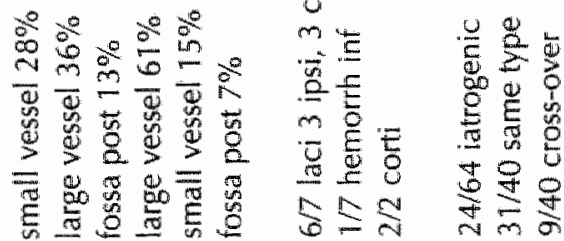

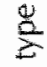

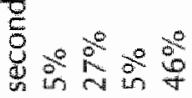

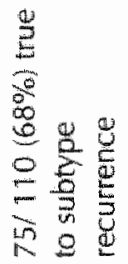

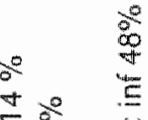

$\pi 0^{2}$

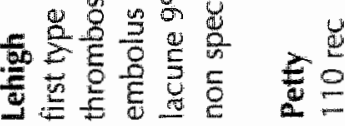




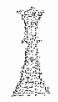

days if in the same, and $630 \pm 533$ (SD) days if in a different brain territory (table 8.7), this difference was not statistically significant (independent $T$-test 0.154 ). For AT recurrences the figures were 258 , and 251 days, respectively, and for CE: 324 , and 356 days, respectively (table 7.4). Table 7.5 shows the results of the logistic regression analyses for independent predictors of lacunar versus non-lacunar recurrent stroke subtype. Lacunar first infarct appeared as a strong predictor. Also, hypertension was an independent predictor of lacunar type stroke recurrence. In table 7.5.1 the results for lacunar or PICH subtype versus nonlacunar nonPICH recurrent stroke (as a measure of small vessel vs nonsmall vessel recurrent type) are given. Table 7.6 shows the results for the AT recurrent stroke subtype. Here, hypertension was inversely related to AT subtype stroke recurrence, whereas first AT stroke subtype was a strong independent predictor. Thirty-day case fatality rate after recurrent stroke was more than double the rate after index infarction ( 23 vs $11 \%$ for the whole group, table 7.7 ).

\section{DISCUSSION}

After a mean follow-up of almost two years in our 998 patients, we found fourteen percent stroke recurrences. Percentage of recurrent stroke and the number per follow-up years were similar among the different stroke subtypes (see chapter 5). Most recurrent strokes were of the same subtype as the first stroke. First stroke subtype was a strong independent predictor of recurrent stroke subtype. These findings indicate a high degree of homogeneity as to the underlying vascular pathology of stroke subtypes over time. We found that over two-third of the "true to type" stroke recurrences were located in the same brain territory as the first stroke in lacunar and atherothrombotic infarcts, which supports the idea of homogeneity of the underlying vascular pathology and predilection as to location over time. Cardioembolic recurrent strokes were significantly less often in the same area than lacunar or atherothrombotic recurrences, which is in line with the idea that cardiogenic emboli have no preference to a certain vascular territory as opposed to atherothrombotic and lacunar stroke. We did not expect to find most lacunar stroke recurrences in the same area as the first lacunar stroke, as we considered cerebral small vessel disease likely to be more generalised instead of more restricted to a certain area. However, most lacunar strokes are probably due 


\section{翟}

to atheromatosis of the small, deep vessels which, as atheromatosis of large vessels obviously shows a territorial predominance over time. So, this predominance may be related to the nature of the vasculopathy which is atheromatosis of the large vessels in atherothrombotic stroke, and small vessel atheromatosis in most lacunar strokes. The other small vessel vasculopathy, which is arteriolosclerosis, may show less territorial restriction over time, and in fact our data in chapter 8 confirms this idea: recurrent lacunar stroke in patients who likely have arteriolosclerosis is not predominantly in the same area as the first stroke.

Not all recurrent strokes were of the same type as the first stroke, especially in the lacunar stroke group. However, six recurrent strokes in the lacunar stroke group were intra-cerebral haemorrhage, most of which are caused by small vessel disease. About twenty percent of the recurrences in the lacunar group were atherothrombotic infarcts, and about ten percent in the atherothrombotic group recurrences were of lacunar type. Obviously, the two types of cerebral vascular diseases are not mutually exclusive. This may be due to extension of atheromatosis to different territories as it progresses over time. However, the degree of difference in the clinical manifestation of small or large vessel disease, even if pathologically of similar nature, is greater than its degree of similarity over time, as most recurrent ischemic strokes were of the same subtype as the first stroke, and occurred in the same brain area. Non-lacunar recurrent strokes in the cardioembolic subgroup, are by definition cardioembolic again, unless the cardiogenic cause at the time of first stroke disappeared. But there were no recurrent lacunar strokes in this group, which confirms the idea that cardiogenic strokes are basically different from strokes caused by (pre-)cerebral vascular disease. This difference is also reflected in the effect of secondary stroke prevention by oral anticoagulants, which, as currently known, is quite different between cardioembolic and remaining other ischemic stroke subtypes.

Many studies state that stroke recurrences are predominantly of the same type as the first stroke. However, they rarely provided sufficient details to verify that statement. As mentioned in the introduction, most studies suffered from significant methodological flaws, largely invalidating interpretations. Whether recurrent stroke was "true to type" was best investigated in series of lacunar stroke patients, and percentages varied from 23 to $63 .[29,41,65,90,132,175,227,229,231,231,284]$ Other lacunar stroke series however were not able to comment on the pathological type of the recurrent stroke at all. $[34,111,145,226]$ These series, of course, gave 


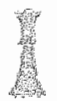

no information on the percentage of similar recurrent stroke in non-lacunar patients.

From the patient's perspective it is important to know that the risk of stroke recurrence is independent of stroke subtype. For lacunar stroke patients it may be comforting to know that they have a more than fifty percent chance that a recurrence is again lacunar. Diligent treatment of hypertension may especially be relevant for these patients, as we found hypertension to be an independent predictor of recurrent lacunar infarction, despite the fact that our patients received usual preventive therapy. However, we did not measure compliance to these therapies, and it is known that many stroke patients do not receive or take standard preventive treatment (see chapter 5).

A major finding in this chapter is that small and large vessel disease show a high degree of homogeneity as to vascular pathology and vascular territory involved over time. However, some ten to twenty percent of patients have, or develop, manifestations of both vasculopathies over time. Hypertension is an independent predictor of recurrent lacunar infarcts. Further study into the nature of especially cerebral small vessel disease may be linked to the study of hypertension, but further distinction of two different lacunar stroke subtypes may be relevant in this respect (see chapter eight). What causes atheromatosis to manifest itself in large or small vessel territory, remains unclear. The reason for this difference may be a target within reach to be studied on a cell biological level, to further explore the basic nature and cause of cerebral vascular disease. 
$\mathrm{CHATER} 7$

Subtype and brain territory of recurrent stroke 


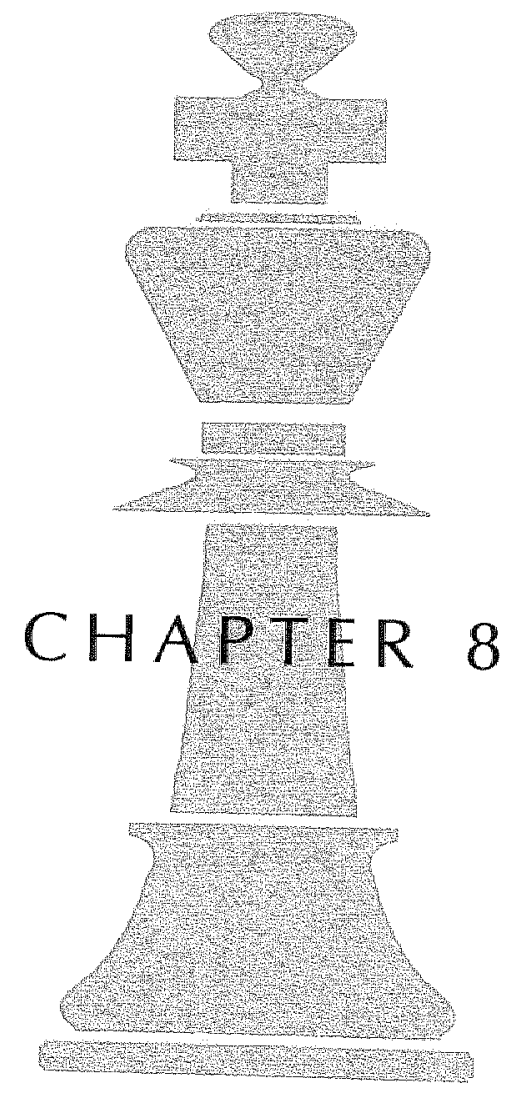




\section{TWO TYPES OF LACUNAR INFARCTS:}

Further evidence from a study on prognosis

C. de Jong 1, 1. Lodder', F. Kessels 3

'Dept of Neurology, Isala clinics location Weezenlanden Zwolle, The Netherlands; ${ }^{2}$ Dept. of Neurology, University Hospital Maastricht, The Netherlands; ${ }^{3}$ Clinical Epidemiology and Medical Technology Assessment, University Hospital Maastricht, The Netherlands 


\section{INTRODUCTION}

Lacunar infarcts are mainly caused by small vessel disease occluding a small perforating artery. At autopsy, Fisher distinguished two types of underlying vascular pathology: lipohyalinosis and micro-atheromatosis. $83,84,85,86,87]$ Lipohyalinosis was mainly present in patients who had hypertension during life, whereas the lacunes Fisher found were small, multiple, and asymptomatic. Microatheromatosis was mainly found in cases with single, larger, symptomatic lacunes. Periventricular white matter hypodensities on CT, or so-called leukoaraiosis, has also been shown to be caused by lipohyalinosis of white matter perforating small arteries. $[113,14,151,280]$ Leukoaraiosis has also been associated with hypertension. [151,73,79,152,263] Earlier we found that lacunar stroke patients with one or more asymptomatic lacunar infarcts on CT, significantly more often had leukoaraiosis and hypertension than patients without asymptomatic small deep infarcts. 40$]$ Moreover, we found that the symptomatic lacunar infarcts were larger than the asymptomatic ones. These data concurred with Fisher's pathologic findings. Based on these data we hypothesized that the two types of underlying small vessel pathology (lipohyalinosis and microatheromatosis) could be distinguished during life, and that hypertension, and probably especially severe hypertension, is more strongly related to lipohyalinosis. Pathological studies suggested that the term "arteriolosclerosis" would be more appropriate than lipohyalinosis, although the reasons behind this preference differed between studies. $[144,264]$

Results from clinical studies, [170,245] a study on CBF in lacunar stroke, [176] studies on cerebrovascular reactivity, ${ }^{178,191]}$ a study on cerebral bloodflow, 190$]$ and from a study in neurologically normal people [24,255] concur with our hypothesis. Further evidence that a similar small vessel vasculopathy underlies both leukoaraiosis and nultiple small deep infarcts came from a follow-up CT study, that showed marked progression of both these phenomena, occurring mainly in lacunar stroke patients. 267$]$ Two other studies also showed progression of white matter lesions in lacunar stroke. ${ }^{236.249]}$ Others found no evidence in favour of the hypothesis on two different types of lacunar strokes, $[165,227]$ or stated that similar underlying pathology in silent lacunar stroke and leukoaraiosis remains unclear. $[82,113,114]$ It is unknown how lesion progression influences prognosis following a first lacunar stroke. If patients with a single symptomatic lacunar stroke would 


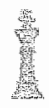

have better prognosis over time than those with silent lacunar lesions besides the symptomatic lacunar stroke, this would provide further arguments in favour of two distinct types of lacunar stroke. To test this hypothesis we performed a follow-up study in 339 patients with a first lacunar stroke.

\section{PATIENTS AND METHODS}

These were extensively described in chapter 2 . Specifically, the lacunar stroke type was divided in two separate subtypes: lacunar patients with evidence of asymptomatic lacunar lesions on CT (LACI+), versus lacunar patients without such lesions (LACI-). To contrast both types even further, we also used a second division of the lacunar stroke type: lacunar patients with both at least one asymptomatic lacunar lesion and leukoaraiosis $(\mathrm{LACl}+/+)$, versus patients with neither (LACI-/-).

\section{STUDY POPULATION}

Of 998 patients $339(34 \%)$ had lacunar stroke. Of these, 333 had at least one CT when they had the first stroke. Of the 48 patients with a recurrent stroke after a first lacunar infarct, 37 patients were admitted to our hospital, and in 36 (75\%) of all recurrences a $\mathrm{CT}$ was made.

Mean time between first stroke and final follow-up was 785 days for the group with asymptomatic lesions (SD 479), and for the group without 865 days (SD 545). For the survivors mean duration of follow-up was 872 days (SD 459) for the group with asymptomatic lesions versus 953 days (SD 526) for those without.

\section{STATISTICAL EVALUATION}

For both lacunar subtypes we calculated and compared the baseline characteristics, testing for significance of difference (univariate analysis, chi square, odds ratio with $95 \%$ confidence interval. When a variable was significant differently distributed between the two types, a p-value was calculated as well). We 
compared 30-day, one-year and total mortality, and 30-day, one-year and total stroke recurrence, as well as ultimate functional outcome between stroke subtypes with the same tests.

We performed a logistic regression analysis with the lacunar subtype as the dependent variable, and sex, age, diabetes, ischemic heart disease, and hypertension as independent variables in a standard model, with later inclusion of leukoaraiosis in the model (associations are expressed as odds ratio with $95 \%$ confidence intervals, p-values for significant associations).

We also performed logistic regression analyses with 30-day and 1-year mortality, and 30-day and one-year stroke recurrence, and ultimate functional outcome, and vascular death as the respective dependent variables with the same standard model as defined above with later stepwise inclusion of leukoaraiosis and the lacunar subtype in the standard model. Cox regression analysis for survival, and for stroke recurrence were done with the lacunar subtype added to the standard model, with later addition of leukoaraiosis to look for significant predictors in a time dependent analysis.

We also determined the influence of both lacunar subtype and leukoaraiosis on the brain area of recurrent stroke.

Finally, we performed Kaplan-Meier analyses for survival, and for recurrence (survival free of stroke) with the lacunar subtype as the different strata, and with log rank tests for significance.

For the comparison of recurrent subtypes in the lacunar subtypes we used univariate chi square analysis.

\section{RESULTS}

Six of the 339 lacunar strokes had no CT done at the time of first stroke and were left out of the analysis. Of the 333 remaining LACl, 104 had at least one symptomatic small deep ischemic lesion on $\mathrm{CT}$, and these were compared with the 229 without such lesions. Table 8.1 shows the characteristics of these two groups. Hypertension was more frequent in the LACI+ group, but this was not a statistically significant difference. LA was highly statistically significant more frequent among LACI with, than those without silent lesion(s). Logistic regression analysis 


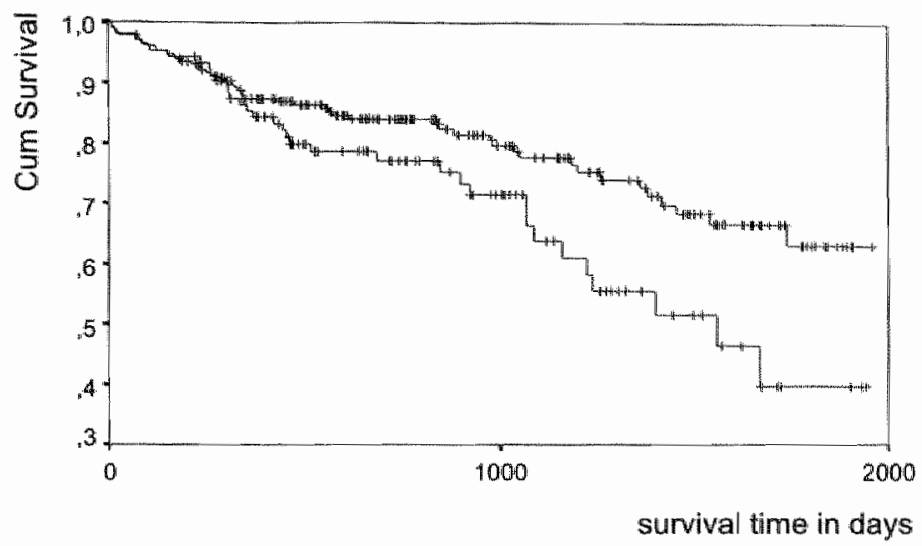

figure 8.1 survival time in days, comparison between laci-and laciupper line $=$ laci-, lower line $=$ lacit; $\log$ rank 5.26; sign 0.0218

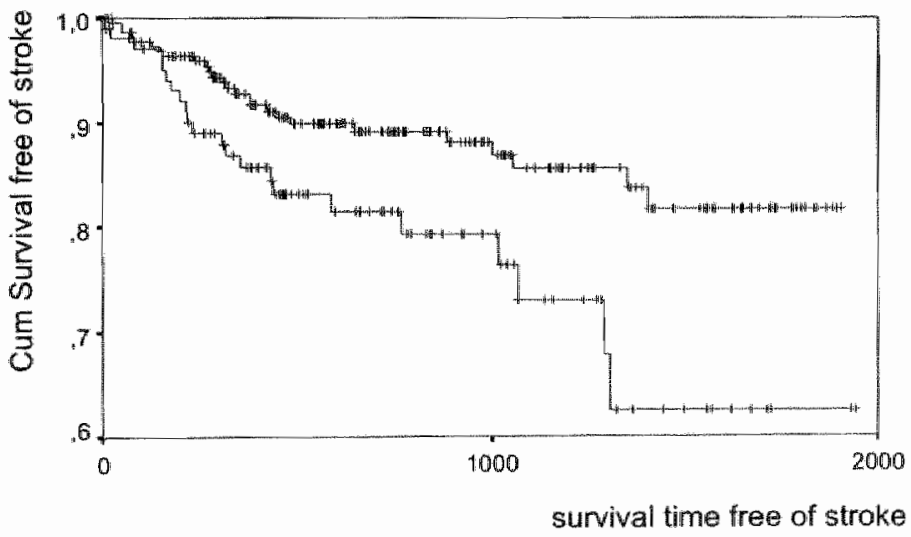

figure 8.2 survival time free of stroke in days, comparison between laci-and lacit upper line $=$ laci-, lower line $=$ laci $;$; log rank 6.30; sign 0.0121 


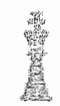

table 8.1 characteristics of 104 lacunar strokes with at least one silent small deep lesion (lacit) and 229 without (laci-)

\begin{tabular}{llll}
\hline & LACI & LACI & OR (95\% CI) \\
\hline mean age in years & 72 & 70 & \\
diabetes melitus & $23(22)$ & $42(18)$ & $1.26(0.63-2.55)$ \\
ischemic heart disease & $19(18)$ & $48(21)$ & $1.26(0.63-2.55)$ \\
hypertension & $51(49)$ & $90(39)$ & $1.46(0.88-2.41)$ \\
ICA stenosis & $4(5)$ & $21(11)$ & $0.40(0.12-1.35)$ \\
COPD & $16(15)$ & $23(10)$ & $1.63(0.74-3.56)$ \\
cardiac source of embolism & $16(15)$ & $32(14)$ & $1.12(0.31-4.06)$ \\
leukoaraiosis & $63(61)$ & $33(14)$ & $9.13(5.48-15.21)^{*}$ \\
\hline
\end{tabular}

* $p<0.001$; numbers are absolute numbers; numbers in brackets are percentages

table 8.2 features associated with lacit vs laci-by logistic regression analysis

\begin{tabular}{lccr} 
& OR & $95 \% \mathrm{Cl}$ & P-value \\
\hline sex & 0.77 & $(0.47-1.26)$ & \\
age 1 & 1.61 & $(0.92-2.83)$ & \\
age 2 & 2.37 & $(1.29-4.36)$ & 0.0057 \\
diabetes mellitus & 1.23 & $(0.69-2.21)$ & \\
IHD & 0.78 & $(0.43-1.43)$ & \\
hypertension & 1.69 & $(1.05-2.74)$ & 0.0322 \\
LA & 10.01 & $(5.49-18.25)$ & $<0.0001$ \\
\hline
\end{tabular}


CHAPTER

Two types of lacunar infarcts

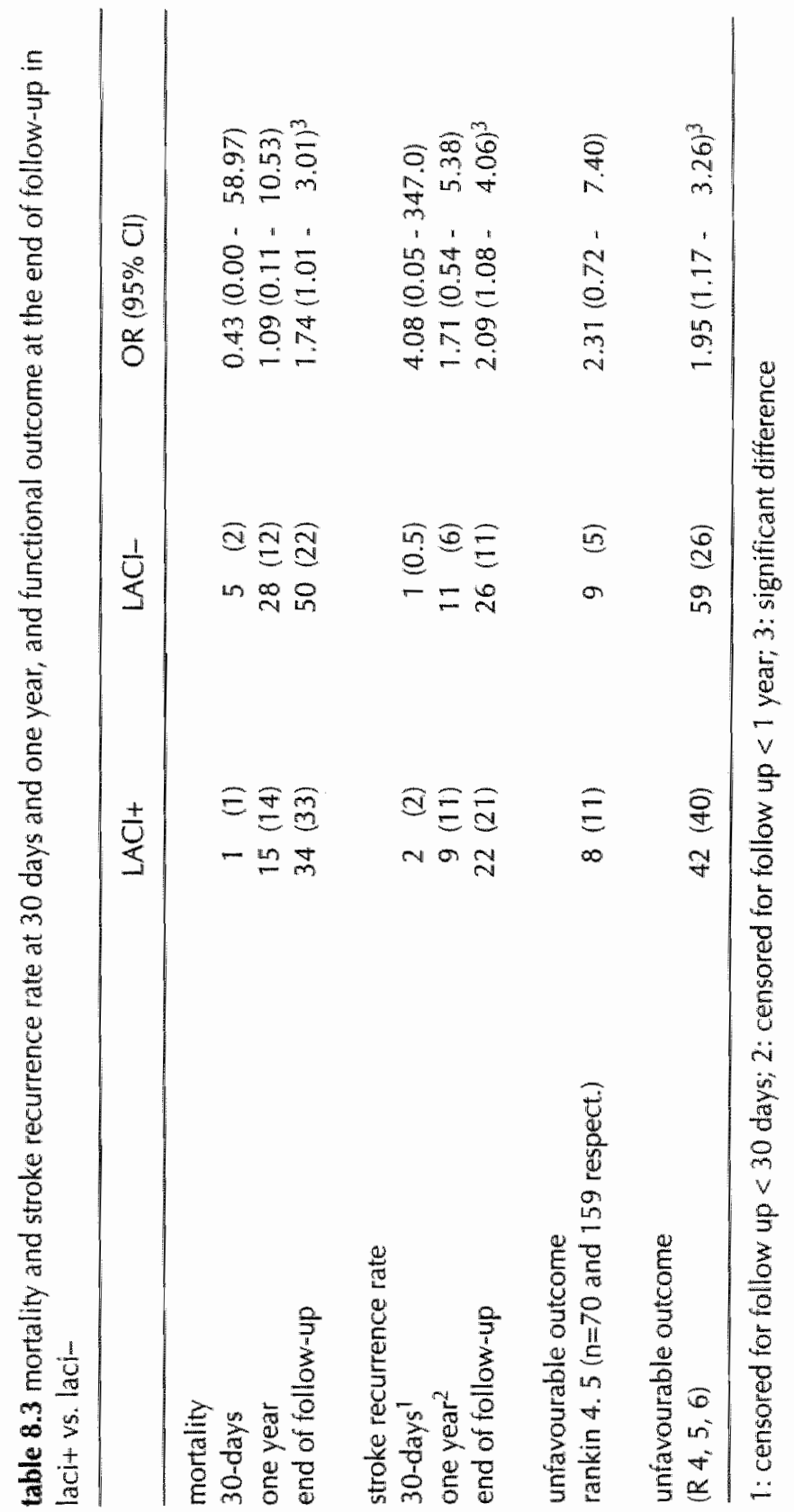




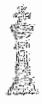

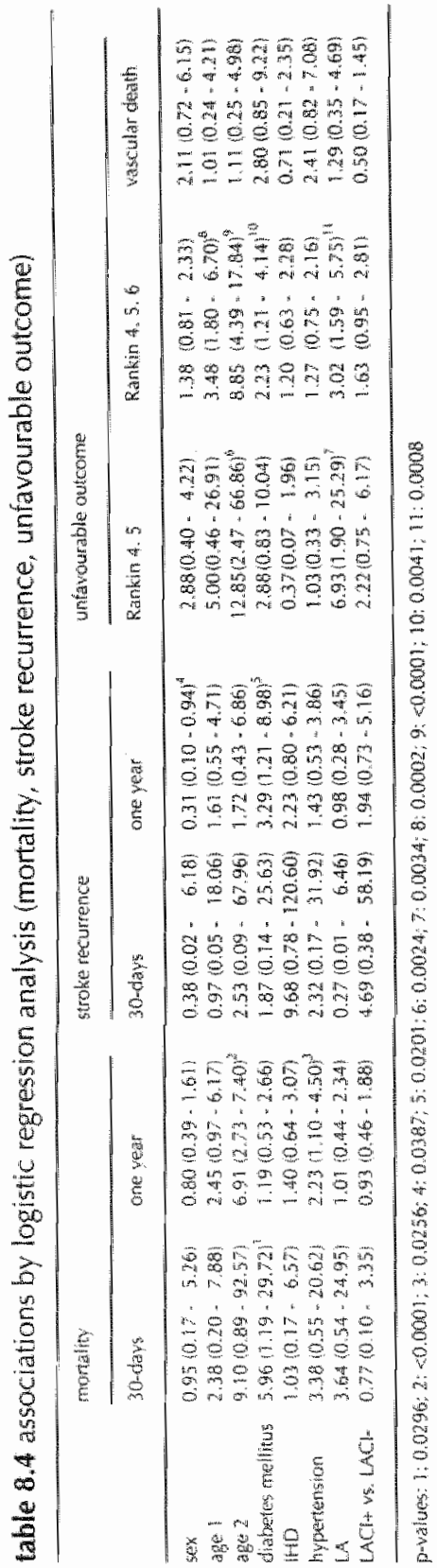


showed higher age, hypertension and leukoaraiosis to be independently associated with LACI+ (table 8.2).

\section{MORTALITY}

A higher percentage of patients had died at the end of follow-up in the LACI+ group (table 8.3). Logistic regression showed diabetes mellitus to be associated with 30-day case fatality rate, whereas higher age and hypertension were associated with one-year mortality (table 8.4). Cox regression showed age and diabetes mellitus as independent predictors ofdeath, whereas LACI+ (versus LACI-), and LA were not (table 8.5). The Kaplan-Meier survival curves are shown in figure 8.1. LACIt had less favourable survival than LACI-(log rank test: 0.0218).

\section{RECURRENT STROKE}

There were twice the number (\%) of recurtent strokes in the LACI+ group (table 8.3) at the end of follow-up. Although the point estimate of the OR for 30-day stroke recurrence rate in LACI + versus $\mathrm{LACI}$ - was 4.08, the difference was not statistically significant. The same applies to LACI subtype as independent predictor for early recurrence by logistic regression analysis. Sex and diabetes mellitus were significant predictors of one-year recurrent stroke (table 8.4). Cox regression detected diabetes mellitus and LACI + versus LACI- as independent predictors of stroke recurrence (table 8.5). Six recurrent strokes were intracranial hemorhages, and five of these occurred in the LACI+ group, constituting a quarter of all recurrences in this group, only four percent of recurrences were brain hemorrhages in the LACI- group (table 8.6). Nine of the fourten non-lacunar recurrent infarcts occurred in the LACI-group. Kaplan-Meier curves on survival free of recurrent stroke are shown in figure 8.2. LACIt had less favourable survival free of stroke than LACI-(log-Rank test: 0.0121$)$.

\section{FUNCTIONAL OUTCOME AT THE END OF FOLLOW-UP}

LACI+ survivors had worse functional outcome (Rankin 4, 5), but this was not statistically significant (table 8.3). Prognosis for major handicap or death (Rankin 4-6) was significantly more unfevourable for LACIH.

High age and especially LA were independent predictors of unfavourable functional outcome (table 8.3). LACIt was more than twice as strongly associated with unfawourable functional outcome, but the difference did not reach the level 
table 8.5 cox proportional hazard analysis for mortality and recurrent stroke lacunar subtype included in standard model

\begin{tabular}{lll}
\hline & mortality & recurrent stroke \\
\cline { 2 - 3 } & HR $(95 \% \mathrm{Cl})$ & HR $(95 \% \mathrm{CI})$ \\
\hline sex & $1.06(0.68-1.65)$ & $0.70(0.39-1.27)$ \\
age & $2.45(1.31-4.55)^{1}$ & $1.23(0.63-2.38)$ \\
age 2 & $5.94(3.14-11.06)^{2}$ & $1.55(0.72-3.34)$ \\
diabetes mellitus & $1.62(1.00-2.61)^{3}$ & $2.08(1.12-3.88)^{4}$ \\
IHD & $1.30(0.79-2.16)$ & $1.27(0.64-2.51)$ \\
Hypertension & $1.32(0.85-2.06)$ & $1.28(0.71-2.30)$ \\
LA & $1.74(0.72-2.15)$ & $1.75(0.84-3.68)$ \\
LAClw vs. LACI- & $1.40(0.89-2.18)$ & $1.94(1.08-3.48)^{5}$ \\
\hline
\end{tabular}

p-Yalues; $1.0 .0048 ; 2 .<0.0001 ; 3.0 .05 ; 4.0 .0213 ; 5.0 .0255$

table $\$ .6$ recurrent stroke type in the lacunar subtypes at end follow-up

\begin{tabular}{llll}
\hline recurrent stroke type & $\mathrm{LACl}$ & $\mathrm{LACl}$ & $\mathrm{OR}(95 \% \mathrm{Cl})$ \\
\hline lacunar & $12(55)$ & $14(58)$ & $1.03(0.82-1.29)$ \\
atherothrombotic & $4(18)$ & $6(25)$ & $0.74(0.00-7.03)$ \\
cardio embolic & $1(5)$ & $3(13)$ & $0.12(0.00-104.10)$ \\
intra cerebral hematoma & $5(23)$ & $1(4)$ & $7.35(0.57-94.27)$ \\
undetermined & 0 & $2(8)$ &
\end{tabular}

numbers are absolute numbers; numbers in brackets are percentages; leaving undetermined out

table 8.7 influence of both asymptomatic lacunar infarction and leukoaraiosis on burain area of recurrence

\begin{tabular}{|c|c|c|c|c|c|}
\hline \multicolumn{3}{|c|}{$\operatorname{laci}+/ 4$} & \multicolumn{3}{|c|}{$\operatorname{laci}-1$} \\
\hline rec & same area & different area & rec & same area & different area \\
\hline 15 & $7(54)$ & $6(46)$ & 19 & $14(74)$ & $5(26)$ \\
\hline
\end{tabular}

recurrences are absolute numbers with known side of recurrence; number in brackets are percentages; odds ratio; for ipsilateral recurrence in laci -1 - compared with laci $+t+$ is; OR 2.40 95\% Cl $0.27-21.57$ 
of statistical significance, which was also the case for final major handicap or death (Rankin 4-6).

\section{RESTRICTED ANALYSIS OF LACI + $/$ + VERSUS LACI-}

There were $63 \mathrm{LACI} / /+$, and $196 \mathrm{LACI}-/-; 19 \%$ and $59 \%$ of all $333 \mathrm{LACl}$, respectively. Hypertension (OR: $2.21 ; 95 \% \mathrm{CI}: 1.18-4.15$ ) was beside age (age group 2 versus 1 OR 2,$25 ; 95 \%$ CI 1,06-4,77; age group 3 versus $1 \mathrm{OR} 6,81$; 95\% CI 3,09-15,03) associated with $\mathrm{LACl}+/+$ in the logistic regression analysis. At the end of the follow-up, there were 27 (43\%) deaths and 7 (11\%) severely handicapped patients in the IACI $+/+$ group, and $37(19 \%)$, and $4(2 \%)$, in the LACI-/-group, respectively; OR: 5.79 (95\% CI: $1.60-20.95)$, OR: 3.22 (95\% $\mathrm{CI}: 1.73-6.02)$, respectively.

There were 16 (25\%) stroke recurrences in the LACI + $/+$ group (LACI: 6, AT: 5, PICH: 5), and 19 (10\%) (LACI: 9, AT: 4, PICH: 1, CE: 3, undetemined: 2) in LACI -/-group; OR: $3.17(95 \% \mathrm{CI}: 1.48-6.81)$. Notice that five of the six PTCH occurred in the $\mathrm{LACI}+/+$ group, being almost one third of stroke recurrences in this subgroup. DM (OR: $2.31 ; 25 \%$, CI: $1.12-4.78$ ) and LACI + $/+$ type (OR: $2.78,95 \% \mathrm{CI}: 1.33-5.83)$ were significantly associated with recurrent stroke in the multivariate time-dependent proportional hazard analysis (Cox analysis).

Time interval between index and stroke recurrence was longer in the lacitit group (mean 495 days) than in the laci-/-type (mean 340 days).

Ipsilateral stroke recurrence occured more often in the patient group without both asymptomatic laci and leukoararosis (table 8.7 ), although the difference does not reach statistical significance.

\section{DISCUSSION}

In this rather large, well-defined group of lacunar stroke patients we found hypertension and leukoaraiosis associated with lacunar stroke with one or more silent, deep, small ischemic lesions on CT. This finding concurs with that from an initial, smaller series of our patients. $[40]$ Pathological studies found that medullary small vessel arteriolosclerosis was the underlying vasculopathy in leukoaraiosis. 
\{ $83,84,85,86,87,1447$ Clinical and epidemiological studies related hypertension to facunar infarcts, $[79,86,247]$ and hypertension to leukoaraiosis. $[73,158,152,236,238,289]$ Therefore, we hypothesized that small vessel arteriolosclerosis may be the main underlying vasculopathy in lacunar stroke patients with concomitant small, deep, silent lesions with hypertension as major risk factor, more severe hypertension perhaps being even more important. ${ }^{[40]}$ Some authors found no evidence in favour of this hypothesis, but their study design did not allow reliable conclusions in this respect. 165,227$]$ Others, however, sustained the idea of two different types of lacunar stroke. $[170,176,178,241,245,255]$ A CT follow-up study supported the hypothesis, and also showed lesions to progress over time, despite customary secondary stroke prevention treatment ${ }^{[267]}$

Our present results add further evidence to the idea of two different lacunar stroke types, as prognosis differed between the two groups, being more unfavourable in the patients with one or more silent lesions on CT. Difference in prognosis was even more pronounced when we contrasted the groups more sharply, by comparing lacunar stroke patients with leukoaraiosis in addition to one or more silent lacunar infarcts with patients without either of these features. Therefore, as risk factors differ, the association with leukoaraiosis differs, and lesion progression as well as prognosis differ, one may well speak of two lacunar stroke entities, with likely different underlying vasculopathies: small vessel atheromatosis in most patients with a single symptomatic lacunar stroke, and arteriolosclerosis in those with one or more silent lacunar lesions. Arteriolosclerosis is also the most frequent underlying vasculopathy in primary intracerebral haemorrhage, $\{37,124,136,140,189,214,215,235]$ with hypertension as most significant risk factor. Lacunar infarction and hypertension are predictors of primary intracerebral hemorrhage, [121.123] whereas white matter lesions are also related to primary intracerebral hemorrhage. Samuelsson and Norrving $[230,231]$ found $1.5 \%$ of stroke recurrences in first lacunar infarction to be a hemorrhage. The fact that one quarter of all recurrent strokes in our patients with one or more silent lesions, and even one third of the more selected group, were PICH, further sustains the idea of arteriolosclerosis as the underlying vasculopathy in those patients.

Earlier we found that most first-ever symptomatic lacunar infarcts are located in the area supplied by the anterior choroidal artery, whereas most asymptomatic lesions were located in the area supplied by the lenticulostriate penetrators. 140,119$]$ Besides being heterogeneous as to the pathological vessel wall reaction to hyper- 
tension, these two different vascullar systems may also differ in susceptibility to hypertension: more severe hypertension may be required for the development of arteriolosclerosis. Absence of nocturnal blood pressure dipping may play a role, as this was related to the presence of leukoaraiosis. $[256,286]$ This, however, remains for further study. Another possibility is that severe hypertension and cerebral arteriolosclerosis have a common, still unknown, cause. It is obvious that the two types of lacunar stroke are not mutually exclusive. More than one pathophysiological mechanism may be present in the various ischemic stroke subtypes. ${ }^{[179]}$ Especially hypertension is an important primary or attributing risk. factor for stroke in general. ${ }^{[53]}$

Trying to distinguish different ischemic stroke subgroups is more than just epidemiological hair splitting ${ }^{[58]}$ To pinpoint well defined separate stroke entities may facilitate research into the underlying causes of the disease on a cell-molecular level. Although various genetic abnormalities are known that increase the risk of stroke, the molecular basis of atherosclerotic cerebrovascular disease in general remains elusive. Also, the screening of measurable genomic polymorphisms has so far not led to a substantial increase in insight into cell-biological abnormalities underlying the disease. The "lumping side" of the spectrum how to study the disease has led to considerable insight into the pathogenesis and treatment possibilities of cerebrovascular disease. The "splitting side" may just be a timely, additional route to follow in order to obtain further insights into the pathophysiology underlying ischemic brain infarction. 


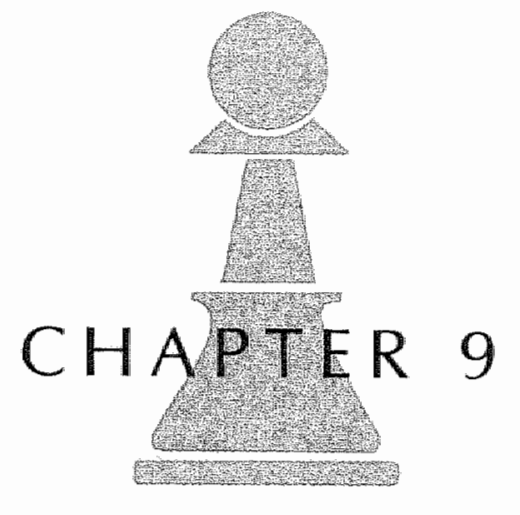


GENERAL DISCUSSION 
In the studies described in this thesis we hypothesized that the frequently used division in ischemic stroke subtypes, if founded on differences in underlying pathophysiology, should be reflected in differences in prognosis. In this respect recurrent stroke, functional outcome, and mortality were studied in a series of 998 first-ever cerebral infarct patients, prospectively registered in the Maastricht Stroke Registry. The second goal of the study was to measure prognosis, given the current array of therapeutic and secondary preventive measures, which would allow better estimates on prognosis from an individual patient's perspective. The study, therefore, is not a "natural history" study of ischemic stroke. During the study period the Maastricht University Hospital was equipped with a stroke unit. Thrombolysis was not yet implemented during the period, but treatment with aspirin as soon as possible following stroke was, after the results of the IST' became available. Carotid endarterectomy was performed within the ECST, until the end of this study, when benefit was shown for selected patients, with immediate implementation of the evidence. However, on the average, approximately twenty patients per year had carotid endarterectomy thereafter. Beside the strategy of risk factor modification following first stroke, aspirin was generally prescribed as a secondary preventive measure.

A drawback of the study may be that, as final follow-up was in 1995, findings may be a bit out of date, and may no longer be applicable today because changes in acute stroke treatment or better secondary prevention measures may have changed prognosis. Such measures may be: admittance to a stroke unit, thrombolysis, treatment with anti-platelet regimes better than ASA, or treatment with statins or ace-inhibitors. However, thrombolysis can only be performed in a small percentage of patients, whereas new anti-platelet regimes unlikely change prognosis dramatically. Statins were not generally prescribed during the study period. If changes in therapy had changed prognosis significantly in a more to-date study, had such study been performed, it might also have blunted relationships as we studied them. In that sense, the timing of the present study is not to its disadvantage. Therefore, findings in this study seem largely valid, especially those concerning inferences made with regard to underlying stroke causes.

With respect to mortality we showed that patients with a lacunar infarct, compared to both atherothrombotic and cardioembolic infarct, have a statistically significant better prognosis. Patients with an atherothrombotic infarct have a better prognosis for mortality, compared to those with a cardioembolic infarct. 
However, even lacunar stroke is a life-threatening affliction in the patient's near future. Initial stroke severity appeared a strong, independent predictor of future death. From our data we argued that for reduction in mortality following stroke, most is to be expected from treatments that lower initial stroke severity. Our data argue in favor of early admittance of stroke patients to a stroke unit, the implementation of thrombolysis in all hospitals that admit stroke patients, whereas a diligent search for potential neuroprotective strategies should continue, possibly in conjunction with the evaluation of recent MRI possibilities, especially with respect to diffusion and perfusion measurement early following stroke onset.

We found no differences in stroke rearrence rates between the ischemic stroke subtypes. On Kaplan-Meier testing however, there was a statistically significant difference between both lacunar and atherothrombotic infarcts on the one hand, and cardioembolic infarcts on the other. There was no difference between lacunar and atherothrombotic infarcts. We found an early clustering of stroke recurrences in both atherothrombotic and cardioembolic, but not in lacunar stroke patients. This finding supports the hypothesis of an underlying diseased large vessel, or cardiac source of embolism, respectively, with an ongoing, active source of embolism in both conditions, whereas in lacunar infarct patients a new lacunar infarct results from the occlusion of another perforating artery, a process apparently more evenly distributed in time. These data on recurrent stroke sustain the validity to consider the stroke subtypes as separate, ischemic stroke entities. Somewhat unexpectedly, we found chronic obstructive pulmonary disease as an independent predictor of stroke recurrence in all three subtypes, probably reflecting arhythmogenesis of sympathomimetic pulmonary drugs, or influence of associated pulmonary infections as risk factor for stroke. Much has been written on the possible role of especially Chlamydia Pneumoniae in this respect, but the evidence regarding stroke is conflicting. However, considering the evidence for a possible role of micro-organisms in causing, or more likely sustaining atherosclerosis or plaque instability, potential therapeutical options in ischemic stroke should further be evaluated.

We found a high degree of similarity with regard to the rype of recurrent stroke and that of the first stroke, which may point to homogeneity in underlying stroke cause over time in the particular stroke subtypes as distinguished in the present study. Our data on recurrent stroke location concur with this idea. However, we also pointed out that the vascular pathology in lacunar and atherothrombotic 


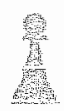

stroke may be similar, namely atheromatosis in both, as the two stroke subtypes are not mutually exclusive over time. Because the difference as to the clinical phenotype of the two stroke subtypes is larger than the similarity, different types of atheromatosis may be distinguished at the cell-biological level; a hypothesis that remains for future study.

Hypertension was detected as a risk factor for stroke recurrence in patients with first lacunar stroke. Hypertension was also independently related to a lacunar stroke subtype, which probably has arteriolosclerosis as underlying vasculopathy. However, whether this represents a causal relationship, or whether hypertension and cerebral small vessel disease, especially small. vessel arteriolosclerosis, have common determinants, should both remain optional for further study. Another possibility is that the relationship between hypertension and the various features of lacunar stroke progression over time, is due to a too diligent treatment of hypertension. Especially in lacunar stroke patients night time blood pressure dipping may be preserved, which may render these patients more liable to the effect of unduly night time blood pressure lowering, that eventually results in extension of leukoaraiosis, and an increase in the number of small deep silent lesions, or both.

Our data further sustain the idea of two separate lacunar stroke entities. Such distinction, besides being relevant for patient management, may facilitate the idea of different determinants for different phenotypes of cerebral small vessel disease. This should have consequences for further study into the nature of these entities on a cellular level. 
CHAPTER 9

General discussion

$\sqrt{1}$ 


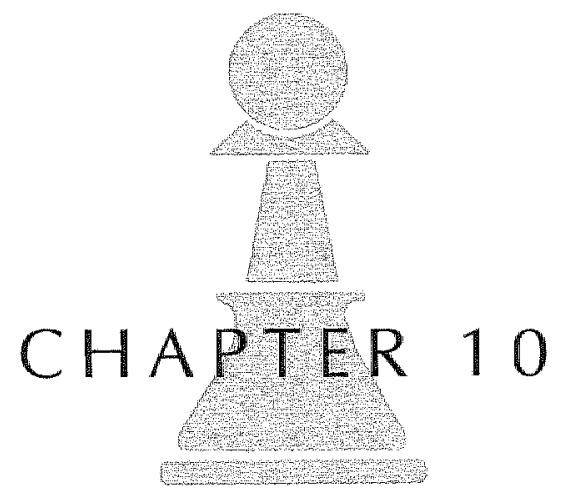


SUMMARY 
In the introduction we discussed the importance of valid prognostic data for individual patient management. One of the aims of the study was to provide arguments to sustain the idea that separate ischemic stroke subtypes must be distinguished because of assumed, inherently differences in prognosis. Such distinctions could also be relevant for future study of possible genetic and molecular biological determinants of different types of underlying vascular pathology in stroke. Another goal was to try and distinguish separate clinical entities within the lacunar stroke type. Defining the clinical phenotype of a certain stroke subtype more accurately may facilitate future research into its vascular pathology.

In chapter 2, we described the Maastricht Stroke Databank (MSR), and the definitions and methods we used. This registry included 998 patients between july 1987 and march 1992 with a first ever ischemic brain infarction. Last follow-up was completed in may 1995. All patients were included prospectively and consecutively, including outpatients. Cerebral CT scanning was performed in 96 percent of all patients, and in 61 percent of all recurrent strokes. We are not aware of any other stroke registry that reported CT scan data in such rather high proportion in stroke recurrence following a first-ever brain infarct. In this chapter, we presented the baseline characteristics for the whole group, and data for mortality and stroke recurrence at 30 days, one year, and at the end of follow-up. Furthermore, we presented data on disability at stroke onset and at the end of the study.

This hospital based registry, with inclusion of outpatients, thus provided the opportunity to study an unselected series of patients, with every patient seen by a neurologist, and with most of them having a large array of ancillary investigations, whereas no patient was lost to our cross-sectional follow-up. Case ascertainment, therefore, especially in regard to subtype diagnosis and stroke recurrences, may have been more valid in this study than in other stroke registries.

In chapter 3, we compared the baseline characteristics of the Maastricht Stroke Registry with other, mostly Western registries. For reasons of comparison, we recalculated the data on distribution of ischemic subtypes in the other registries, as most of these were originally given as part of the whole stroke spectrum including PICH, SAB, and TIA. We found that our data on mortality and stroke recurrence, for both the whole group and the ischemic subtypes, were very 


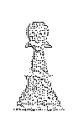

similar to those in the literature. This was an argument for the internal consistency and validity of our data.

In chapter 4 , we presented data on mortality after first ischemic stroke, and the influence of different risk factors (predictors). We calculated mortality rates for 30 days, one year, and for the end of follow-up. To identify independent predictors, we used both logistic regression analysis and time dependent Cox analysis. Mortality was highest in the CE type and lowest in the LACI type at all points of measurement. Mortality was highest in the first year, and especially in the first month after stroke, for AT and CE. Kaplan-Meier analysis with log rank testing for significance showed a significant difference between the three stroke subtypes. In all patients, DM, high age, stroke subtype, and stroke severity were predictors for early mortality, whereas recurrent stroke just missed statistical significance. In LACI, DM and stroke severity were independent predictors. In AT, DM, high age, recurrent stroke, and stroke severity were predictors, while in $\mathrm{CE}$ high age and stroke severity were the only predictors for early mortality. Logistic regression analysis for one year mortality detected DM, IHD, high age, stroke subtype, stroke recurrence, and COPD as predictors, whereas ipsilateral carotid artery stenosis just missed statistical significance. In LACI, higher age and stroke recurrence were predictors, with hypertension just missing statistical significance. In AT, DM, high age, recurrent stroke, stroke severity and ICA stenosis were independent predictors of one year mortality, while in CE high age and stroke severity were predictors with DM just missing significance. In the time dependent analyses, stroke recurrence lost its significance in all types. In $\mathrm{LACI}$, it added COPD as predictor. In AT, carotid stenosis lost significance. In $\mathrm{CE}, \mathrm{DM}$ and $\mathrm{COPD}$ were added as predictors. So, in $\mathrm{LACl}$, stroke severity was only a predictor of early mortality, whereas in AT and CE it remained an independent predictor over time. Recurrent stroke was an independent predictor of especially one year mortality in LACI and AT, but not in CE. DM was a significant predictor in AT but not in LACI, whereas its significance increased over time in $\mathrm{CE}$. Our data indicate that a cerebral infarct significantly lowers life expectancy, not only early after stroke, but likely for the remaining survival period following stroke. Mortality rates and independent predictors of mortality vary significantly between ischemic stroke subtypes. This may reflect the difference in their underlying pathology, a difference that is consistent over time. 
In chapter 5, we presented our data concerning stroke recurrence after first cerebral infarction, with the influence of different risk factors (predictors). There were no statistically significant differences in stroke recurrence rates between stroke subtypes at 30 days, one year, or at the end of follow-up. Log rank testing of survival free of recurrent stroke showed a difference between $\mathrm{CE}$ and both $\mathrm{AT}$ and $\mathrm{LACl}$, but no difference between $\mathrm{AT}$ and $\mathrm{LACI}$. The recurrence rates were higher in the first year, and especially in the first month for AT and CE. For LACI however, we found a more evenly distributed recurrence rate in time. Logistic regression analysis detected IHD and COPD as significant predictors in the whole group for early recurrence. When we analyzed the three subtypes separately, various point estimates indicated increased risk of recurrent stroke, but these were not statistically significant, probably due to the small numbers of events involved. At one year, IHD and COPD were independent predictors in the whole group. In the subtypes, DM was a strong predictor in LACI and CE. Time dependent analyses in the whole group showed DM, IHD, COPD and LA as independent predictors. In LACI, DM, asymptomatic lacunar lesions on CT, and LA were significant predictors. For the AT type, IHD, COPD, and an ipsilateral carotid artery stenosis were predictors, whereas in CE only DM was a predictor. The association of ASLA and LA in lacunar stroke points to a kind of coherence in underlying vascular pathophysiology, which is small vessel disease in most lacunar patients.

In chapter 6 we investigated functional outcome after stroke, using the modified Rankin scale. At the end of the follow-up period, significantly more patients in the LACI type were functionally independent, compared to both AT and CE. There was no significant difference however between AT and CE. In stroke survivors, higher age, stroke subtype, degree of neurological deficit at first stroke, ASLA, LA, and stroke recurrence were independent predictors of unfavourable functional outcome. More severe neurological deficit was the most powerful predictor of unfavourable outcome, and lacunar stroke subtype the most powerful predictor of favourable functional outcome. In LACI, high age, stroke severity, and recurrent stroke were independent powerful predictors of unfavourable outcome. In AT, high age, severity, and recurrence predicted unfavourable outcome, and in CE: initial severity and ASLA. The classical vascular risk factors had hardly any effect on functional outcome. Therefore, unfavourable 


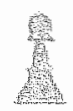

functional outcome in stroke survivors is not very likely influenced by treatment of these classical risk factors. Attempts to lower the initial degree of stroke severity seem more promising in this respect.

In chapter 7 , we explored the relationships between subtype and location of first brain infarction on one hand, and subtype of recurrent stroke (including PICH), and location of recurrent stroke on the other hand. We found that $57 \%$ of $\mathrm{LACI}$, $83 \%$ of AT, and $94 \%$ of CE (as recurrent strokes) were of the same type as the first stroke. Of "true to type" lacunar recurrences, $70 \%$ occurred in the same brain territory as the first stroke. For "true to type" AT recurrences, this percentage was $79 \%$. However, in CE only $39 \%$ of "true to type" recurrences were in the same brain territory as the first stroke. First stroke subtype was an independent predictor of lacunar versus nonlacunar recurrent stroke subtype. Hypertension also predicted a lacunar type recurrence. In the same way, first AT type predicted an AT recurrence, but here however, hypertension was inversely related to AT stroke subtype recurrence. So, in this chapter we found further evidence for the existence of pathophysiologically different vasculopathies underlying different brain infarction subtypes, as stroke subtype manifestation, measured by recurrent stroke subtype, and the area of recurrent stroke occurrence, were consistent over time.

In chapter 8 , we provided further evidence for the existence of two separate subtypes of lacunar stroke: LACr with asymptomatic lacunar lesions on CT versus $\mathrm{LACI}$ without such lesions ( $\mathrm{LACI}+$ versus $\mathrm{LACI}$-). As for baseline characteristics, LA was significantly more frequent among $\mathrm{LACl}+$. The $\mathrm{LACl}+$ type also had a significantly higher mortality rate and a significantly higher recurrence rate at the end of the follow-up period. LACI + versus LACI- was an independent predictor for stroke recurrence, but not for mortality. LACI+ survivors had worse functional outcome, but not statistically significant so. Prognosis for major handicap or death however was significantly worse for $\mathbb{L A C l}+$. $\mathrm{LACl}+$ versus $L A C I$ - however, was not an independent predictor for unfavourable functional outcome (or unfavourable functional outcome or death), despite the numerically strong association. When we restricted the analysis to lacunar patients with both ASLA and LA, hypertension was a significant predictor for the $+/+$ versus $-/-$ type. Furthermore, five of the six PICH recurrences occurred in 
the LACI $+/+$ type, being almost one third of all recurrences in this subgroup. Time interval between index and recurrent stroke was shorter in the LACI $-1-$ group. Our findings support the existence of two lacunar entities, with different underlying risk factors, association with $\mathrm{LA}$, and prognosis for mortality, (type of) recurrence, functional outcome and underlying vasculopathy: small vessel atheromatosis in patients with a single symptomatic lacunar stroke, and arteriolosclerosis in those with one or more silent lacunar lesions. 
CHAPTER 10

Summary

臯

经 


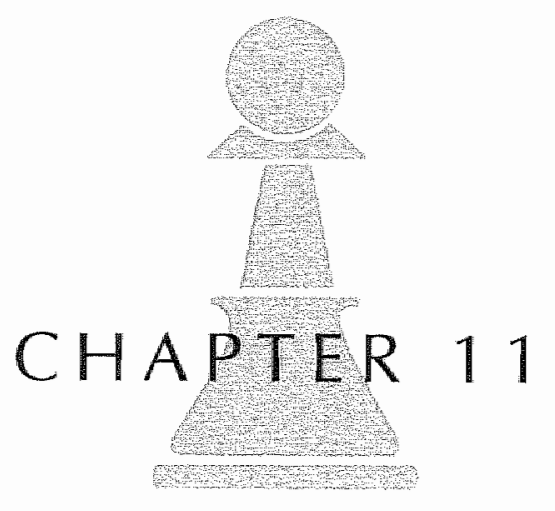


SAMENVATTING 
De hypothese dat de gebruikelijke indeling van ischemische herseninfarcten, als deze is gebaseerd op verschillen in onderliggende vasculaire pathofysiologie, ook tot uiting zou moeten komen in de prognose van patiënten met een herseninfarct, lag ten grondslag aan de onderzoeken in dit proefschrift. Een tweede doel was het leveren van aanvullend bewijs voor het bestaan van een onderverdeling binnen het lacunaire herseninfarct: patiënten met een of meerdere asymptomatische lacunaire laesies, tegenover patiënten zonder een dergelijke laesie. Vanuit dit perspectief onderzochten we het optreden van eventuele recidief herseninfarcten of hersenbloedingen, functionele uitkomst en sterfte in een groep van 998 patiënten met een eerste herseninfarct, geregistreerd in de Maastricht Stroke Registry.

We vonden een grote mate van overeenkomst tussen het subtype van het eerste herseninfarct en een tweede beroerte, infarct of bloeding. Dit wijst in de richting van een consistentie in onderliggende vaat pathologie in de tijd in de onderscheiden typen herseninfarcten: lacunaire, atherothrombotische en cardioembole infarcten. Deze verschillende vormen van vaat pathologie sluiten elkaar echter niet uit, en meer dan één type vaat pathologie kan bij een individuele patiënt voorkomen. Recidief beroertes komen significant meer voor bij cardioembole dan bij lacunaire of atherothrombotische herseninfarcten. Er bestaat een vroege clustering van recidief beroertes in atherothrombotische en cardioembole herseninfarcten, passend bij de theorie van een in de tijd geclusterde embolische aktiviteit van een ziek groot vat of van een cardiale emboliebron. Bovendien komen recidieven bij lacunaire en atherothrombotische infarcten vooral voor in hetzelfde hersengebied als het eerste infarct, in tegenstelling tot recidieven bij cardioembole infarcten. Opvallenderwijs vonden we chronisch obstructieve longziekten als onafhankelijke predictor van recidief beroerten, mogelijk als arrhytmogene bijwerking van vaak bij deze patiënten gebruikte medicatie, of als gevolg van de bij deze patiënten vaak optredende infecties.

Ten aanzien wan sterfte hadden lacunaire infarcten een betere prognose dan de beide andere typen. De atherothrombotische infarcten lhadden een betere prognose dan de cardioembole. Het subtype van een eerste herseninfarct, en de mate van initiële neurologische uitvalsverschijnselen waren de krachtigste voorspellers van sterfte. Uit deze onderzoeken volgt dat de beste manier om de sterfte na een eerste herseninfarct terug te dringen, bestat uit het verminderen van de initiele 
uitvalsverschijnselen. Methoden om dit te bereiken zijn opname op een stroke unit, thrombolyse, en mogelijk in de toekomst neuroprotectie.

Patienten met een lacunair herseninfarct hadden ook de beste prognose voor de witeindelijke mate van functionele onafhankelijkheid. Ook in dit opzicht bleken de initiële mate van uitvalsverschijnselen en het infarct subtype de krachtigste voorspellers. De klassieke vasculaire risicofactoren bleken nauwelijks enig effect op de uiteindelijke mate van invaliditeit te hebben.

Binnen het lacunaire subtype hadden de patiënten met een of meer asymptomatische lacunaire laesies de slechtste prognose voor sterfte, recidief beroerte en functionele uitkomst. Bovendien bleek een grote meerderheid van de recidief hersenbloedingen in deze groep patiënten voor te komen, wijzend op een specifieke onderliggende aandoening van de kleine hersenvaten (arteriolosclerosis of lipohyalinosis), in tegenstelling tot microatheromatose bij patienten zonder asymptomatische lacunaire infarcten.

Concluderend hebben onze studies nieuwe argumenten gevonden voor het bestaan van verschillende typen herseninfarcten met verschillende onderliggende vasculaire pathofysiologie, en een hierop berustende verschillende prognose ten aanzien van het tijdstip van voorkomen en het type van recidieven, functionele uitkomst en sterfte.

Bovendien vonden we nieuwe argumenten voor het bestaan van een onderverdeling in de lacunaire herseninfarcten. 


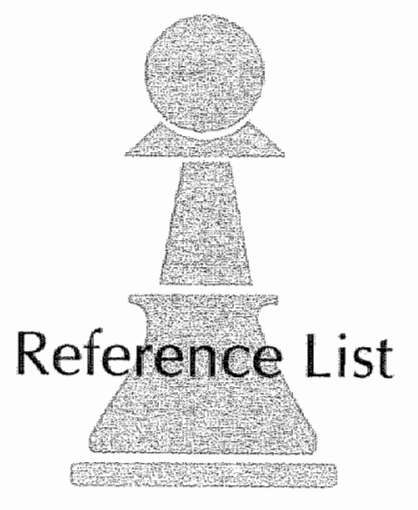


1. Anonymous. - A randomised, blinded, trial of clopidogrel versus aspirin in patients at risk of ischaemic events (CAPRIE). CAPRIE Steering Committe [see comments] - Lancer 1996 Nov 16;348(9038):1329-39 1329-1399.

2. Anonymous. - A comparison of two doses of aspirin ( $30 \mathrm{mg} \times 3.283 \mathrm{mg}$ a day) in patients after a transient ischemic attack or minor ischemic stroke. The Dutch TIA Trial Study Group [see comments]. - N Engl J Med 1991 Oct 31;325(18):1261-61261-1266.

3. Anonymous. - Atherosclerotic disease of the aortic arch as a risk factor for recurrent ischemic stroke. The French Study of Aortic Plaques in Stroke Group [see comments] - N Engl] Med 1996 May 9;334(19):1216-21 1216-211.

4. Anonymous. - PROGRESS - Perindopril Protection Against Recurrent Stroke Study: characteristics of the study population at baseline. Progress Management Committee. - I Hypertens 1999 Now; 17(11): 1647-55 1647-555.

5. Anonymous. - Randomised trial of endarterectomy for recently symptomatic carotid stenosis: final results of the MRC European Carotid Surgery Trial (ECST) [see conments]. - Lancet 1998 May 9;351(9113):1379-87 1379-1877.

6. Anonymous. - CAST: randomised placebo-controlled trial of early aspirin use in 20,000 patients with acute ischaemic stroke. CAST (Chinese Acute Stroke Trial) Collaborative Group [see comments]. - Lancet 1997 Jun 7;349(9066):1641-9 1641-1699.

7. Anonymous. - The International Stroke Trial (IST): a randomised trial of aspirin, subcutaneous heparin, both, or neither among 19435 patients with acute ischaemic stroke. International Stroke Trial Collaborative Group [see comments]. - Lancet 1997 May $31 ; 349(9065): 1569-811569-1811$.

8. Anonymous. - Tissue plasminogen activator for acute ischemic stroke. The National Institute of Neurological Disorders and Stroke rt-PA Stroke Study Group [see comments]. - N Engl J Med 1995 Dec 14;333(24):1581-7 1581-77.

9. Anonymous. - Post-stroke antihypertensive treatment study. A preliminary result. PATS Collaborating Group. - Chin Med J (Engl) 1995 Sep;108(9):710-7 710-777.

10. Anonymous. - Secondary prevention in non-rheumatic atrial fibrillation after transient ischaenic attack or minor stroke. EAFT (European Atrial Fibrillation Trial) Study Group [see comments] - Lancet 1993 Now 20;342(8882):1255-62 1255-1622.

11. Anonymous. - Trial of secondary prevention with atenolol after transient ischemic attack or nondisabling ischemic stroke. The Dutch TTA Trial Study Group. - Stroke 1993 Apr; $24(4) \div 543-8543 \sim 588$.

12. Anonymous. - Beneficial effect of carotid endarterectomy in symptomatic patients with high-grade carotid stenosis. North American Symptomatic Carotid Endarterectomy Trial Collaborators [see comments]. - N Engl J Med 1991 Aug 15;325(7):445-53 445-533.

13. How do stroke units improve patients outcone? Stroke unit trialists collaboration. Stroke. 199728 2139-44. 2001. (GENERIC) Ref Type: Generic

14. Collaborative overview of randomised trials of antiplatelet therapy. Br Med II 1994308 71-106. 2001. (GENERIC) Ref Type: Generic

15. Fact sheet Nederlandse Hartstichting. Hart en vatatekten in Nederland 1999. Cijfers over ziekte en sterfte. 2001. (GENERIC) Ref Type: Generic 
6. Abu-Zeid HA, Choi NW, Hisu WH, Main KK. - Prognostic factors in the survival of 1,484 stroke cases observed for 30 to 48 months. T. Diagnostic types and descriptive wariables. Arch Neurol 1978 Mar; $35(3): 121-5$ 121-155.

17. Adachi $T$, Takagi $M$, Hoshino $H$, Inafuku $T$. - Effect of extracranial carotid artery stenosis and other risk factors for stroke on periventricular hyperintensiry. - Stroke 1997 Nov:28(11):2174-92174-2199.

18. Adachi T;, Kobayashi $S$, Yamaguchi $S_{n}$ Okada K. - MRI findings of small subcortical \&quot; lacunar-like\&quot; infarction resulting from large vessel disease. - INeurol 2000 Apr;247(4):280)-5 280-55.

19. Adams HPJ, Bendixen BH, Kappelle LJ, Biller J, Love BB, Gordon DL, et al, - Classification of subtype of acute ischemic stroke. Definitions for use in a multicenter clinical trial. TOAST. Trial of Org 10172 in Acute Stroke Treatment. - Stroke 1993 Jan;24(1):35-41 35-411.

20. Albers $\mathrm{CW}$, Choice of endpoints in antiplatelet trials. Which outcomes are most relevant to stroke patients? Neurology 2000;54:1022-8.

21. Allen CM. - Clinical diagnosis of the acute stroke syndrome. - Q J Med 1983 Autumn; $52(208): 515-23.515-523$.

22. Alter M, Friday G, Lai SM, O'Connell J, Sobel E. - Hypertension and risk of stroke recurrence. - Stroke 1994 Aug;25(8):1605-10 1605-100.

23. Alter M, Friday G, Sobel E, Lai SM. - The Lehigh Valley Recurrent Stroke Study: descrip tion of design and methods. - Neuroepidemiology 1993;12(4);241-8 241-288.

24. Alter M, Sobel E, McCoy RI, Francis ME, Davanipour Z, Shofer F, et al - Stroke in the Lehigh Valley: risk factors for recurrent stroke. - Neurology 1987 Mar;37(3);503-7 503-577.

25. Alter M, Sobel E, McCoy RL, Francis ME, Shofer F, Levitt LP, et al - Stroke in the Lehigh Valley: incidence based on a community-wide hospital register. - Netroepidemiology $1985 ; 4(1): 1-151-155$.

26. Anderson C, Stewart-Wynne E, Jamrozik K, Burvill P, Chakera T. - Perth Community Stroke Study: design and preliminary results, - Clin Exp Neurol 1990;27:125-9 125-199.

27. Anderson CS, Janrozik KD, Broduhurst RJ, Stewart-Wyne EG. - Predicting survival for 1 year among different subtypes of stroke. Results from the Perth Community Stroke Study [see comments]. - Stroke 1994 Oct:25(10):1935-44 1935-444.

28. Anderson CS, Jamrozik KD, Burvill PW, Chakera TM, Johnson GA, Stewart-Wynne EG. - Determiming the incidence of different subtypes of stroke: results from the Perth Conmu nity Stroke Study, 1989-1990. - Med J Aust 1993 Jan 18:158(2):85-9 85-99.

29. Arboix A, Marti-Vilaltat JL, Garcia JH. - Clinical study of 227 patients with lacunar infarcts. - Stroke 1990 Jun;21(6):842-7 842-877.

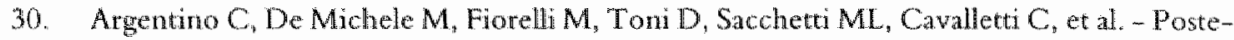
rior circulation infarcts simulating anterior circulation stroke. Perspective of the acute phase Ipublished erratum appears in Stroke 1997 Feb;28(2):466]. - Stroke 1996 Aug;27(8):1306-9 $1306-1399$. 


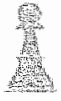

31. Banford J, Dennis $M$, Sandercock P, Burn I. Warlow $C$. - The frequency, causes and timing of death within 30 days of a first stroke: the Oxfordshire Community Stroke Project. - I Neurol Neurosurg Psychiatry 1990 Oct;53(10):824-9 824-899.

32. Bamford J, Sandercock P, Demnis M, Burn J, Warlow C. - Classification and natural history of clinically identifiable subtypes of cerebral infarction. - Lancet 1991 Jun $22 ; 337(8756): 1521-61521-1566$

33. Bamford I, Sandercock P, Dennis M, Warlow C, Jones L, McPherson K, et al. - A prospective study of acute cerebrovascular disease in the community: the Oxfordshire Community Stroke Project 1981-86. 1. Methodology, demography and incident cases of first-ever stroke. - J Neurol Neurosurg Psychiatry 1988 Nov; 5 il (1.1):1373-80 1373-1800.

34. Bamford J, Sandercock $P$, Jones $L$, Warlow $C$. - The natural history of lacunar infarction: the Oxfordshire Community Stroke Project. - Stroke 1987 May-Jun:18(3):545-51 $545-511$.

35. Berglund, $G$. Long-term outcome of the Malmo preventive project: mortality and candiovascular morbidity. J Inten Med 2000247 19-29. 2001. (GENERIC) Ref Type: Generic

36. Bergman $\mathrm{L}$, van der Meulen JH, Limburg M, Habbema JD. - Costs of medical care afuer first-ever stroke in The Netherlands. - Stroke 1995 Oct; 26(10):1830-6 1830-1866.

37. Bogousslavsky J, Castillo V, Kumral E, Henriques 1, Melle GV. - Stroke subtypes and hypertension. Primary hemorrhage vs infarction, Large- vs small-artery disease. - Arch Neurol 1996 Mar;53(3):265-9 265-299.

38. Bogousslavsky J, van Melle G, Regli F. - The Lausanne Stroke Registry: analysis of 1,000 consecutive patients with first stroke. - Stroke 1988 Sep; 1999:1083-92 1083-1922.

39. Bogousslavsky, J. The etiology of posterior circulation infarcts neurology 199943 1528-1533. 2001. (GENERIC) Ref Type: Generic

40. Boiten J, Lodder J, Kessels F. - Two clinically distinct lacunar infarct entities? A hypothesis. - Stroke 1993 May;24(5):652-6 652-666.

41. Boiten, J. and Lodder, J. Prognosis for survival, handicap and recurrence of stroke in lacunar and superficial infarction. Cerebrovasc Dis $19933221-226.2001$. (CENERIC)

Ref Type: Generic

42. Bonita $R$, Anderson CS, Broad JB, Jamrozik KD, Stewart-Wynne EG, Anderson NE. Stroke incidence and case fatality in Australasia. A comparison of the Auckland and Perth population-based stroke registers. - Stroke 1994 Mar; 25(3):552-7 552-577.

43. Bonita R, Beaglehole R, Asplund K. - The worldwide problem of stroke - Curr Opin Neurol 1994 Feb:7(1),5-10 5-100.

44. Bonvita R, Stewart A, Beaglehole R. - International trends in stroke mortality: 1970-1985 [see conments]. - Stroke 1990 Jul;21(7):989-92 989-922.

45. Bonita $\mathrm{R}$, Beaglehole $\mathrm{R}$ - Increased treatment of bypertension does not explain the decline in stroke mortality in the United States, 1970-1980. - Hypertension 1989 May; 13 (5 Suppl):169-73 $169-733$

46. Bonita R, Beaglehole R. - Does treatment of hypertension explain the decline in mortality from stroke? - Br Med J (Clin Res Ed) 1986 Jan 18;292(6514):191-2 191-22. 
47. Bonita R, Beaglehole $R$, North JD. - Event, incidence and case fatility rates of cerebrovascular disease in Auckland, New Zealand. - Am J Epidemiol 1984 Aug: $120(2): 236-43236-433$.

48. Brainin M. Seiser A, Czvitkowits B, Pauly E. - Stroke subtype is an age-independent predictor of first-year survival. - Neuroepidemology 1992;11(4-6):190-5 190-55.

49. Brainin M. - Overview of stroke data banks. - Neuroepidemiology 1994:13(6):250-8 $250-288$.

50. Brandt T, Steinke W, Thie A, Pessin MS, Caplan LR. - Posterior cerebral artery territory infarcts: clinical features, infarct topography, causes and outcome. Multicenter results and a review of the literature. - Cerebrovasc Dis 2000 May-Jun;10(3):170-82 170-822.

51. Brilley DP, Haroon S, Sergent SM, Thomas S. - Does leukoaraiosis predict morbidity and mortality? - Neurology 2000 Jan $11 ; 54(1): 90-490 \times 44$.

52. Broderick JP, Phillips SJ, O'Fallon WM, Frye RL, Whisnant JP. - Relationship of cardiac disease to stroke occurrence, recurrence, and mortality. - Stroke 1992 Sep;23(9):1250-6 $1250-1266$.

53. Bronner, L. L. Primary prevention of stroke. NEJM 1995333 1392 1400. 2001. (GENERIC) Ref "Type: Generic

54. Brott, T. and Bogousslavsky J. Treatment of acute ischemic stroke. NEJM 2000343 710-722. 2001. (GENERIC) Ref Type: Generic

55. Brown RD, WhisnantJP, Sicks JD, O'Fallon WM, Wiebers DO. - Stroke incidence, prewalence, and survival: secular trends in Rochester, Minnesota, through 1989 [sec comments]. - Stroke 1996 Mar;27(3):373-80 373-800.

56. Burn J, Dennis M, Banford J. Sandercock P, Wadte D, Warlow C. - Long-term risk of recurrent stroke after a first-ever stroke. The Oxfordshire Community Stroke Project [published erratum appears in Stroke 1994 Sep;25(9):1887]. - Stroke 1994 Feb;25(2):333-7 $333-377$.

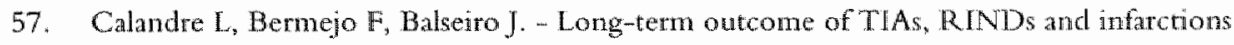
with mininum residum. A prospective study in Madrid. - Acka Neurol Scand 1990 Aug:82(2):104-8 104-188.

58. Caplan LR. - TIAs: we need to return to the question. "What is wrong with Mr. Jones?', Neurology 1988 May $38(5), 791-3791-33$.

59. Caro J, Huybrechts KF, Duchesne 1. - Matagement patterns and costs of acute ischemic stroke: an international study. For the Stroke Economic Analysis Group. - Stroke 2000 Mar;31(3):582-90.582-590.

60. Celani MG, Ceravolo MG, Duca E, Minciott P, Caputo N, Orlandini M, et al - Was it infaretion or haemornage? A clinical diagnosis by means of the Allen scone. - J Neurol 1992 Aug:239(7):411-3 411-433.

61. Chambers BR, Norris JW, Shurvell BL, Hachinski VC. - Prognosis of acute stroke. Neurology 1987 Feb:37(2):221-5221-255

62. Chambers BR, Donnan GA, Bladin PF. - Patterns of stroke. An analysis of the first 700 consecutive admissions to the Austin Hospital Stroke Unit. - Aust N Z J Med 1983 Feb; $13(1): 57-6457-644$. 
63. Chamorro A, Saiz A, Vila N, Ascaso C, Blanc R. Alday M, et al. - Contribution of arterial blood pressure to the clinical expression of lacunar infarction. - Stroke 1996 Mar;27(3):388-92 388-922.

64. Cillessen JP. Kappelle L], wan Swieten JC, Algra A, van Gijn J. - Does cerebral infarction after a previous warning occur in the same vascular tertitory? - Stroke 1993 $\operatorname{Mar} ; 24(3): 351-4351-44$.

65. Clavier 1, Hommel M, Besson G, Noelle B, Perree JE. - Long-term prognosis of symptomatic lacunar infarcts. A hospital-based study. - Stroke 1994 Oct;25(10):2005-9 2005-2099.

66. Collins R, MacMahon S. - Blood pressure, antihypertensive drug treatment and the risks of stroke and of coronary heart disease. - Br Med Bull 1994 Apr;50(2):272-98. 272-298.

67. Collins R, Peto R, MacMahon S, Hebert P, Fiebach NH, Eberlein KA, et al. - Blood pressure, stroke, and coronary heart disease. Part 2, Short-term reductions in blood pressure: overview of randomised drug trials in their epidemiological context. - Lancet $1990 \mathrm{Apr}$ $7 ; 335(8693): 827-38.827-838$.

68. Czlonkowska A, Ryglewicz D, Lechowicz W. - Basic analytical parameters as the predictive factors for 30-day case fatality rate in stroke. - Acta Neunol Scand 1997 Feb;95(2):121 -4 $121-144$

69. Czlonkowska A, Ryglewicz D, Weissbein T, Baranska-Gieruszczak M, Hier DB. - A prospective community-based study of stroke in Warsaw, Poland. - Stroke 1994 Mar;25(3):547-51547-511.

70. D'Alessandro G, Di Giovanni M, Roveyaz L, Iannizzi L, Compagnoni MP, Blanc S, ut al. Incidence and prognosis of stroke in the Valle d"Aosta, Italy. First-year results of a community-based study. - Stroke 1992 Dec;23(12):1712-5 1712-1755.

71. de Haan R, Horn J, Limburg M, van der Meulen J, Bossuyt P. - A comparison of five stroke scales with measures of disability, handicap, and quality of life [see comments]. - Stroke 1993 Aug:24(8):1178-81 1178-1811.

72. de Haan $R$, Limburg $M$, Bossuyt $P$, van der Meulen J, Aaronson $N$, - The clinical meaning of Rankin 'handicap' grades afcer stroke. - Stroke 1995 Nov;26(11):2027-30. 2027-2030.

73. de Leeuw FE, de Groot $\mathbb{C}$, Oudkerk $M$, Wittenan JC, Hofnan A, van Gijn J, ct al. - A follow-up study of blood pressure and cerebral white matter lesions. - Antin Neurol 1999 Dec;46(6):827-33 $827-333$.

74. Dennis M, ORourke $S$, Lewis $S$, Sharpe $M$, Warlow $C$. A quantitative study of the emotional outcome of people caring for stroke surviwors. - Stroke $1998 \mathrm{Sep} ; 29(9): 1867-72$. $1867-1872$

75. Dennis MS, Burn JP, Sandercock PA, Banford JM, Wade DT, Warlow CP. - Long-term survival after first-ever stroke: the Oxfordshire Community Stroke Project. - Stroke 1993 Jun;24(6):796-800 796-8000.

76. Diaz-Arrastia, R. Homocysteine and Neurologic disease arch neurol. 2000557:1422-1428. 10-1-2000. (GENERIC) Ref Type: Generic

77. Diener HC, Cunha L, Forbes C, Sivenius J, Smets P, Lowenthal A. - European Stroke Prevention Study. 2. Dipyridamole and acerylsalicylic acid in the secondary prevention of stroke [see comments]. - J Neurol Sci 1996 Nov $143(1-2): 1-131-133$. 
78. Dippel DW, Koudstal PJ. - We need stronger predictors of major vascular evenis in patients. with a recent transicnt ischemie attack or nondisabling stroke. Dutch TIA Trial Study Group. - Stroke 1997 Apr;28(4):774-6 774-66.

79. Dozono $K$, Ishii $N$, Nishihara $Y$, Horie A. - An autopsy study of the incidence of lacunes in relation to age, hypertension, and arteriosclerosis. - Stroke 1991 Aug;22(8):993-6 993-66.

80. Elkind MS, Lin IF, Grayston JT, Sacco RL. - Chlamydia pneumoniae and the risk of first ischemic stroke: The Northern Manhattan Stroke Study. - Stroke 2000 Jul;31(7):1521-5 $1521-1555$.

81. Erkinjuntti, T. and Hachinski, V. C. Rethinking vascular dementia. Cerebrovascular Dis 1993 33-23, 2001. (GENERIC) Ref Type: Generic

82. Fazekas F, Kleinert R, Roob G, Kleinert G, Kapeller P, Schmidt R, et al. - Histopathologic analysis of foci of signal loss on gradient-echo $12^{*}$-weighted MR images in patients with spontaneous intracerebral hemorrhage: evidence of microangiopathy-related microbleeds. AJNR Am J Neuroradiol 1999 Apr;20(4):637-42 637-422.

83. Fisher CM. - Lacunat strokes and infarcts: a review. - Neurology 1982 Augg 32(8):871-6 $871-66$.

84. Fisher CM. - Capsular infarcts: the underlying vascular lesions. - Arch Newrol 1979 Feb; $36(2): 65-7365-733$.

85. Fisher CM. - The arterial lesions underlying lacunes. - Acta Neuropathol (Berl) 1968 Dec $18 ; 12(1): 1-151-155$.

86. Fisher, C. M. Lacunar infarcts-A rewiew. Cerebrovasc Dis $19911311-320.2001$. (GENERIC) Ref Type: Generic

87. Fisher, C. M. Lacunes: small deep cerebral infarcts. neurology $196515774-784.2001$. (GENERIC) Ref Type: Generic

88. Foulkes MA, Wolf PA, Price TR, Mohr JP, Hier DB. - The Stroke Data Bank: design, methods, and baseline characteristics. - Stroke 1988 May;19(5):547-54 547-544.

89. Fukuda $\mathrm{H}$, Kitani M. - Differences between treated and untreated hypertensive subjects in the extent of periventricular hyperintensities observed on brain MRI. - Stroke 1995 Sep; $26(9): 1593-71593-77$.

90. Gandolfo C. Moretti C, Dall'Agata D, Primavera A, Brusa G, Loeb C. - Longmterm prognosis of patients with lacunar syndrones. - Acta Neurol Scand 1986 Sep;74(3):224-9 $224-299$.

91. Garraway WM, Whisnant JP, Drury L - The changing pattern of survival following stroke. - Stroke 1983 Sep-Oct; 14(5):699-703 699-7033.

92. Giroud M, Beuriat P. Vion P, D'Athis PH, Dusserre L, Dumas R. - Stroke in a French prospective population study. - Neuroepidemiology 1989:8(2):97-104 97-1044.

93. Gritoud M, Milan $C$, Beuriat P, Gras P, Esayagh E, Arveux P, et al. - Incidence and survival tates during a two-year period of intracerebral and subarachnoid haemorrhages, cortical infurcts, lacunes and tansient ischaemic attacks. The Stroke Registry of Dijon: 1985-1989. - Int J Epidemiol 1991 Dea,20(4):892-9 892-899.

94. Giroud M, Gras P. Milan C, Arveux P, Beuriat P, Vion P, et al. - Natural history of lacunar syndromes. Contribution of the Dijon registry of cerebrovascular complications]. - Rev Neurol (Paris) 1991;147(8-9):566-72 566-722. 
95. Goldstein LB, Perry A. - Early recurrent ischemic stroke. A case-control study. - Stroke 1992 Jul:23(7): 1010-3 1010-1033.

96. Greshan GE, Kelly-Hayes M, Wolf PA, Beiser AS, Kase CS, D'Agostino RB. - Surwiwal and functional status 20 or more years after first stroke: the Framingham Study. - Stroke 1998 Apr;29(4):793-7 793-77.

97. Gross CR, Kase CS, Mohr JP, Cunningham SC, Baker WE. - Stroke in sonth Alabama: incidence and diagnostic features - a population based study. - Stroke 1984 Mar-Apr; $15(2)$ 249-55 249-555.

98. Hachinski VC, Potter P, Merskey H. - Leuko-araiosis. - Arch Neurol 1987 Jan;44(1):21-3 $21-33$.

99. Hack-Gun Bae. Recurrence of bleeding in patients with hypertensive intracerebral hemorThage. Cerebrovasc Dis 19989 102-108. 2001. (GENERIC) Ref Type: Generic

100. Hacke W, Kaste M, Fieschi C, von Kummer R, Dawalos A, Meier D, et al. - Randomised double-blind placebo-controlled trial of thrombolytic therapy with intravenous alteplase in acute ischaemic stroke (ECASS II). Second European-Australasian Acute Stroke Study Investigators. - Lancet 1998 Oct $17 ; 352(9136): 1245-51$. 1245-1251.

101. Hankey GJ, Slattery JM, Warlow CP. - Transient ischaemic attacks: which patients are at high (and low) risk of serious vascular events? - 』Neurol Neurosurg Psychiatry 1992 Aug; $55(8): 640-52640-522$.

102. Hankey GJ, Jamurozik K, Broadhurst RJ, Forbes S, Burvill PW, Anderson CS, et al. Five-year survival after first-ever stroke and related prognostic factors in the Perth Community Stroke Study. - Stroke 2000 Sep;31 (9):2080-6 2080-66.

103. Hankey GJ. - Stroke: how large a public health problem, and how can the neurologist help? - Arch Neurol 1999 Jun :56(6):748-54 748-544.

104. Hankey GJ, Jamrozik K, Broadhurst RJ, Forbes S, Burvill PW, Anderson CS, et al. Long-term risk of first recurrent stroke in the Perth Community Stroke Study [see comments]. - Stroke 1998 Dec,29(12):2491-500 2491-5000.

105. Hankey GJ, Dennis MS, Slattery JM. Warlow CP. - Why is the outcome of transient ischaemic attacks different in different groups of patients? - BMII 1993 Apr 24:306(6885):1107-111107-1111.

106. Heinsius T, Bogousslavsky J, van Melle G. - Large infarcts in the middle cerebral artery territory. Etiology and outcome patterns [published erratum appears in Neurology 1998 Jun; 50(6): 1940-3] [see comments]. - Neurology 1998 Feb; $30(2): 341-503441-500$.

107. Henon $\mathrm{H}$, Godefroy $\mathrm{O}$, Leys $\mathrm{D}$. Mounier-Vehier $\mathrm{F}$, Lucas $\mathrm{C}$, Rondepierre $\mathrm{P}$, et al. - Early predictors of death and disability after acute cerebral ischemic event [see comments]. Stroke 1995 Mar; 26(3):392-8 392-88.

108. Henriques IL, Bogousslavsky J. - Value of stroke data banks for the analysis of clinical syndromes. - Neuroepidemiology 1994;13(6):296-300 296-3000.

109. Herman B, Schulte BP, wan Luijk JH, Leyten AC, Frenken CW. - Epidemiology of stroke in Tilburg, The Netherlands. The population-based stroke incidence register: 1 . Introduction and preliminary results, - Stroke 1980 Mar-Apr; I 1 (2):162-5 162-55.

110. Herman B, Leyten AC, van Luijk JH, Frenken CW, Op dCA, Schulte BP. - Epidemiology of stroke in Tilburg, the Netherlands. The population-based stroke incidence register: 2. 
Incidence, initial clinical picture and medical care, and three-week case fatality. - Stroke $1982 \mathrm{Sep}-\mathrm{Oct} ; 13(5): 629-34629-344$.

111. Hier DB, Foulkes MA, Swiontoniowski M, Sacco RL, Gorelick PB, Mohr JP, et all. Stroke recurrence within 2 years after ischemic infarction. - Stroke 1991 Feb;22(2):155-61 155-611.

112. Hier $D B$, Edelstein $G$. - Deriving clinical prediction rules from stroke outcome research. Stroke 1991 Now;22(11):1431-61.431-1466.

113. Hijdra A, Verbeeten B. - Leukoaraiosis and wentricular enlargement in patients with ischemic stroke. - Stroke 1991 Apr;22(4):447-50 447-500.

114. Hijdra A, Verbeeten BJ, Verhulst JA. - Relation of leukoaraiosis to lesion type in stroke patients. - Stroke 1.990 Jun;21(6):890-4 890-44.

115. Hillen T, Dundas R, Lawrence E, Stewart JA, Rudd AG, Wolfe CD. - Antithrombotic and antihypertensive managenent 3 months after ischemic stroke: a prospective study in atm inner city population. - Stroke 2000 Feb; 31(2):469-75 469-755.

116. Hommel M, Besson G, Le Bas JF, Gaio JM, Pollak P, Borgel F, et al. - Prospective study of lacunar infarction using magnetic resonance imaging. - Stroke 1990 Apr;21(4):546-54. 546-554.

117. Hornig CR, Lammers $C_{n}$ Buttner T, Hoffnann $O$, Dorndorf W. - Long-term prognosis of infratentorial transient ischemic attacks and minor strokes. - Stroke 1992 Feb;23(2):199-204 199-2044.

118. Howard $G_{\text {, Evans }} \mathrm{GW}$, Murros KE, Toole JF, Letkowitz D. Truscott BL. - Cause specific mortality following cerebral infarction. - J Clin Epidemiol 1989;42(1):45-51 45-511.

119. Hupperts RM, Lodder J, Heuts-wan Raak EP, Kessels F. - Infarcts in the anterior choroidal artery territory. Anatomical distribution. clinical syndromes, presumed pathogenesis and early outcome [see comments]. - Brain 1994 Aug;117 (Pt 4):825-34 825-344.

120. Inowe T, Fushimi H, Yamada Y, Udaka F, Kameyama M. Asymptomatic multiple lacunae in diabetics and non-diabetics derected by brain magnetic resonance imaging. - Diabetes Res Clin Pract 1996 Mar;31(1-3):81-681-66.

121. Inzitari D, Diaz F, Fox A, Hachinski VC, Steingart A, Lau C, et al. - Vascular risk factors and leuko-araiosis. - Arch Neurol 1987 Jan:44(1):42-7 42-77.

122. Inzitari D, Elliasziw $M$, Sharpe BL, Fox AJ, Bamett HJ. - Risk factors and outcome of patients with carotid artery stenosis presenting with lacunar stroke. North American Symptomatic Carotid Endarterectomy Trial Group. - Neurology 2000 Feb 8:54(3):660-6 $660-666$

123. Inzitari D, Giordano GP. Ancona AL, Pracucci G, Mascalchi M, Amaducci L. Leukoaraiosis, intracerebral hemorrhage, and arterial hypertension. - Stroke 1990 Oct;2l(10):1419-23 1419-233.

124. Janssens E, Mounier-Vehier E, Hamon M, Leys D. - Small subcontical infarcts and primary subcortical haemorrhages may have different risk factors. - J Neurol 1995 Jul;242(7):425-9 $425-499$.

125. Jerntorp P, Berglund G. - Stroke registry in Malmo, Sweden. - Stroke 1992 Mar;23(3):357-61 357-611 
126. Jorgensen HS, Nakayana H, Raschou HO, Olsen TS. - Intracerebral hemornage versus infarction: stroke severity, risk factors, and prognosis. - Ann Neurol 1995 Jul; 38(1):45-50 45-500.

127. Jorgensen HS, Kammersgard LP, Houth J, Nakayama H, Rasaschou HO, Larsen K., et al. Who benefits from treatment and rehabilitation in a stroke Unit? A community-based study. - Stroke 2000 Feb; $31(2): 434-9434-499$.

128. Jorgensen HS, Nakayama $\mathrm{H}$, Raschou $\mathrm{HO}$, Olsen TS. - Stroke. Neurologic and functional recovery the Copenhagen Stroke Study. - Phys Med Rehabil Clin N Am 1999 Now; 10(4):887-906 887-9066.

129. Jorgensen HS, Kammersgard LP, Nakayama H, Raschou HO, Larsen K, Hubbe P, et al. Treatment and rehabilitation on a stroke unit inproves 5-year survival. A commanity-based study. - Stroke 1999 May;30(5):930-3 930-933.

130. Jorgensen HS, Nakayama H, Reith J, Raschou HO, Olsen TS. - Stroke recurrence: predictors, severity, and prognosis. The Copenhagen Stroke Study. - Neurology 1997 Apr;48(4):891-5 891-55

131. Jorgensen HS, Nakayama H, Rasschou HO, Larsen K. Hubbe P, Olsen TS. - The effect of a stroke unit: reductions in mortality, discharge rate to aursing home, length of loospial stay, and cost. A community-based study. - Stroke 1995 Jul;26(7):1178-82 1178-1822.

132. Kappelle LJ, van Latum JC, wan Swieten JC, A Jgra A, Kondstal PJ, van Gijn J - Recurrent stroke after transient ischaemic attack or minor ischaenic stroke: does the distinction between small and large wessel disease remain true to type? Dutch TIA Trial Study Group. J Neurol Neurosurg. Psychiatry 1995 Aug;59(2):127 31 127 311.

133. Kelly-Hayes M, Wolf PA, Kannel WB, Sytkowski P, D'Agostino RB, Giesham GE. Factors infuencing survival and need for institutionalization following stroke: the Framingham Study, - Arch Phys Med Rehabil 1988 Jun;69(6):415-8 415-488.

134. Kesteloot H, Sasaki S, Xie J, Joossens JV. - Secular trends in cerebrovascular mortality. - J Hum Hypertens 1994 Jun; $8(6): 401-7$ 401-4.77.

135. Khaw, K. T. Epidemiology of stroke. JNNP 1996 61:333-338. 2001. (GENERIC) Ref Type: Generic

136. Konishi M. Iso H, Konachi $Y$, Iida M, Shimanoe T, Jacobs DRJ, et all - Associations of serum total cholesterol, different types of stroke, and stenosis distribution of cerebral arteries. The Akuta Pathology Study. - Stroke 1993 Jul;24(7):954-64.

137. Kotila M, Waltimo O, Niemi ML, Laaksonen R, Lempinen M. - The profile of recovery from stroke and factors influencing outcome. - Stroke 1984 Nov-Dec;15(6):1039-44 1039-1444.

138. Kumral E Oekaya B, Sagduyu A, Sirin H, Vardarli E, Pellivan M. - The Ege Stroke Registry: a hospital-based study in the Acgean region, 1zmir, Turkey. Analysis of 2,000 stroke patients. - Cerebrovase Dis 1998 sep-Oct; 8 (5):278-88 278-888.

139. Kunitz SC, Gross CR, Heyman A, Kase CS, Mohr JP, Price TR, et al, - The pilot Stroke Data Bank: definition, design, and data. - Stroke 1984 Jul-Ang, 15(4):740-746.

140. Kwa VI, Franke CL. Verbeeten B], Stam J. - Silent intracerebral microhemorrhages in patients wh ischemic stroke. Amsterdan Vascular Medicine Group fsec comments]. - Ann Neurol 1998 Sep; $44(3): 372-7372-377$. 
141. Kwakkel G, Wagenar RC, Kollen BJ, Lankhorst GJ. - Predicting disability in stroke-a critical review of the literature. - Age Ageing $1996 \mathrm{Nov} ; 25(6): 479-89479-899$.

142. Lai SM, Alter M. Friday $G$, Sobel E. - Prognosis for survival after an inicial stroke. - Stroke 1995 Nov:26(11):2011-5 2011-2055.

143. Lai $S M$, Alter $M$, Friday $G$, Sobel $E$ - A multifactorial analysis of risk factors for recurrence of ischemic stroke. - Stroke 1994 May;25(5),958-62 958-622.

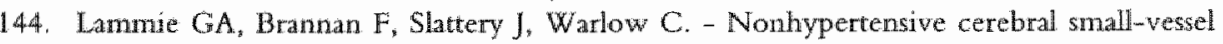
disease. An autopsy study. - Stroke 1997 Now;28(11):2222-2229.

145. Landi $G$, Cella $E$, Boccardi $E$, Musicco M. - Lacunar versus non-Jacunar infarcts: pathogenetic and progmostic differences. - I Neurol Neurosurg Psychiatry 1992 Jur $; 55(6): 441-5441-455$.

146. Langhome P, Williams BO, Gilchrist W, Howie K. - Do stroke units save lives? [see comments]. - Lancet 1993 Aug 14;342(8868):395-8 395-88.

147. Lanska DJ, Mi X. - Decline in US stroke mortality in the era before antilhypertensive therapy. - Stroke 1993 Sep:24(9):1382-8 1382-1388.

148. Lauria $G$, Gentile M, Fassetta $G$, Casetta II, Agnoli F, Andreotta $G$, et al. - Incidence and prognosis of stroke in the Belluno province, Italy. First-year results of a community-based study. - Stroke 1995 Oct;26(10):1787-93 1787-1933.

149. Le Pira F, Giuffida S, Giammona G, Saponara R, Larza S, La Spina V. - Leukoaraiosis and lacunar infarcts in ischemic stroke: role of age and vascular risk factors. - Ann Ital Med Int 1997 Apr-Jun; $12(2): 72-572-55$.

150. Lemesle M, Milan C, Faivre J, More.a T, Giroud M, Dumas R. - Incidence trends of ischemic stroke and transient ischemic attacks in at well-defined French population from 1985 through 1994. - Stroke 1999 Feb;30(2):371-7 371-377.

151. Leys D, Englund E, Del Ser T, Inzitari D, Fazekas F, Bornstein N, et al - White matter changes in stroke patients. Relationship with stroke subtype and outcome. - Eur Neturol $1999 ; 42(2): 67-75$.

152. Liao D, Cooper L, Cai J, Toole JF, Bryan NR, Hutchinson RG, et al - Presence and sewerity of cerebral white matter lesions and hypertension, its treatment, and its control. The ARIC Study. Atherosclerosis Risk in Communities Study. - Stroke 1996 Dec:27(12):2262-70 2262-2700.

153. Lindgren A, Rojjer A, Norrving B, Wallin L, Eskilsson J. Johansson BB. - Carotid artery and heart disease in subtypes of cerebral infarction. - Stroke 1994 Dec;25(12):2356-62 2356-2622.

154. Lodder J, Banford J, Kappelle J, Boiten J. - What causes false clinical prediction of small deep infarts? - Stroke 1994 Jan;25(1):86-91 86-911.

155. Lodder], Bouter LM. - [Future numbers of patients with a cerebrovascular accident in The Netherlands (see comments)). - Ned Tijdschr Geneeskd 1992 Feb 29;136(9):425-8 $425 \times 488$.

156. Lodder J, Banford JM, Sandercock PA, Jones LN, Warlow CP. - Are hypertension or cardiac embolism likely causes of lacunar infarction? - Stroke 1990 Mar;21(3):375-81 $375-811$. 
157. Lodder J, Krijne-Kubat B, van der Lugt PJ. - Timing of autopsy-confimed hemorthagic infarction with reference to cardioembolic stroke. - Stroke 1988 Dec;19(12):1482-4 $1482-44$.

158. Longstreth WTY, Manolio TA, Annold A, Burke GL, Bryan N, Jungreis CA, et al - Clinical correlares of white matter findings on cranial magnetic resonance imaging of 3301 eldery people. The Cardiovascular Health Study [see comments]. - Stroke 1996 Aug:27(8):1274-82 1274-1822.

159. Macciocchi SN, Diamond PT, Alves WM, Mertz T. - Ischemic stroke: relation of age, lesion location, and initial neurologic deficit to functional outcome. - Arch Phys Med Rehabil 1998 Oct; $79(10): 1255-7$ 1255-1277.

160. MacMahon S, Pero R, Cutier J, Collins $\mathbb{R}$, Sorlie P. Neaton J, et al. - Blood pressure, stroke, and coronary heart disease. Part 1 , Prolonged difterences in blood pressure: prospective observational studies corrected for the regression dilution bias. - Lancet $1990 \mathrm{Mar}$ $31,335(8692): 765-74.765-774$.

161. MacMahon S, Rodgers A. - Primary and secondary prevention of stroke. - Clin Exp Hypertens 1996 Apr-May:18(3-4):537-46. 537-546.

162. MacMahon S, Rodgers A. - Blood pressure, antihypertensive treatment and stroke risk - I Hypertens Suppl 1994 Dec; $12(10): S 5-14$, S5-14.

163. MacMahon. S, Rodgers A - The effects of blood pressure reduction in older patients: an overview of five randomized controlled trials in elderly hypertensives. - Cin $\mathbb{E x p}$ Hypertens 1993 Now; 15(6):967-78. 967-978.

164. Malmgren $\mathbb{R}$, Warlow C, Bamford J, Sandercock P. - Geographical and secular trends in stroke incidence, - Lancet 1987 Nov 21;2(8569):1196-200 1196-2000.

165. Mantyla R, Aronen HJ, Salonen O, Pohjasvaara T, Korpelainen M, Peltonen T, et al. Magnetic resonance imaging white matter hyperintensities and mechanism of ischemic stroke. - Stroke 1999 Oct;30(10):2053-8 2053-2088.

166. Markus HS, Lythgoe D], Ostegaard L, O'Sullivan M, Williams SC. - Reduced cerebral blood flow in white matter in ischaemic leukoaraiosis demonstrated using quantitative exogenous contrast based perfusion MR1. - J Neurol Neurosurg Psychiatiry 2000 Jul;:69(1):48-53 48-533.

167. Marti-Vilalta JL, Arboix A. - The Barcelona Stroke Registry. - Eur Neurol $1999 ; 41(3): 135-42 \quad 135-422$

168. Martin PJ, Chang HM, Wiryk R, Caplan LR - Midbrain infarction: associations and actiologies in the New England Medical Center Posterior Circulation Registry. - I Neurol Neurosurg Prychiatry 1998 Mar;64(3):392-5 392 55.

169. Massing MW, Rywik SL, Jasinski B, Manolio TA, Williams OD, Tyroler HA. - Opposing national stroke mortality trends in Poland and for African. Americans and whites in the United States, 1968 to 1994 [see comments]. - Stroke 1998 Jul;29(7):1366-1372.

170. Mast H, Thompson JL, Lee SH, Mohr JP, Sacco RL. - Hypertension and diabetes mellitus as determinants of multiple lacunar infarcts. - Stroke 1995 Jan;26(1):30-3 30-33.

171. Mast H, Thompson JL, Voller H, Mohr JP. Marx P. - Cardiac sources of embolism in patients with pial artery infarcts and lacunar lesions. - Strake 1994 Apr;25(4):776-81 $776-811$ 
172. Matsumoto N, Whisnant JP, Kurland LT, Okazaki H. - Natural history of stroke in Rochester, Minnesota, 1955 through 1969: an extension of a previous study, 1945 through 1954. - Stroke 1973 Jan-Feb; $4(1): 20-920-99$.

173. McGoven PG, Burke GL, Sprafka JM, Xue S, Folsom AR, Blackburn H. - Trends in mortality, motbidity, and risk factor levels for stroke from 1960 through 1990 . The Minnesota Heart Survey. - JAMA 1992 Aug 12;268(6);753-9753-799.

174. Meisner 1, Whisnant JP, Garraway WM. - Hypertension management and stroke recurrence in a community Rochester, Minnesota, 1950-1979). - Stroke 1988 Apr: 19(4):459 63 $459-633$.

175. Miyao S, Takano A, Teramoto J, Takahashi A - Lenkoaraiosis in relation to prognosis for patients with lacunar infarction. - Stroke 1992 Oct;23(10):1434-8 1434-1488.

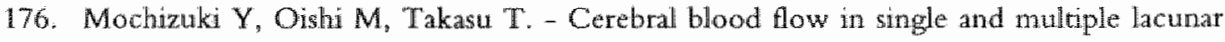
infarctions. - Stroke 1997 Jul:28(7):1458-60 1458-1600.

177. Mohr JP, Caplan LR, Melski JW, Goldstein RJ, Duncan GW, Kistler JP, et al. - The Haryard Cooperative Stroke Registry: a prospective registry. - Neurology 1978 Aug:28(8):754-62 754-622.

178. Molina C, Sabin JA, Montaner J, Rovira A, Abilleira S, Codina A. - Impaired cerebrovascular reactivity as a risk marker for first-ever lacunar infarction: A case-control study. - Stroke 1999 Nov;30(11):2296-301 2296-3011.

179. Moncayo J, Dewuyst $\mathrm{G}$, van Melle $\mathrm{G}$, Bogousslawsky J. - Coexisting causes of ischemic stroke. - Arch Neurol 2000 Aug $_{5} 57(8): 1139-441139-1444$.

180. Moroncy JT, Bagiella E, Paik MC, Sacco RL, Desmond DW. - Risk factors for early recurrence after ischemic stroke: the role of stroke syndrome and subtype. - Stroke 1998 Oct;29(10):2118-24 2118-2244.

181. Moulin T, Tatu L, Vuilier F, Berger E, Chavot D, Rumbach L. - Role of a stroke data bank. in evaluating cerebtal infarction subtypes: patterns and outcome of 1,776 consecutive patients from the Besancon stroke registry. - Cerebrovasc Dis 2000 Jul-Aug; 10(4):261-71 $261-711$.

182. Moulin T, Tatu L, Crepin-Leblond T, Chavot D. Berges S, Rumbach T" - The Besancon Stroke Registry: an acute stroke registry of 2,500 consecutive patients. - Eur Neurol $1997,38(1): 10-2010-200$.

183. Nadeau SE, Jordan JE, Mishra SK, Haerer AF. - Stroke rates in patients with lacunar and large vessel cerebral infarctions. - J Nearol Sci 1993 Feb;114(2): 128-37 128-377.

184. Nadeau SE, Jordan JE, Mishra SK. - Factors associated with occurrence of large vessel and lacunar cerebral infarctions. - I Neurol Sci 1993. Feb;114(2):156-9 156-199.

185. Neall B, Anderson C, Chalmers J. MacMahon S, Rodgers A. - Blood pressure lowering in patients with cerebrovascular disease: results of the PROGRESS (Perindopril Protection Against Recurrent Stroke Study) pilot phase. - Clin Exp Pharmacol Physiol 1996 May: $23(5): 444-6,444-446$.

186. Neal B, MacMahon S, Chapman N. - Efects of ACE inhibitors, calcium antagonists, and other blood-pressure-lowering drugs: results of prospectively designed overviews of randomised trials. Blood Pressure Lowering Treatment Trialists' Collaboration. - Lancet 2000 Dec $9 ; 356(9246): 1955-64.1955-1964$. 
187. Niessen LW, Barendregt JI, Bonneux L, Koudstaal PJ. - Stroke trends in an aging population. The Technology Assessment Methods Project Tean. - Stroke 1993 Jul;24(7):931-9 $931-999$.

188. Norrving B, Cronquist S. - Clinical and radiologic features of lacunar versus nonlacunar minor stroke. - Stroke 1989 Jan;20(1):59-64 59-644.

189. Offenbacher $H_{3}$ Fazekas $F_{8}$ Schmidt $R$, Koch $M_{*}$ Fazekas $G$, Kapeller P. - MR of cerebral abnomalities concomitant with primary intracerebral hematomas. - AJNR Am J Neurotadiol 1996 Mar; $17(3): 573-8573-588$.

190. Oishi M, Mochizuki $Y$, Takasu T. - Blood flow differences between leuko-araiosis with and without lacunar infarction. - Can J Neurol Sci 1998 Feb;25(1):70-5 70-55.

191. Oishi M, Mochizuki $X$, Shikata E, Mirutani $T$. - Acetazolamide reactivity in atherothrombotic, cardioembolic and lacunat infarctions. - Keio J Med 2000 Feb; 49 Suppl 1:A117-9 A117-A199

192. Olsson T, Vitanen M, Asplund K, Eriksson S, Hagg E. - Prognosis after stroke in diabetic. patients. A controlled prospective study. - Diabetologia 1990 Apr;33(4):244-9 244-299.

193. Paciaroni $M$, Arnold $P$, van Melle $G$, Bogousalawsky J. - Severe disability at hospital discharge in ischemic stroke surviwors. - Eur Neurol 2000;43(1):30-4 30-44.

194. Panczel G, Bonoczk P, Voko Zx, Spiegel D, Nagy $Z$. - Impaired vasoreactivity of the basilar: artery system in patients with brainstem lacunar infarcts. - Cerebrovasc Dis 1999 Jul-Aug; $9(4)=218-23218-233$.

195. Pantoni L, Garcia JH. - Pathogenesis of leukoaraiosis: a review. - Stroke 1997 $\operatorname{Mar}_{i} 28(3): 652-9652-699$.

196. Prolucci S, Antonueci G, Pratesi L, Traballesi M, Lubich S, Grasso MG. - Functional outcome in stroke inpatient rehabilitation: predicting no, low and high response patients. Cerebrowasc Dis 1998 Jul-Aug; $8(4): 228-34228-344$.

197. Peltonen M, Stegmayr B, Asplund K. - Time trends in long-tem survival after stroke: the Northern Sweden Multinational Monitoring of Trends and Determinants in Cardiovascular Disease (MONICA) study, 1985-1994. - Stroke 1998 Jul:29(7):1358-65 1358-1655.

198. Peltonen M, Asplund K. - Age-period-cohort effects on stroke nortality in Sweden 1969-1993 and forecasts up to the year 2003. - Stroke 1996 Nov;27(11):1981-5 1981-55.

199. Perry HM, Davis BR, Price TR, Applegate WB, Fields WS, Guralnik JM, en all. - Effect of treating isolated systolic hypertension on the risk of developing various types and subtypes of stroke: the Systolic Hypertension in the Elderly Program (SHEP). - JAMA 2000 Jul $26 ; 284(4): 465-71.465-471$.

200. Petty GW, Brown RDJ, Whisnant JP, Sicks JD, O Fallon WM, Wiebers DO. - Ischemic stroke subtypes: a population-based study of uncidence and risk factors. - Stroke 1999 Dec;30(12):2513-6 2513-2566.

201. Petry GW, Brown RDJ, Whisnant JP, sicks JD, O'Fallon WM, Wiebers DO. - Survival and recurrence after frst cerebral incrarction: a population-based study in Rochester, Minnesota, 1975 through 1989. - Neurology 1998 Jan; $50(1): 208-16208-166$.

202. Percy GW, Brown RDJ, Whisnant JP, Sicks JD, O'Fallon WM, Wiebers DO - Ischemic stroke subtypes: a population-based study of functional outcome, survival, and recurrence. Stroke 2000 May;31(5):1062 -8 1062-1088. 
203. Plehn JF, Davis BR, Sacks FM, Rouleau JL, Pfeffer MA, Bernstein V, ct al. - Reduction of stroke incidence after myocardial infarction with pravastatin: the Cholesterol and Recurrent Events (CARE) study. The Care Investigators. - Circulation 1999 Jan 19;99(2):216-23. 216-223.

204. Prencipe M, Culasso F, Rasura M, Arzini A, Beccia M, Cao M, et al - Long-term prognosis after a minor stroke: 10-year mortality and major stroke recurrence rates in a hospital-based cohort [see comments]. - Stroke 1998 Jan;29(1):126-32 126-322.

205. Read SJ, Petrigrew L, Schimmel L, Levi CR, Bladin CF, Chambers BR, et al - White matter medullary infarcts: acute subcortical infarction in the centrum ovale. - Cerebrovasc Dis 1998 Sep-Oct;8(5):289-95. 289-295.

206. Reitma JB, Limburg M, Kleinen J, Bonsel GJ. Tijssen JG. - Epidemiology of stroke in The Netherlands from 1972 to 1994: the end of the decline in stroke mortality. Neuroepidemiology 1998:17(3):121-31 121-311.

207. Ricci S, Celani MG, La Rosa F, Vitali $R$, Duca E, Ferraguzzi $R$, et al. - SEPIVAC: a community-based study of stroke incidence in Umbria, Italy. - J Neurol Neurosurg Psychiatry $1991 \mathrm{Aug} ; 54(8): 695-8695-88$.

208. Ricci $S_{*}$ Celani $M G_{*}$ La Rosa $F$, Vitali $R$, Duca $\mathbb{E}$, Ferraguzzi $\mathbb{R}$, et al - A communiry-based study of incidence, risk factors and outcome of transient ischaemic attacks in Umbria, Italy: the SEPIVAC study. - I Neurol 1991 Apr;238(2):87-90 87-900.

209. Ricci $S$, Celani MG, Guercini $G$, Rucireta $P$, Vitali R, La Rosa F, et al. - First-year results of a community-based study of stroke incidence in Umbria, Italy. - Stroke 1989 $\mathrm{Jul} ; 20(7): 853-7853-877$.

210. Riggs JE. - The decline of mortality due to stroke: a competitive and deterministic perspective. - Neurology 1991 Sep;419):1335-8 1335 1388.

211. Rodgers A, MacMahon S, Gamble G, Slattery J, Sandercock P, Warlow C. - Blood pressure and risk of stroke in patients with cerebrovascular disease. The United Kingdom Transient Ischaemic Attack Collaborative Group. - BMJ 1996 Jul 20;313(7050):147. 147

212. Ronning $O M$, Guldvog $B$. - Stroke unit versus general medical wards, II: neurological deficits and activities of daily living: a quasi-randomized controlled trial. - Stroke 1998 Mar,29(3):586m,90586-900.

213. Ronning $O M$, Guldwog B. - Stroke units versus general medical wards, I: twelve- and eightecn-month survival: a randomized, controlled trial. - Stroke 1998 Jan;29(1):58-62 58-622.

214. Roob G, Schnidt R, Kapeller P, Lechner A, Hartung HP, Fazekas F. - MRI evidence of past cercbral microbleeds in a healihy elderly population. - Neurology 1999 Mar $23 ; 52(5): 991-4991-44$.

215. Roob G, Fazekas F, - Magnetic resonance imaging of cerebral microbleeds. - Curr Opin. Neurol 2000 Feb; 13(1):69-73 69-733.

216. Roob G, Lechner A, Schmidt R, Flooh E, Hartung, HP, Fazekas F. - Frequency and location of microbleeds in patients with primary intracerebral hemorrhage [In Process Citation]. - Stroke 2000 Now;31(11):2665-92665-2699.

217. Rothwell PM. - Carotid artery disease and the risk of ischaemic stroke and coronary vascular events. - Cerebrovasc Dis 2000;10 Suppl 5:21-33. 21-33. 
218. Ryglewicz D, Baranska-Gieruszczak M, Calonkowska A, Lechowicz W, Hier DB. - Stroke recurrence among 30 days survivors of ischemic stroke in a prospeckive community-based study. - Neurol Res 1997 Aug;19(4):377-9 377-399.

219. Sacco RL, Wolf PA, Kamel WB, MeNamara PM. - Survival and recurrence following stroke. The Framingham study. - Stroke 1982 May-Jun; 13(3):290-5 290-55.

220. Sacco RL, Shi $T$, Zamanillo MC, Kargman DE. - Predictors of mortality and recurrence after hospitalized cerebral infarction in an urban community: the Northern Manhatcan Stroke Study. - Neurology 1994 Apr;44(4):626-34 626-344.

221. Sacco RL, Hauser WA, Mohr JP, Foulkes MA. - One-year outcome after cerebral infarction in whites, blacks, and Hispanics. - Stroke 1991 Mar;22(3):305-11 305-111.

222. Sacco RL, Ellenberg JH, MohrJP, Tatemichi TK, Hier DB, Price TR, et al. - Infarcts of undetermined cause: the NINCDS Stroke Data Bank. - Ann Neurol 1989 Apr;25(4):382-90 382-900.

223. Sacco RL, Foulkes MA, Mohr JP, Wolf PA, Hier DB, Price TR - Deteminants of early recurrence of cerebral infarction. The Stroke Data Bank. - Stroke 1989 Aug;20(8):983-9 983-999.

224. Sacco RL, Wolf PA, Gorelick PB. - Risk factors and their management for stroke prevention: outlook for 1999 and beyond. - Nenrology 1999;53(7 Supp] 4):S15-24 \$15-244

225. Sacco RL - Risk factors, outcomes, and stroke subtypes for ischemic stroke. - Neurology 1997 Nov; $49(5$ Suppl 4):\$39-44 $\$ 39 \cdots 444$.

226. Sacco SE, Whisnant JP, Broderick JP, Phillips SJ, OFallon WM. - Epidemiological characteristics of lacunar infarcts in a population. - Stroke 1991 Oct;22(10):1236-1241.

227. Salgado AV, Ferro JM; Gouveia-Oliweira A. - Long-term prognosis of first-ver lacunar strokes. A hospital-based study. - Stroke 1996 Apr;27(4):661-6 661-666.

228. Samsa GP, Bian J, Lipscomb J, Matchar DB. - Epidemiology of recurrent cerebral infarction: a medicare clainns-based comparison of first and recurrent strokes on 2-year survival and cost. - Stroke 1999 Feb;30(2):338-49 338-499.

229. Samuelsson $M$, Soderfeldt $B$, Olsson $G B$. - Functional ontcome in patients with lacunar infarction. - Stroke 1996 May;27(5):842-6 842-866.

230. Sarnuelsson, M. Lacumar infarcts: a 1 year clinical and MRI follow-up study. Cercbrowasc Dis 1994 4 265-272. 2001. (GENERIC) Ref Type: Generic

231. Samuelsson, M. Presumed pathogenetic mechanisms of recurrent stroke after lacunar infarction. Cerebrovasc Dis 19966 128-136. 2001. (GENERIC) Ref Type: Generic

232. Sandercock $P$, Bamford J, Dennis M, Burn J, Slattery J, lones $L$, et al - Atrial fibrillation and stroke: prevalence in different types of stroke and influence on early and long term prognosis (Oxfordshire community stroke project) [see comments]. - BMJ 1992 Dec 12;305(6867):1460-5 1460-55.

233. Sandercock PA, Allen CM, Corston RN, Harrison MJ, Warlow CP. - Clinical diagnosis of intracranial haemorthage using Guy"s Hospital score. - Br Med J (Clin Res Ed) 1985 Dec $14 ; 291(6510): 1675-71675-1677$.

234. Sarti $C$, Rastenyte D, Cepaitis $Z$, Tuomilehto J. - International trends in mortality from stroke, 1968 to 1994. - Stroke 2000 Jul;31(7):1588-601 1588-6011. 


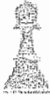

235. Schmal M, Marini C, Carolei A, Di Napoli M, Kessels F, Lodder J- Different vascullar risk factor profles among cortical infarcts, small deep infarcts, and primary intracerebral haemorthage point to different types of underlying vasculopathy. A study from the L'Aquila Stroke $\mathbb{R}$ egistry, - Cerebrovasc Dis 1998 Jan-Feb;8(1):14-9 14-99.

236. Schmidt R, Fazekas F, Kapeller P, Schmidt H, Hartung HP. - MRI white matter hyperintensities: three-year followy -up of the Austrian Stroke Prevention Study. Neurology 1999 Jul 13,53(1):132-9 132-199.

237. Schmidt R, Schmidt H, Fazekas F. - Vascular risk factors in dementia. - J Neurol 2000 $\mathrm{Feb} ; 247(2): 81-781-77$

238. Schmidt R, Fazekas F, Hayn M, Schmidt $\mathbb{H}$, Kapeller P, Roob G, et al. - Risk factors for microangiopathy-related cerebral damage in the Austrian stroke prevention study. - J Neurol Sci 1997 Nov 6; $152(1): 15-21$ 15-211.

239. Scholte oRW, de Haan RJ, Rijnders PT, Limburg M, van den Bos GA. - The burden of caregiving in partners of long-term stroke survivors. - Stroke 1998 Aug;29(8):1605-11. $1605-1611$.

240. Somidt EV, Smimov VE, Ryabova VS. - Results of the seven-year prospective study of stroke patients. - Stroke 1988 Aug; 19(8):942-9942-999.

241. Shintani S, Shiigai $T$, Arinami $T$. - Silent lacunar infarction on magnetic resonance imaging (MRD): risk factors. - J Neurol Sci 1998 Sep 18;160(1):82-6 82-66.

242. Silver FL, Norris JW, Lewis AJ. Hachinski VC. - Early mortality following stroke: a prospective review. - Stroke 1984 May-Jun; 15(3):492-6 492-66.

243. Sobel E, Alter M, Davanipour Z, Friday $G_{n}$ McCoy R, Levitt LP, et al. - Stroke in the Lehigh Valley: combined risk factors for recurrent ischemic stroke. - Neurology 1989 May;39(5):669-72 669-722.

244. Solzi $P$, Ring $H$, Najenson $T, L u z Y$. - Hemiplegics after a first stroke: late survival and risk. factors. - Stroke 1983 Sep-Oct;14(5):703-9 703-799.

245. Spolveri S, Baruffi MC, Cappelletti C, Semerano F, Rossi S, Pracucci G, et al. - Vascular risk factors linked to multiple lacunar infarcts. - Cerebrovasc Dis $1998 \mathrm{May}$ Jun;8(3):152-7 $152-177$.

246. Stegmayr B, Vinogradowa T, Malyutina S, Peltonen M, Nikitin $Y$, Asplund K. - Widening gap of stroke between east and west. Eight-year trends in occurrence and risk factors in Russia and Sweden, - Stroke 2000 Jan; 31 (1):2-3, 2-88.

247. Takao M, Koto A, Tanahashi N, Fukuchi $Y$, Takagi M, Morinaga $S_{\text {. }}$ - Pathologic findings of silent hyperintense white matter lesions on MRI. - J Neurol Sci 1999 Aug $15 ; 167(2): 127-31127-311$

248. Tarvonen-Schroder S, Kurki T, Raiha 1, Sourander L - Leukoaraiosis and cause of death: at five year follow up. - J Neurol Neurosurg Psychiatry 1995 May;58(5):586-9 586-599.

249. Taronen-Schroder S, Raiha I, Kurki T, Rajala T, Sourander L - Clinical characteristics of papidly progressive keuko-araiosis. - Acta Neurol Scand 1995 May;91(5):399-404 $399-4044$.

250. Tarvonen-Schroder S, Royta M, Raiha I, Kurki T, Rajala T, Sourander L. - Clinical Peatures of leuko-araiosis. -J Neuroll Neurosurg Psychiatry 1996 Apr;60(4):431-6 431-466. 
251. Tegeler CH, Shi F, Morgan T. - Carotid stenosis in lacunar stroke [see comments]. - Stroke $1991 \operatorname{Sep} ; 22(9): 1124-81124-1188$.

252. Thompson DW. Furlan A]. - Clinical epidemiology of stroke. - Nenrol Clin 1996 May; 14(2):309-15. 309-315.

253. Timsit SG, Sacco RL, MohrJP, Foulles MA, Tatemichi TK, WolfPA, et al - Brain infarction severity differs according to cardiac or arterial embolic source. - Neurology 1993 Apr;43(4):728-33 728-333.

254. Timsit SG, Sacco RL, Molr JP, Foulkes MA, Tatemich TK, Wolf PA, et al - Early clinical differentiation of cerebral infarction from severe acherosclerotic stenosis and cardioembolism. - Stroke 1992 Apr;23(4):486-91486-911.

255. Uehara $T$, Tabuchi $M$, Mori $E$. R isk factors for silent cerebral infarcts in subcortical white matter and basal ganglia. - Stroke 1999 Feb; 30(2):378-82 378-822.

256. van Boxtel MP, Gaillard C. Houx PJ, Buntinx F, de Leeuw PW, Jolles J. - Is nondipping in 24 h ambulatory blood pressure related to cognitive dystunction? - J Hypertens 1998 Oct; $16(10): 1425-32: 1425-322$.

257. van der Worp HB, Kappelle LJ - Complications of acute ischaemic stroke. - Cerebrovasc Dis 1998 Mar-Apr; $8(2): 124-32$ 124-322.

258. wan der Zwan A, Hillen B, Tulleken CA. Dujowny M. - A quantitative inwestigation of the variability of the major cerebrall arterial territories. - Stroke 1993 Dec,24(12):1951-.9. $1951-1959$.

259. van der Zwan A, Hillen B. Tulleken CA, Dujovny M, Dragovic L. - Variability of the territorjes of the major cerebral arteries. - J Neurosurg 1992 Dec;77(6):927-40. 927-940.

260. van Merwijk $G$, Lodder J, Bamford J, Kester AD. - How often is non-valvular atrial fibrillation the cause of brain infarction? - J Neurol 1990 Jan;237(3):205-7 205-277.

261. Van Overbeke J, Hillen B, Tulleken CA. - A comparative study of the circle of Willis in fetal and adult life. The configuration of the poskerior bifurcation of the posteriot communim cating artery. - J Anat 1991 Jun;176:45-54. 45-54.

262. van Swieten JC, Kappelle LJ, Algra $A$, van Latum JC, Koudstaal PJ, van Gijn J. Hypodensiry of the cerebral white matter in patients with transient ischemic attack or minor stroke influence on the rate of subsequent stroke. Dutch TIA Trial Study Group. - Am Neurol 1992 Aug; 32(2):177-83 177-833.

263. Wan Swieten JC. Geyskes GG, Derix MM, Peeck BM, Ramos LM, van Latum JC, ct al. Hypertension in the elderly is associated with white matter lesions and oognive decline. Ann Neurol $1991 \mathrm{Dec} ; 30(6): 825-30825-300$

264. van Swieten JC, van den Hout JH, van Ketel BA, Hijdra A, Wokke JH, van Gijn J. Periventricular lesions in the white matter on magnetic resonance imaging in the elderly. A morphometric contelation with arterioloselerosis and ditated perivascular spaces. - Bram 1991 Apr;114 (Pt 2):761-74 761-744.

265. van Swieten JC, Koudstal PJ, Visser MC. Schouten HJ, van Gijn J. - Interobserver agreement for the assessment of handicap in stroke paticnts. - Stroke 1988 May; 19(5):604-7 $604-677$. 


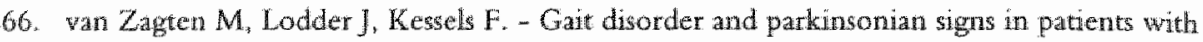
stroke related to small deep infarcts and white matter lesions. - Mov Disord 1998 $\operatorname{Jan} ; 13(1): 89-9589-955$.

267. Wan Zagten M, Boiten J. Kessels F, Lodder J. - Significant progression of white matter lesions and small deep (lacunar) infarcts in patients with stroke. - Arch Neurol 1996 Jul: $53(7): 650-5650-655$

268. Vemmos KN, Takis CE, Georgilis K, Zakopoulos NA, Lekakis JP, Papamichael CM, et al. - The Athens stroke registry: results of a five-year hospital based study. - Cerebrovasc Dis $2000 \mathrm{Mar}-\mathrm{Apr}$ 10(2):133-41 133-411.

269. Vemmos KN, Bot ML. Tsibouris PK, Zis VP, Grobbee DE, Stranjalis GS, et al. - Stroke incidence and case fatality in southern Greece: the Arcadia stroke registry. - Stroke 1999 Feb; $30(2): 363-70363-700$.

270. Vemmos KN, Bots ML, Tsibouris PK, Zis VP, Takis CE, Grobbee DE, et al. - Prognosis of stroke in the south of greece: 1 year mortality, functional outcome and its determinarnts: the arcuidia stroke registry [In Process Citation]. - J Neurol Neurosurg Psychiatry 2000 Now $69(5): 595-600595-6000$

271. Verheul HA, Dekker E, Bossuyt P, Moulijn AC, Dunning AJ. - Background mortaliry in clinical survival studies [see comments]. - Lancet 1993 Apr 3;341(8849):872-5 872-55.

272. Vermeulen $E_{G}$, Rauwerda JA, Erix P, de Jong $5 \mathrm{C}$, Twisk JW, Jakobs $C$, et al. Nomohomocysteinaemia and witamin-treated hyperhomocysteinaemia are associated with similar risks of cardiovascular events in parients with premature atherothrombotic carebrovascular disease. A prospective cohort study. - Neth J Med 2000 Apr;56(4):138-46. $138-146$.

273. Vuitanen M, Eriksson S, Asplund K, Wester PO, Winblad B. - Determinants of long-tem mortality after stroke. - Acta Med Scand 1987;221(4):349-56 349-566.

2\%4. Vitanen M, Eriksson S, Asplund K. - Risk of recurrent stroke, myocardial infarction and epilepsy during long-term follow-up after stroke. - Eur Neurol 1988;28(4):227-31 $227-311$

275. won Arbin $M$, Britton $M$, de Faire $U$. - Mortality and recurrences during eight years following stroke. - J Intern Med 1992 Jan 231(1):43-8 43-88.

276. Westling $B$, Norwing B, Thomgren M. - Strvival following stroke. A prospective populaton-based study of 438 hospitalized cases with prediction according to subrype, severity and age. - Acta Neutol Scand 1990 Mayn81(5):457-63 </XMP></BODY $></ H T M L>$ $457-463$.

277. White HD, Simes RJ. Andetson NE, Hamkey GJ, Watson JD, Hunt D, et al. - Pravastatin therapy and the risk of stroke. - N Engl J Med 2000 Aug 3,343(5):317-26 317-266.

278. Williams GR, Jiang JG. - Development of an ischemic stroke survival score - Stroke 2000 Oct;31(10):2414-20. 2414-2420.

279. Wilterdink $\int \mathrm{L}$, Easton JD. - Vascular event rates in patients with atherosclerotic cerebrovascular disease. - Arch Neurol 1992 Ang;49(8):857-63 857-633.

280. Wiszniewska $M$, Devityst $G$, Bogousslavsky J, Ghika J, van Melle $G$. - What is the significance of leukoaniosis in patients with acute ischemic stroke? - Arch Neurol 2000 Jul; $57(7): 967-73.967-973$. 
281. Wolf, P. A. An overwiew of the epidemiology of stroke. Stroke 199021 supp 4-6. 2001. (GENERIC) Ref Type: Generic

282. Wu T, Trevisan M, Genco RJ, Dorn JP, Falkner KL, Sempos CT. - Periodontal disease and risk of cerebrovascular disease: the first national health and nutrition examination survey and its follow-up study. - Arch Intern Med 2000 Oct 9;160(18):2749-55. 2749-2755.

283. Yamamoto H, Bogousslawsky J, wan Melle G. - Different predictors of neurological wors ening in different causes of stroke. - Arch Neurol 1998 Apr;55(4):481-6 481-66.

284. Yamamoto H, Bogousslavsky ]. - Mechanisms of second and further strokes [see comments]. - J Neurol Neurosurg Psychiary 1998 Jun;64(6):771-776.

285. Yamamoto X, Georgiadis AL, Chang HM, Caplan LR. - Posterior cerebral artery temitory infarcts in the New England Medical Center Posterior Circulation Registry. - Arch Neurol $1999 \mathrm{Jul}: 56(7): 824-32824-322$.

286. Yamamoto, Y. Adverse effect of nighttime blood pressure on the outcome of lacunar infart patients. Stroke.1998 29 570-576, 2001. (GENERIC) Ref Type: Generic

287. Yamauchi $H$, Fukuyana $H$, Nagahama Y, Shiozaki T, Nishizawa S, Konishi J, et al. - Brain arteriolosclerosis and hemodymamic disturbance may induce leukoaraiosis. - Neurology 1999 Nov $10 ; 53(8): 1833-81833-1888$.

288. Yamauchi H, Fukuyama H, Shio H. - Corpus callosum atrophy in patients with leukoaraiosis may indicate global cognitive impaiment. - Stroke 2000 Jul;31(7):1515-20 $1515-200$.

289. Yao H, Sadoshima S, Ibayashi S, Kuwabara $Y$, Ichiya Y, Fujishima M. - Leukoaraiosis and dementia in hypertensive patients. - Stroke 1992 Nov;23(11):1673-7 1673-1677.

290. Yusuf S, Sleight P, Pogue J, Bosch J, Davies R, Dagenais G. - Effects of an angiotensin-converting-enzyme inhibitor, ramipril, on cardiovascular events in high-risk patients. The Heart Outcomes Prevention Evaluation Study Investigators. - N Engl J Med 2000 Jan $20 ; 342(3): 1.45-53.145 \% 153$. 


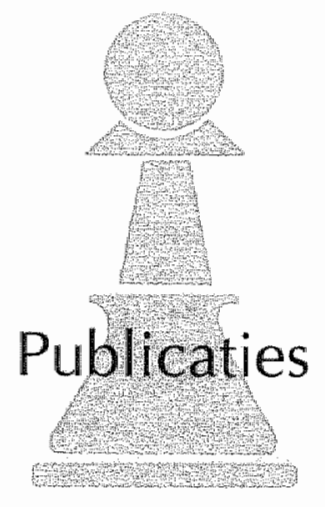


TRANSOESOPHAGEAL ECHOCARDIOGRAPHY IN THE DETECTION OF INTRACARDIAC EMBOLIC SOURCES IN PATIENTS WITH TRANSIENT ISCHEMIC ATTACKS. Pop G, Sutherland GR, Koudstaal PJ Sit TW, De Jong G, Roelandt JR. Stroke 1990; 21:560-5.

OVERT HEPATIC ENCEPHALOPATHY PRECIPITATED BY' ZINC DEFICIENCY. Van Der Rijt CC, Schalm SW, Schat H, Foeken K, De Jong G. Gastroenterology 1991; 100: 1114-8.

HET CAPSULAR WARNING SYNDROME. Ned Tijdschr Neurol 2000;3:166-8. Fennis Th F M, De Jong $G$, Kwa VIH.

SYMPTOMATISCHE CLUSTERHOOFDPIN. Ned Tijdschr Neurol 2001;1:29-31. Trip J, De Jong G.

TRANSIENT ISCHEMIC ATTACKS. Vasculaire Zorg nr 1 1998. G. de Jong.

ACUTE VISUSSTOORNISSEN VAN VASCULAIRE ORIGINE. Vasculaire Zorg nr 2 1998. G. de Jong.

PARADOXALE CEREBRALE EMBOLIEËN. Vasculaire Zorg nr 1 1999. G. de Jong.

ATRIUMFIBRILLEREN IN DE HUISAR TSENPRAKTIJK. Vasculaire Zorg nr 4 1999. G. de Jong.

DIABETISCHE NEUR OPATHIE. Vasculaire Zorg nr 5 1999. G. de Jong. 


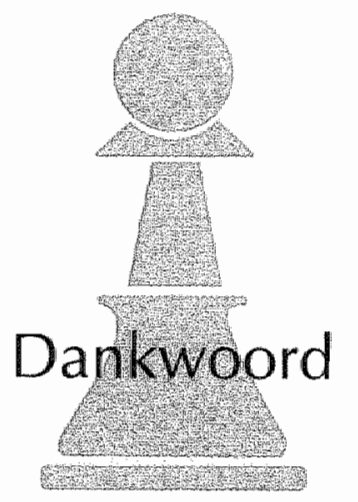




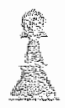

Veel proefschriften zouden niet zijn voltooid zonder veel hulp, maar voor dit proefschrift geldt dit wel in hoge mate.

Prof. Dr. I. Troost. Beste Jaap, al vroeg in mijn opleiding, en later opnieuw kruisten onze wegen zich. Vanaf het eerste moment, en nog steeds, ben ik onder de indruk van je kwaliteiten als neuroloog, manager, maar vooral als mens. Ik ben je zeer dankbaar voor alle adviezen van vroeger en nu, en voor de mogelijkheid dit proefschrift te mogen schrijven.

Dr. J. Lodder. Beste Jan, woorden schieten te kort. Zonder jouw hulp, ondersteuning, bemoediging, aanmoediging en daadwerkelijk meedenken en meewerken was dit proefschrift niet voltooid. We delen een grote belangstelling voor de filosofische aspecten van het bestaan, nast veel andere zaken, op basis warvan we mogelijk nog meer uren en dagen hebben doorgebracht dan werkend aan dit proefschrift. Een promovendus kan zich geen betere co-promotor of promotor wensen. Woorden schieten te kort, mar zoals jij wel weet: the Tao that can be spoken of is not the true Tao.

Wylai Lodder. Lieve Lai, veel dank voor je ongekende gastwrijheid. Deze zal ik de komende tijd minder vaak genieten, evenals je heerlijke Thaise maaltijden. (mogelijk is dit beter voor mijn gewicht!)

Dr. I. Boiten. Beste Jelis, je zorgde er voor dat dit onderzoek in gang gezet kon worden. Ik ben je daar zeer dankbaar voor. Soms is de loop der dingen niet goed voorspelbaar.

Drs. Ir. F. Kessels. Beste Fons, ik voel me wat bezwaard dat deze promotie plaatsvindt, waar ik van mening ben dat een promotie beter bij jou zou passen. Je kennis van epidemiologie, statistiek en andere duistere zaken is welhast onbegrensd, evenals je vemogen om deze kennis (gedeeltelijk) over te brengen, en jo geduld en bereidheid tot herhaling in dit proces.

Dr. Lisette van Rakk. Lieve Lisette, ik ben je veel dank verschuldigd voor je onbatzuchtige bereidheid me te laten delen in de vruchten van je beheer van de data wan de Mastricht Stroke Registry.

Alle stafleden en arts-assistenten van de afdeling neurologie van het AZM. Jullic allen ben ik veel dank verschuldigd voor de hantwerwarmende wijze waarop een relatieve buitenstaander door jullie is ontwangen, zowel op de afdeling alls elders in Mastricht. 


\section{s}

Thera van Lieshout. Lieve Thera, ik ben jou en al je medewerksters veel dank verschuldigd, niet alleen voor de hulp bij het zoeken naar gegevens van de patiënten.

Dr. G.W.H. Mantel en dr J. P. Schipper. Beste Joep, beste Geert, behalve uitstekende neurologen zijn jullie nog betere vrienden. Zonder jullie hulp in de laatste fase zou ik het heel wat moeilijker heben gehad.

Mijn ouders. Lieve Heit en Mem, zonder jullie offers en steun was mijn studie niet mogelijk geweest. Ik dank jullie zeer - voor alles.

Geke, Jelle en Gosse, jullie zijn mijn alles. 
DANKWOKO

$\sqrt{1}$ 


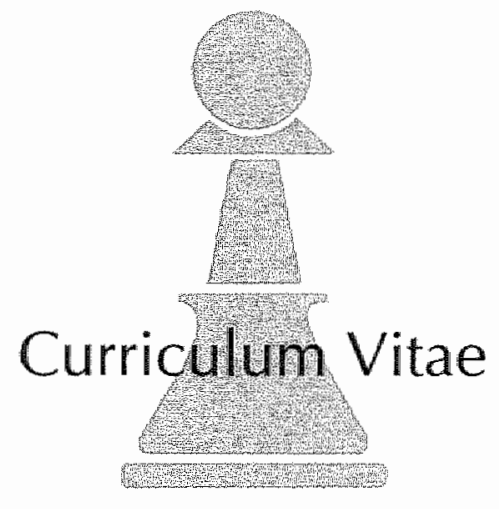


De schrijver van dit proefschrift bracht zijn jeugd, inclusief middelbare school en studie geneeskunde, door in Rotterdam. Het arts-examen werd afgelegd in 1981 , waarna een periode als dienstplichtig militair arts volgde.

Van 1983 tot medio 1985 was hij arts-assistent neurologie in het toenmalige Gemeenteziekenhuis te Arnhem (B opleiding, opleider Dr. G. Schouwink). Daarna werd het tweede deel van de opleiding tot neuroloog gevolgd in het Academisch Ziekenhuis Dijkzigt te Rotterdam (opleider Prof. Dr. A. Staal, opleider klinische neurofysiologie Dr. K. Mechelse). Van 1989 tot 1992 was de auteur verbonden als neuroloog aan het Onze Lieve Vrouwe Gasthuis te Amsterdam, sindsdien tot heden aan de Isala klinieken te Zwolle, locatie Weezenlanden. 